\title{
Estudo da Dinâmica Molecular em Nanocompostos Sólidos Híbridos Orgânicos-Inorgânicos (ormolitas) por RMN.
}

\section{André Luis Bonfim Bathista e Silva}

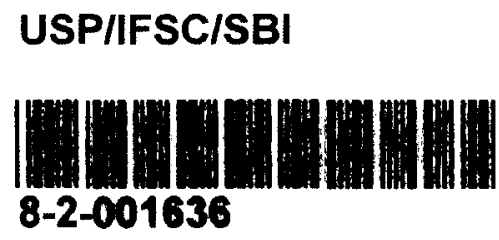

Dissertação apresentada à Área
Interunidades em Ciência e
Engenharia de Materiais, da
Universidade de São Paulo, para
obtenção do título de Mestre em
Ciências e Engenharia de
Materiais.

Orientador: Prof. Dr. Tito José Bonagamba 


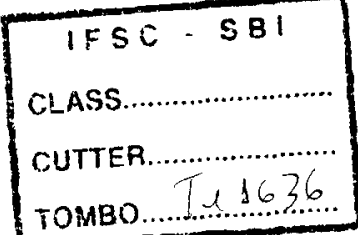

Silva, André Luis Bonfim Bathista e

"Estudo da Dinâmica Molecular em Nanocompostos Sólidos Hibridos Orgânico-Inorgânico (ormolitas) por RMN."

André Luis Bonfim Bathista e Silva - São Carlos, 2004

Dissertação (Mestrado) - Área Interunidades Ciência e Engenharia de Materiais

2004 - Páginas: 79

Orientador: Prof. Dr. Tito José Bonagamba

1. Nanocompostos; Ormolitas

I. Título 


\section{Universidade de São Paulo}

\section{Ciência e Engenharia de Materiais}

MEMBROS DA COMISSÃO JULGADORA DA DISSERTAÇÃO DE MESTRADO DE ANDRE LUIS BONFIM BATHISTA, APRESENTADA À ÁREA INTERUNIDADES CIENNCIA E ENGENHARIA DE MATERIAIS, UNIVERSIDADE DE SÃO PAULO, EM 30/11/2004.

COMISSÃO JULGADORA:

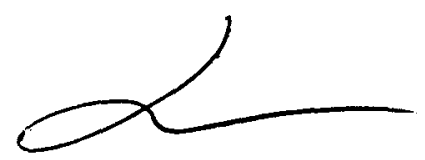

Prof. Dr. Tito José Bonagamba ( Orientador e Presidente) - IFSC/USP

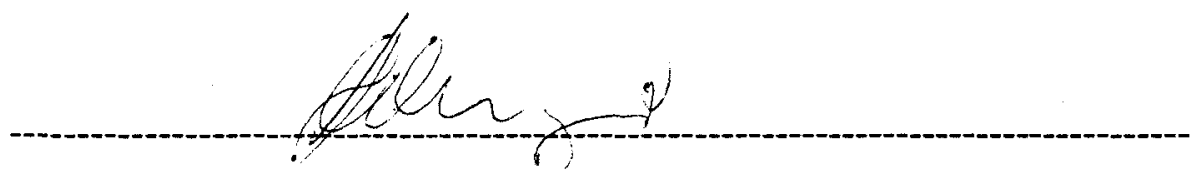

Prof. Dr. Luiz Alberto Colnago - EMBRAPA

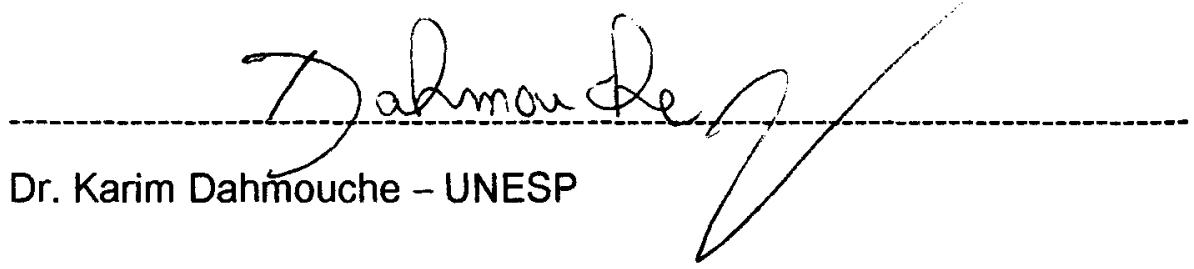


In Memorian Deoclides Bathista e Silva \& Leila dos Santos Bonfim. 


\section{AGRADECIMENTOS}

Primeiramente a Deus, pela graça em minha vida e por toda a minha alegria de viver.

Ao Professor Doutor Tito José Bonagamba, pela Recepção, orientação, dedicação e convite de realizar este trabalho no laboratório do seu grupo de pesquisa LEAR-IFSC/USP, Muito obrigado Professor Tito;

Ao Prof. Dr. Eduardo Ribeiro de Azevedo, pela inestimável ajuda no Laboratório de espectroscopia, nas análises e interpretações de resultadós durante todo o processo;

A Secretária do grupo Isabel A. Possato, pela grande ajuda que me deu em muitas vezes.

Ao Dr. Antonio Carlos Bloise, na realização de alguns experimentos;

Aos meus irmãos Fabiano, Andrea, Jean e cunhado Célio Bispo pela atenção e cuidados com compromissos particulares - Abraços para vocês;

A Professora e mãe carioca Maria Inês Bruno Tavares (IMA-UFRJ) e Alberto Tavares (Polícia Federal - Rio de Janeiro);

Ao Prof. Dr. Nicolau Priante Filho e Josita Coreto pelo apoio que me foi dado durante dois anos que estive trabalhando com eles (UFMT- Coorimbatá).

Aos amigos do Instituto de Macromoléculas, Emerson, Eduardo, Leandro, Regina (COPPE), Paula, Terezinha (INPI) e André;

Ao Professor Doutor Karim Dahmouche de Instituto de Química da UNESP de Araraquara, pela ajuda na discussão deste trabalho e pela sintetização das ormolitas;

Aos Professores que lecionaram disciplinas a qual fiz, Maria Cristina Terrile (Espectroscopia Física), Prof. Dr. José Pedro Donoso (Relaxação Magnética Nuclear), Antônio Carlos Hernandes (CEM), Waldeck Bose (CEM), Prof. Dr. Luiz Alberto Colnago (Caracterização de Materiais por RMN - EMBRAPA), Prof. Dr. Fontanari (Praticas Pedagógicas), Albérico Borges Silva (Química Quântica Avançada), Milan Tsirc (Métodos em Mecânica Quântica Molecular);

Fábio (Fafáx) e Isabela, pela agradável recepção durante o estágio realizado no LEAR e todos os momentos engraçados que tivemos;

Aos técnicos do LEAR, João Gomes da Silva, José Carlos Gazziro, Odir Adolfo Canevarollo e Dr. Edson Luiz Gea Vidoto;

Aos amigos José de Souza Nogueira e Emerson de Oliveira Silva, pela ajuda dos e-mails que enviaram me no período do estágio e do mestrado;

Ao primo Vitor Borges Silva \& Thiago de Paula pelo carinho e recepção durante todo o estágio no LEAR, pelas festas, pelos colegas da RODOX, conhecimento da cidade de São Carlos um grande abraço;

Ao Amigo Paulo Henrique que sempre esteve morando comigo desde o princípio que cheguei em São Carlos.

Aos novos colegas Laerte e Waldemir pela recepção à cidade de São Carlos.

Ao amigo Paulo César e Kátia Paelo, pela saudável amizade Cristã. Que Deus abençoe esta Família.

Aos colegas do Lear, Gerson Luís Mantovani, Fábio Aurélio Bonk, José Roberto Tozoni, Carlos Alexandre Brasil e Nilson Camargo Mello. 
As Secretárias da Pós-Graduação Wladerez e Cristiane pela ajuda e apoio.

Aos familiares da Igreja Assembléia de Deus Elvis Felippe, Abigail Cardoso Luz, Toninho, Elke e Sara.

A toda Mocidade da Assembléia de Deus e Obreiros do Evangelismo.

A minha amiga Dra. Inês Marciano, da Assembléia de Deus.

Aos amigos da Interunidades, Eduardo Antonelli, Edna Moura, Fabrício, Elen Morales, Humberto, Fábio Leite e Marcelle Bedouch. 


\section{SUMÁRIO}

Lista de Figuras viii

Lista de Tabelas $\quad$ xii

Lista de Siglas e Abreviaturas xii

Resumo xiii

Abstract xiv

Introdução $\quad$ XV

Capítulo 1: Compostos Híbridos Orgânico-Inorgânicos $\quad 01$

$\begin{array}{ll}1 \text { Introdução } & 01\end{array}$

$\begin{array}{ll}1.1 \text { Eletrólitos Poliméricos } & 01\end{array}$

$\begin{array}{ll}1.2 \text { Ormolitas } & 03\end{array}$

1.2.1 Tipos de Ormolitas 04

1.2.2 Síntese das Ormolitas 05

$\begin{array}{ll}1.3 \text { Referências } & 08\end{array}$

Capítulo 2: Ressonância Magnética Nuclear Convencional. $\quad 09$

2 Ressonância Magnética Nuclear $\quad 09$

2.1 Princípios Básicos de Ressonância Magnética Nuclear. 09

$\begin{array}{ll}2.2 \text { Interações de spin nuclear }(S=1 / 2) \text { no estado sólido } & 10\end{array}$

$\begin{array}{ll}2.2 .1 \text { Interação Zeeman } & 11\end{array}$

$\begin{array}{ll}\text { 2.2.2 Excitação do Sistemas de Spins com RF } & 13\end{array}$

$\begin{array}{ll}\text { 2.2.3 Interação Dipolar } & 14\end{array}$

2.2.4 Interação de Deslocamento Químico 15

2.3 Métodos utilizados para a intensificação do sinal e para o aumento da 19 resolução dos espectros de RMN em amostras sólidas

$\begin{array}{ll}\text { 2.3.1 Polarização Cruzada } & 19\end{array}$

2.3.3 Desacoplamento Dipolar $\quad 21$

$\begin{array}{ll}2.4 \text { Referências } & 23\end{array}$ 
Capítulo 3: Técnicas de Ressonância Magnética Nuclear de 25 destinadas ao Estudo da Dinâmica Molecular.

3.1 Introdução 25

3.2 Cálculo do Espectro de RMN sob a ação de Movimentos Moleculares. $\quad 26$

3.3 Experimento de Exchange. 31

3.4 RMN de Exchange Bidimensional - Exchange 2D. 34

3.4.1 Padrões de Intensidade para Espectros de Exchange 2D 35

3.4.2 Movimento Molecular em RMN do Estado Sólido. 39

3.5 Experimento PUREX: Pure Exchange 41

3.5.1 Conceito do Experimento PUREX 41

3.5.2 Função de modulação PUREX.

3.5.3 Informações Sobre a escala de tempo do movimento molecular. $\quad 45$

3.5.4 Distribuição de tempos de correlação.

3.6 Referência: $\quad 55$

Capítulo 4: Resultados Experimentais e Discussões do estudo 56 de nanocomposto Orgânico-Inorgânicos.

4.1 Materiais e Métodos 56

4.2. Parâmetros experimentais. 57

4.3 Introdução. $\quad 58$

4.4 Espectros de Carbono em função da Temperatura. $\quad 60$

4.5. Espectros de 2D Exchange NMR de ${ }^{13} \mathrm{C}$ estático. 66

4.6. Resultados 1D PUREX NMR das ormolitas. 69

4.7 Energia de Ativação por PUREX 1D. 72

4.8 Resultados 1D PUREX do - $\left(\mathrm{CH}_{2}\right)_{3}-(\mathrm{PEG}) \mathrm{n}$. 73

4.9 Conclusões e Perspectivas.

4.10 Referências: $\quad 79$ 


\section{LISTA DE FIGURAS}

Figura 1.1 Ormolitas do Tipo I sintetizada com catalisador a) básico e b) ácido.

Figura 1.2 Ormolita Tipo II apresenta as fases orgânicas e inorgânicas unidas por ligações químicas covalentes. $\mathrm{O}$ polímero utilizado possui grupos nas extremidades do tipo - $\left(\mathrm{CH}_{2}\right)_{3}-\mathrm{NH}-\mathrm{CO}-\mathrm{NH}$, que podem ligar-se quimicamente ao aglomerado de sílica.

Figura 2.1 Autovalores da energia de um núcleo com momento magnético $\mu$ em um campo magnético $B_{0}$.

Figura 2.2 Formato da linha de RMN do estado sólido: a) simetria não-axial, b) 18 simetria axial, c) simetria cúbica.

Figura 2.3 Representação de um reservatório térmico nuclear de prótons

Figura 2.4 Sequência de pulso Polarização cruzada estabelecimento da condição de Hartmann-Hahn . Tc é o tempo de contato térmico, Ta é o tempo de aquisição.

Figura 2.5 O efeito do desacoplamento heteronuclear. Devido à rápida rotação do momento magnético do núcleo I, o seu campo dipolar local, , na direção do campo (direção z), é em média reduzido a zero no sítio do núcleo II.

Figura 3.1 conjunto de espectros simulados para diferentes tempos de correlação do núcleo de 13C.

Figura 3.2 Princípio do experimento 2D Exchange para detecção de movimentos reorientacional. As frequências dependentes dos ângulos em dois instantes de tempo distintos, os quais são separados por um tempo de mistura $t_{m}$. Um reorientação (uma mudança dos ângulos $(\theta, \phi)$ ) é detectada através da mudança concomitante das freqüências $\omega_{1}\left(\theta_{1}, \phi_{1}\right)$ to $\omega_{1}\left(\theta_{2}, \phi_{2}\right)$.

Figura 3.3 Esquema da reorientação molecular de $\omega_{1}\left(\theta_{1}, \phi_{1}\right)$ para $\omega_{2}\left(\theta_{2}, \phi_{2}\right)$, devido ao processo de Exchange do movimento lento.

Figura 3.4 Seqüência da evolução do espectro Exchange 2D com função de $t_{m}$ para $o$ processo de reorientaça molecular entre os sítios $A$ e $B$. (a) $\left.t_{m}=0, b\right) t_{m}=$ intermediário e c) $\mathrm{t}_{\mathrm{m}}=$ indeterminado.

Figura 3.5 Sequêencia de pulsos utilizada para obtenção do espectro de 2D Exchange NMR através do deslocamento químico anisotrópico. A evolução nos tempos $t_{1}$ e $t_{2}$ é feita sob desacoplamento heteronuclear. Na primeira parte da sequência de pulso, enriquecemos o ${ }^{13} \mathrm{C}$ para que haja uma melhor magnetização como também a relação sinal ruído apartir da Polarização Cruzada. Em $t_{1}$ temos a decodificação de fase, $t_{m}$ temos a reorientação molecular (informação em $t_{1}$ é transferida para $t_{2}$ ). E Detecção do sinal com amplitude modulada através dal informação contida em $\mathrm{t} 1$. 
Figura 3.6 Conjunto de espectros de Exchange 2D simulados para vários ângulos de reorientação para $\eta=0$.

Figura 3.7 Sequêencia de pulsos utilizada para obtenção do espectro de ID Purê Exchange NMR (PUREX) através do deslocamento químico anisotrópico. A evolução dos dois períodos $\tau$ é feita sob desacoplamento heteronuclear. $\mathrm{Na}$ primeira parte da sequência de pulso, enriquecemos o ${ }^{13} \mathrm{C}$ para que haja uma melhor magnetização como também a relação sinal ruído apartir da Polarização Cruzada.

Figura 3.8 Funções de modulação do experimento PUREX obtidas somando $N$ funçð̃es de modulação com $\tau_{1}=250 \mu$ s. a) $\left.\mathrm{N}=1, \mathrm{~b}\right) \mathrm{N}=2$, c) $\mathrm{N}=3$, d) $\mathrm{N}=4$. A função de modulação aproxima-se de uma constante na faixa de $0 \leq\left|\Omega_{1}-\Omega_{2}\right| \leq 2 \pi / \tau$, mas permanece igual a zero em $\left|\Omega_{1}-\Omega_{2}\right|=0$.

Figura 3.9 Simulaçðes da intensidade $E\left(t_{m}, \delta \tau\right)$ versus $t_{m}$. Podemos ver que, quanto maior for $o$ tempo de correlação, maior é o $t_{m}$ dado ao experimento. Através desta análise aparente podemos construir uma Janela Dinâmica do Sistema onde envolve movimentos na escala de $1 \mathrm{~ms}$ a $1 \mathrm{~s}$.

Figura 3.10 Curvas obtidas por simulaç̃es da intensidade $E\left(t_{m}, \delta \tau\right)$ versus $t_{m}$. Para regimes intermediários de movimentos moleculares.

Figura 3.11 Distribuição de tempos de correlação em função da temperatura

Figura 3.12 Simulação das curvas versus temperatura como função dos parâmetros de Arrhenius $\mathrm{Ea} e \tau 0$. a) versus $\mathrm{T}$ como função da energia de ativação: Somente um deslocamento da curva em temperatura é observado. b) versus $\mathrm{T}$ como função de $\tau 0$ : além do deslocamento em temperatura, uma variação na taxa de crescimento da curva é observado.

Figura 3.13 Curvas versus temperatura obtidas por meio de simulação do sinal PUREX 1D no regime intermediário.

Figura 3.14 a) Conjunto de funçð̃es distribuição de tempos de correlação do tipo log Gaussian. b) Curvas versus temperatura obtidas por meio de simulação do sinal PUREX ID no regime intermediário considerando diferentes distribuições de tempos de correlação.

Figura 4.1 Presença de heterogeneidades dinâmicas na amostra $[50]_{47}[08]-I I$, a parte diagonal no espectro indica a restrição do movimento enquanto que porção não-diagonal do espectro indica o movimento molecular do polímero. Evento medido pelo experimento 2D Exchange.

Figura 4.2 As Figuras 4.2a-d) mostram as formas de linhas do espectros de ${ }^{13} \mathrm{C}$, utilizando a técnica de Polarização Cruzada em função da temperatura para Ormolitas do Tipo II, [50] $]_{47}[08]-$ II. As Figuras 4.2e-h) mostram as formas de linhas do espectros de ${ }^{13} \mathrm{C}$, utilizando a técnica de Polarização Direta em função da temperatura para Ormolitas do Tipo II, [50 ${ }_{47}[08]$-II. A Figura 4.2-i) apresenta a curva obtida à partir da largura de linha espectral à dois terços da altura, $\Delta v_{2 / 3}$, do experimento de Polarização Cruzada e Polarização Direta. 
Figura 4.3 As Figuras 4.3a-d) mostram as formas de linhas do espectros de ${ }^{13} \mathrm{C}$, utilizando a técnica de Polarização Cruzada em função da temperatura, onde a linha contínua espectro experimental e a linha pontilhada é o espectro simulado, para Ormolitas do Tipo II, [50] $]_{47}[08]-$ II. As Figuras 4.2e-h) mostram as formas de linhas do espectros de ${ }^{13} \mathrm{C}$, para Ormolitas do Tipo II, [50 $]_{47}[30]$-II. A Figura 4.2-i) apresenta a curva obtida à partir da largura de linha espectral à dois terços da altura, $\Delta v_{2 / 3}$, do experimento de Polarização Cruzada, onde os pontos são as larguras de linhas à $\Delta v_{2 / 3}$ experimental e a linha contínua é a simulação.

Figura 4.4 As Figuras 4.4a-d) mostram as formas de linhas do espectros de ${ }^{13} \mathrm{C}$, utilizando a técnica de Polarização Cruzada em função da temperatura, onde a linha continua espectro experimental e a linha pontilhada é o espectro simulado, para Ormolitas do Tipo II, [50 ${ }_{11}[08]-$ II. As Figuras 4.4e-h) mostram as formas de linhas do espectros de ${ }^{13} \mathrm{C}$, para Ormolitas do Tipo II, [50 $]_{11}[30]-$ II. A Figura 4.4-i) apresenta a curva obtida à partir da largura de linha espectral à dois terços da altura, $\Delta v_{2 / 3}$, do experimento de Polarização Cruzada, onde os pontos são as larguras de linhas à $\Delta v_{2 / 3}$ experimental e a linha contínua é a simulação.

Figura 4.5 Espectro de Exchange 2D realizado $8^{\circ} \mathrm{C}$ abaixo da $T_{\mathrm{g}}\left(-25^{\circ} \mathrm{C}\right)$ da Ormolita $[50]_{47}[08]-$ II. Podemos ver a pequena mobilidade do segmento molecular $\left\{\mathrm{CH}_{2}-\mathrm{CH}_{2}-\mathrm{O}\right\}_{\mathrm{n}}$ na região de 10 a $90 \mathrm{ppm}$ devido a este fato, e na região do link Sílica-NH-CO-NH o espectro é puramente diagonal. O tempo de mistura $\mathrm{t}_{\mathrm{m}}$ foi fixo de $200 \mathrm{~ms}$. O incremento é 0.5 e o máximo do contorno é $50 \% .4 .9$ b) Aqui a amplitude do movimento do segmento molecular no espectro de 2D Exchange, já não é mais diagonal devido a promediação dos tensores do deslocamento químico anisotrópico.

Figura 4.6 Espectro de Exchange 2D da Ormolita [50 $]_{47}[08]-\mathrm{II}$ ampliado na região entre -20 a $100 \mathrm{ppm}$ referente as temperaturas $\mathrm{T}=-33^{\circ} \mathrm{C}, \mathrm{T}=-25^{\circ} \mathrm{C}$ e $\mathrm{T}=$ $-15^{\circ} \mathrm{C}$ e com as suas respectivas simulações.

Figura 4.7 Espectro de Exchange 2D realizado $10^{\circ} \mathrm{C}$ acima da $T_{\mathrm{g}}\left(-5^{\circ} \mathrm{C}\right)$ da Ormoli [50 ${ }_{11}[08]-I I$. A mobilidade do segmento molecular $\left\{\mathrm{CH}_{2}-\mathrm{CH}_{2}-\mathrm{O}\right\}_{\mathrm{n}}$ na regi de 10 a $90 \mathrm{ppm}$ devido é muito intensa, devido a alta temperatura que sistema atingiu. A este fato, a região do link alifático $\mathrm{NH}-\mathrm{CH}_{2}-\mathrm{CH}_{2}-\mathrm{CH}_{2}-$ espectro é não é diagonal, abrangendo uma região de -20 a $30 \mathrm{ppm}$. $O$ tem] de mistura $\mathrm{t}_{\mathrm{m}}$ foi fixo de $200 \mathrm{~ms}$. O incremento é 0.5 e o máximo do contor é $50 \%$.

Figura 4.8 Curvas de $13 \mathrm{C}$ obtidas através da sequeência de pulso PUREX ID a 100 $\mathrm{MHz}$ da Ormolita [50 $]_{47}[08]-$ II e [50] ${ }_{11}[08]$-II com quatro temperaturas diferentes. A variação de somente $5^{\circ} \mathrm{C}$ podemos ver uma diferença na intensidade da curva PUREX 1D.

Figura 4.9 Obtenção da Energia de Ativação a partir da .Escala de tempo em função da temperatura, $\langle\tau c\rangle$ em escala logarítmica.

Figura 4.10 Experimento PUREX $1 \mathrm{D}{ }^{13} \mathrm{C}$ da Ormolita [50 ${ }_{11}[08]$-II com tempo de mistura $\mathrm{t}_{\mathrm{m}}=200 \mathrm{~ms}$ e temperatura de $+10^{\circ} \mathrm{C}$ acima da $T_{\mathrm{g}}$ da amostra. $\mathrm{O}$ espectro $S_{0}$ é a intensidade de referência e o espectro $S$, é a intensidade PUREX, devido a reorientação do segmento molecular (!). 
Figura 4.11 Regime do movimento do segmento molecular $\{\mathrm{CH} 2 \mathrm{CH} 2 \mathrm{O}\} \mathrm{n}$ em ms a s envolvendo a distribuição do tempo de correlação. As linhas são as simulaçðes de cada Ormolita com grau de dopagem diferente. 


\section{LISTA DE TABELAS}

Tabela 4.1 Temperaturas selecionadas para o experimento 2D Exchange, obtidas das 65 larguras de linha $\Delta v_{(2 / 3)}$ do experimento CP versus temperatura..

Tabela 4.2 Energia de ativação das ormolitas obtidas a partir do experimento de CP. 66

$\begin{array}{llll}\text { Tabela 4.3 Parâmetros das curvas PUREX 1D obtidos a partir da função KWW } & 71\end{array}$ stretched exponential para a Ormolita [50 $]_{47}[08]$-II.

Tabela 4.3 Parâmetros das curvas PUREX 1D obtidos a partir da função KWW 72 stretched exponential para a Ormolita [50 $]_{11}[08]-$ II.

\section{LISTA DE SIGLAS E ABREVIATURAS}

$\begin{array}{ll}\text { RMN } & \text { Ressonância Magnética Nuclear } \\ \text { PUREX } & \text { Pure Exchange Solid-State NMR } \\ \text { CP } & \text { Cross Polarization } \\ \text { RF } & \text { Radiofrequência } \\ \text { SEP } & \text { Sistema de eixos principais } \\ \text { CSA } & \text { Chemical Shift Anisotropy } \\ \text { KWW } & \text { Kohrausch-Williams-Watt } \\ T_{\mathrm{g}} & \text { Transição Vítrea } \\ \text { IFSC } & \text { Instituto de Física da São Carlos } \\ \text { LEAR } & \text { Laboratório de Espectroscopia de Alta Resolução } \\ \text { PEG } & \text { Poli(etileno glicol) } \\ \text { UNESP } & \text { Universidade Estadual Paulista } \\ \text { PEO } & \text { Poli (ethylene oxidel) } \\ \text { SM } & \text { Sistema Molecular } \\ \text { DP } & \text { Direct Polarization }\end{array}$




\section{RESUMO}

Nesta dissertação apresentaremos os resultados do estudo da dinâmica molecular em ormolitas ligadas e dopadas com $\mathrm{Li}^{+}$, obtidos com a utilização de métodos de RMN de ${ }^{13} \mathrm{C}$. A análise das mudanças da anisotropia de deslocamento químico provocada por movimentos moleculares ativados termicamente foi realizada. Neste caso, foram utilizados modelos de simulação de espectros sob os efeitos de dinâmica molecular, permitindo a determinação do comportamento dos tempos de correlação em função da temperatura, e conseqüente estimativa das energias de ativação aparentes relativas às transições vítreas em amostras com diferentes dopagens de Li. Técnicas de RMN de Exchange 2D, também foram utilizadas nos estudos, permitindo determinar as amplitudes de movimentos moleculares em diferentes regiões do polímero, e conseqüentemente, estabelecer um quadro geral das reorientações moleculares neste materiais. Mais especificamente, foi mostrado diretamente que os movimentos moleculares em segmentos mais próximos das estruturas de sílica são altamente restritos, enquanto para segmentos afastados destas estruturas, a dinâmica molecular durante a transição vítrea é bastante similar a polímeros totalmente amorfos. De fato, foi observado que este comportamento ocorre somente em amostras com polímeros de maior peso molecular. Para amostras com cadeias poliméricas menores, o efeito da restrição do movimento pelas estruturas de sílica se estendem para a maioria dos segmentos moleculares do polímero. Finalmente, utilizando a técnica PUREX 1D, a distribuição de tempos de correlação do movimentos moleculares envolvidos na transição vítrea foi estimada para amostras com diferentes concentrações de Li. Neste caso, foi verificado que a distribuição de tempos de correlação é menor para amostras com maior concentração de Li. 


\begin{abstract}
In this thesis we will present the results of study of molecular dynamics in several bonded ormolytes doped with $\mathrm{Li}^{+}$obtained with the use of ${ }^{13} \mathrm{C}$ NMR methods. The analysis of the chemical shift anisotropy changes caused by thermicaly-activated molecular motions was accomplished. In this case, the spectra were simulated in order to analyze the effects of molecular dynamics, allowing the determination of the time scale of the correlation times versus temperature and, consequently, estimating the apparent activation energies relative to the sample glass transitions. 2D Exchange NMR, also used in the studies, allowed determining the amplitude of molecular motions of the polymer chain and, consequently, establishing a general picture of the molecular reorientations in these heterogeneous materials. More specifically, it was directly shown that the molecular motions in segments close to the silica clusters is highly restricted, while for segments far from the inorganic structure the molecular dynamics is quite similar the amorphous polymer in bulk. In fact, it was observed that this behavior is pronounced in samples with polymers presenting larger molecular weights. For samples with smaller polymer chains, the effect of the motion restriction due to the silica structures extends along the polymer. Finally, using the PUREX 1D technique, the distribution of correlation times of molecular motions involved in the glass transition was estimated for samples with different concentrations of $\mathrm{Li}$. In this case, it was verified that the distribution of correlation times is smaller for samples with larger Li concentrations.
\end{abstract}




\section{INTRODUÇÃO}

Com a motivação de desenvolver eletrólitos poliméricos sólidos com boas características mecânicas, de modo a substituir os polímeros convencionais da família do polióxido de etileno, há cerca de 10 anos foi proposta a utilização dos nanocompostos híbridos orgânico-inorgânicos denominados ormolitas. As ormolitas são materiais compostos por uma fase inorgânica, formada por estruturas de silicatos, e uma fase orgânica constituída basicamente pelo poli(etileno glicol) (PEG). Pelas diversas rotas de síntese deste material, a ormolita pode ser constituída de uma estrutura composta por combinações uni- (polimérica) ou tri-dimensionais (aglomerados) de silicatos, onde o polímero pode estar ligado física ou quimicamente à fase inorgânica. Deste modo, estes materiais, quando dopados com sais de metais alcalinos, combinam boas propriedades de condução iônica com a vantagem de substituir sistemas líquidos viscosos por materiais sólidos ou elastoméricos. Além disso, devido às interações entre as fases orgânica e inorgânica, estes sistemas apresentam uma grande heterogeneidade dinâmica, que afeta diretamente a mobilidade do cátions, que são os portadores de carga nestes compostos. Conseqüentemente, a utilização da RMN para o estudo da dinâmica tanto dos portadores de carga (normalmente $\mathrm{Li}^{\dagger}$ ), quanto da dinâmica da cadeia polimérica é de grande importância.

Devido à colaboração de nosso grupo com os pesquisadores que primeiro propuseram a confeç̧ão destes materiais, tivemos a exclusividade de estudar estes materiais com a utilização de diversas metodologias de RMN. Inicialmente utilizamos a combinação de técnicas tradicionais de espectroscopia de alta resolução 
em sólidos (dupla ressonância e rotação em torno do ângulo mágico) com métodos de relaxação magnética nuclear (medidas de tempos de relaxação $T_{1}$ e $T_{2}$ ), analisando tanto o portador de carga, com $\mathrm{RMN}$ de ${ }^{7} \mathrm{Li}$, quanto a cadeia polimérica, com $\mathrm{RMN}$ de ${ }^{1} \mathrm{H} \mathrm{e}{ }^{13} \mathrm{C}$. Estes estudos foram muito importantes para o aprimoramento destes materiais e resultaram em algumas teses e diversas publicações importantes. No entanto, estes métodos tradicionais não permitem uma análise detalhada da dinâmica lenta da cadeia polimérica e, por esta razão, começamos a utilizar a técnica de Exchange, a qual permite a obtenção de informação detalhada sobre a escala de tempo (de milissegundos a segundos) e da amplitude dos movimentos da cadeia polimérica. Com este intuito, realizamos recentemente um estudo com esta última técnica em ormolitas não dopadas, onde o polímero encontra-se ligado à fase inorgânica em ambas extremidades através de ligações covalentes (ormolitas ligadas), fato que introduz uma grande heterogeneidade dinâmica à cadeia polimérica, e os resultados mostraram diretamente estes efeitos, sem a necessidade de se utilizar modelos dinâmicos complexos.

Nesta dissertação apresentaremos os resultados no estudo da dinâmica molecular em ormolitas ligadas e dopadas com $\mathrm{Li}^{+}$, obtidos com a utilização de métodos de $\mathrm{RMN}$ de ${ }^{13} \mathrm{C}$. A análise das mudanças na anisotropia de deslocamento químico, causada por movimentos moleculares termicamente ativados foi realizada. Neste contexto, foram utilizados modelos de simulação de espectros sob os efeitos de dinâmica molecular permitindo a determinação do comportamento dos tempos de correlação como função da temperatura, e consequiente estimativa das energias de ativação aparentes relativas às transições vítreas em amostras com diferentes dopagens de Li. Técnicas de RMN de Exchange 2D, também foram realizadas nos 
estudos, permitindo determinar as amplitudes de movimentos moleculares em diferentes regiões das moléculas, e conseqüentemente, estabelecer um quadro geral das reorientações moleculares neste materiais. Mais especificamente, foi mostrado diretamente, que os movimentos moleculares em segmentos mais próximas das estruturas de sílica são altamente restringidos enquanto para segmentos longe destas estruturas, a dinâmica molecular durante a transição vítrea é bastante similar a polímeros totalmente amorfos. De fato, foi observado que este comportamento só ocorre em amostras com maior comprimento de cadeia do polímero, sendo que para amostras com cadeia menores o efeito da restrição do movimento pelas estruturas de sílica se estendem para a maiorias dos segmentos moleculares do polímero. Finalmente, utilizando a técnica PUREX 1D a distribuição de tempos de correlação do movimentos moleculares envolvidos na transição vítrea foi estimada para amostras com diferentes concentrações de $\mathrm{Li}$. Neste caso, foi verificado que a distribuição de tempos de correlação é menor em amostras com maior concentração de Li. Uma possível explicação para este comportamento também será apresentada.

Para apresentar estes resultados, inicialmente apresentaremos como estes materiais são confeccionados (Capítulo 1), neste capítulo contém um breve relato da amostra em estudo, chamado pelo nome de Ormolita. Este comentário faz referência com os eletrólitos poliméricos convencionais e modernos. Onde destaca-se a vantagem de se estudar as ormolitas como também o interesse nesses materiais. A seguir discutiremos os aspectos básicos (Capítulo 2) das técnicas de convencionais de RMN do estado sólido utilizadas como apoio ao estudo da dinâmica das amostras selecionadas neste trabalho. Pois a partir dos dados obtidos pelo uso destas técnicas, é associado a simulações dos espectros 1D do experimento de Polarização Cruzada 
para que possa ser comparado com as larguras de linha dos espectros experimentais de ${ }^{13} \mathrm{C}$ em função da temperatura. No Capítulo 3 técnicas avançadas da Ressonância Magnética Nuclear, onde nova metodologia no estudo da dinâmica de amostras sólidas, as quais vão além do estudo microscópico e visando o estudo molecular de determinados sistemas. Os princípios das técnicas de Exchange e PUREX são apresentadas de um modo abreviado, onde é enfatizado o propósito de se fazer os experimentos de RMN de Exchange. É também discutido neste capítulo uma introdução básica sobre Matriz de Exchange, a qual discute de forma simplificada o princípio do fenômeno de Exchange. Os resultados obtidos, bem como as interpretações e discussões dos mesmos no Capítulo 4 e, finalmente, apresentamos as Conclusões gerais e Perspectivas de extensão deste trabalho. 


\section{Capítulo 1: Compostos Híbridos Orgânico- Inorgânicos.}

\section{Introdução}

\subsection{Eletrólitos Poliméricos.}

Atualmente, os polímeros dominam a indústria de materiais modernos, e possuem um papel fundamental em nossa vida, em aplicações tão variadas desde um simples fio dental até uma prótese humana. A produção anual mundial de polímeros, em geral, excede a produção conjunta de todos os outros materiais manufaturados, empregando muitas pessoas e envolvendo bilhões de dólares. Desta forma, torna-se útil a nossa participação nesta área de pesquisa em materiais tão importante e ao mesmo tempo bem adequada para estudos por Ressonância Magnética Nuclear. O interesse despertado por esses novos materiais está baseado nas suas enormes potencialidades de utilização em dispositivos práticos.

A necessidade de usar os condutores iônicos (eletrólitos) sólidos foi constatada quando se procurou otimizar as propriedades dos dispositivos eletroquímicos como: baterias e sensores. Entretanto, no passado relativamente recente, a grande maioria desses condutores iônicos sólidos eram constituídos por certas cerâmicas ou cristais iônicos. Esses materiais são intermediários entre os sólidos cristalinos ordinários, que apresentam estrutura tridimensional regular com os átomos ou íons móveis e os eletrólitos líquidos, que não têm estrutura ordenada, mas os íons são móveis. Neste caso, a condução ocorre pelo salto dos íons de uma posição vacante a outra. A inconveniência desses materiais é que a condutividade iônica apresenta valores consideráveis somente em temperaturas elevadas. 
É por esta razão que Wright e Fenton abriram uma nova alternativa ao mostrar que certos sistemas poliméricos sólidos dopados com sais de metais alcalinos apresentam boa condutividade iônica,[1]. Os eletrólitos poliméricos sólidos são formados pela complexação de polímeros que possuem hetero-átomos em sua cadeia com sais de metais alcalinos. O sal alcalino utilizado como dopante, por exemplo, $\mathrm{LiClO}_{4}, \mathrm{LiBF}_{4}$ e $\mathrm{LiCF}_{3} \mathrm{SO}_{3}$ fica parcialmente dissociado na matriz polimérica [2]. O processo de solvatação do metal alcalino é facilitado pela presença do hetero-átomo presente no segmento molecular, onde há um excesso de carga negativa. A origem da condutividade iônica deve-se ao movimento contínuo dos íons pelas regiões amorfas do polímero [3, 4] e, principalmente, ao longo das cadeias [5], podendo ocorrer também inter-cadeias [6]. Desta forma, o pré-requisito para que haja mobilidade dos segmentos moleculares e condutividade iônica, é o eletrólito se encontrar acima de sua temperatura de transição vítrea $\left(T_{\mathrm{g}}\right)$ e apresentar baixa cristalinidade.

Recentemente, Gadjourova et al [7] propuseram que a condutividade iônica na fase cristalina de complexos cristalinos polímero-sal, que se formam em alguns casos para altos teores de dopante, pode ser maior que na fase amorfa, e que o processo de transporte iônico ocorre nas regiões cristalinas, através de túneis formados pelo polímero.

Vários estudos foram efetuados para otimizar as características dos polímeros condutores iônicos sólidos tradicionais, cujo exemplo mais importante é o poli(óxido etileno) (PEO) dopado com sais de lítio [8]. Como o PEO apresenta um alto teor de fase cristalina à temperatura ambiente[8], visou-se inicialmente a supressão da cristalinidade através da utilização de compostos de intercalação, de blendas e aditivos [2]. Um dos novos materiais utilizados como eletrólito sólido, ormolita, 
onde o polímero apresenta-se totalmente na fase amorfa, será apresentado na sessão 1.2 .

\subsection{Ormolitas.}

Uma forma inteligente de suprimir a cristalinidade é a utilização de aglomerados de siloxano, o qual pode estar ligado à matriz polimérica de forma física (ligações de Hidrogênio ou forças de van der walls) ou química (ligação covalente). Gerando assim um material amorfo que possui duas fases: uma orgânica (polímero) e outra inorgânica (siloxano), por esta razão também denominado híbridos orgânico-inorgânicos ou ormolitas (do termos em inglês ormolyte, sigla de organically modified eletrolyte).

Os materiais condutores iônicos estudados neste trabalho correspondem a uma classe moderna de materiais que resultaram da evolução de polímeros condutores iônicos tradicionais como o poli(óxido etileno) (PEO) [9-12]. As ormolitas são produzidas pelo processo sol-gel à temperatura ambiente [13]. A estrutura da fase inorgânica (siloxano) pode ser da forma polimérica, onde os silicatos são ligados em cadeia se sintetizados com catalisadores ácidos, ou na forma de aglomerados nanométricos (clusters) se for sintetizado com catalisador básico [13, 14]. Após o processo de solvatação dos sais pelo polímero, os cátions ficam complexados aos átomos de oxigênios e, como há muitas cadeias poliméricas, cada cátion normalmente é compartilhado por várias cadeias ao mesmo tempo, deste modo, as cadeias poliméricas ficam indiretamente ligadas entre si fracamente (cross link)[15], resultando em uma aumento da temperatura de transição vítrea da fase orgânica. 
Como o movimento do cátion é promovido pela dinâmica da cadeia polimérica no estado amorfo [12], é desejável esta fase encontre-se no estado elastomérico. Nestas condições, o movimento do segmento molecular do polímero acima da $T_{\mathrm{g}}$ é quase comparável ao estado líquido. Neste caso, os mecanismos de condutividade ocorrem através de um processo onde os cátions superam a barreira de potencial da complexação e saltam de um sítio de oxigênio para outro. Nos materiais preparados para este estudo, as temperaturas de transição vítrea estão sempre abaixo da temperatura ambiente, condição que pode ser controlada em função do grau de dopagem de lítio, do tipo de interação entre as fases orgânica e inorgânica, do peso molecular do polímero e da massa percentual do polímero no composto.

\subsubsection{Tipos de Ormolitas.}

Compostos contendo poli(etileno glicol) - PEG, podem ter suas extremidades ligadas quimicamente à fase inorgânica [10]. A natureza dessas interfaces é utilizada como critério para classificar as Ormolitas em duas classes distintas. Tipo I, na qual a interação entre as fases orgânica e inorgânica ocorre através de forças "físicas" (ligações de hidrogênio e forças de van der Walls). E Tipo II, na qual as fases orgânica e inorgânica estão unidas por ligações químicas covalentes. Neste trabalho adotaremos a seguinte nomenclatura para as ormolitas: $[\mathrm{X}]_{n}[\mathrm{Y}]-\mathrm{Z}$, onde $[\mathrm{X}]$ é a massa percentual do polímero, $[\mathrm{Y}]=[\mathrm{O}] /[\mathrm{Li}]$ é a razão molar entre os átomos de oxigênio da cadeia polimérica e os átomos de lítio, $n$ é a quantidade de meros e $\mathrm{Z}$ indica o Tipo de híbrido (I ou II). Deste modo, as Ormolitas podem ser preparadas 
em diferentes séries, mudando alternativamente os parâmetros $[\mathrm{X}],[\mathrm{Y}], n$, e $\mathrm{Z}$ $[12,13,16]$.

\subsubsection{Síntese das Ormolitas.}

A síntese das ormolitas do Tipo I envolve duas etapas: a primeira consiste na hídrólise do Tetraetoxisilano (TEOS) em pH ácido $(\mathrm{pH} \sim 2,5)$ sob ultra-som e depois se adiciona o PEG. Por último, adiciona-se o $\mathrm{LiClO}_{4}$. Após dissolução durante 5 min em ultra-som adiciona-se um catalisador básico $\left(\mathrm{NH}_{4} \mathrm{OH}\right)$ para aumentar o $\mathrm{pH}$ do sol e induzir a gelatinização do material. Finalmente, obtém-se um monólito sólido transparente [12] que passa por um processo de secagem a $80{ }^{\circ} \mathrm{C}$ durante $24 \mathrm{~h}$.

A natureza básica do catalisador utilizado na segunda etapa da síntese afeta a estrutura e o grau de condensação da fase inorgânica. $O$ uso de catalisador neutro $\left(\mathrm{NH}_{4} \mathrm{~F}\right)$ ou básico $\left(\mathrm{NH}_{4} \mathrm{OH}\right)$ leva à formação de aglomerados tridimensionais de siloxano compactos e policondensados $[14,15]$, onde predominam estruturas do tipo $Q^{3}$ e $Q^{4}$, onde a notação $Q^{n}(n=1,2,3$ ou 4) é utilizada para informar a respeito do número de conexões que cada silicato faz com os vizinhos, isto é, estrutura unitária $\mathrm{Si}^{*}(\mathrm{OSi})_{n}(\mathrm{OX})_{4-n}(\mathrm{X}=\mathrm{H}$ ou $\mathrm{C})$.

Quando a formação de agregados de siloxano ocorre a partir da utilização do catalisador ácido, por exemplo, $\mathrm{HCl}$, obtém-se estruturas poliméricas de silicato, predominando estruturas $Q^{2}$. Estes parâmetros de preparação influenciam decisivamente as propriedades dinâmicas e mecânicas das ormolitas do Tipo I. A Figura 1.1 ilustra esquematicamente a estrutura da Ormolita Tipo I. 
a)

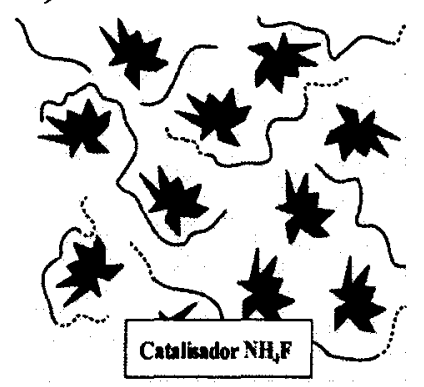

b)

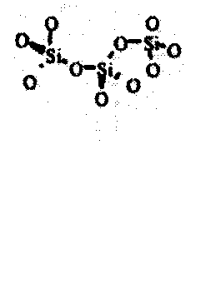

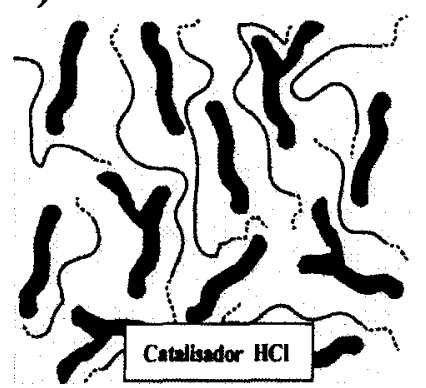

Figura 1.1: Ormolitas do Tipo I sintetizada com catalisador a) básico e b) ácido[16].

A preparação das Ormolitas do Tipo II consiste na mistura, sob refluxo a $80{ }^{\circ} \mathrm{C}$ durante $24 \mathrm{~h}$, do alcóxido de silício modificado 3-Isocianato-propiltetraetoxisilano (isoTREOS) e do PEG modificado O,O'-bis(2aminopropil)poli(etileno glicol) na presença do solvente tetrahidrofurano (THF).

Após reação, obtém-se o precursor híbrido (OEt) $)_{3}-\mathrm{Si}-\mathrm{NH}-\mathrm{CO}-\mathrm{NH}-\left(\mathrm{CH}_{2}\right)_{3}-$ (PEO)- $\left(\mathrm{CH}_{2}\right)_{3}$-NH-CO-NH-Si-(Oet) $)_{3}$, apresentando ligação química entre os componentes orgânico e inorgânico, o que confere ao material uma estabilidade química elevada. O precursor híbrido obtido é então hidrolisado em $\mathrm{pH}$ neutro (catalisador $\mathrm{NH}_{4} \mathrm{~F}$ ) na presença do solvente etanol. Adiciona-se as quantidades desejadas de $\mathrm{LiClO}_{4}$ e após algumas horas um gel úmido é obtido. $\mathrm{O}$ gel úmido passa por um processo de secagem a $80^{\circ} \mathrm{C}$ durante $24 \mathrm{~h}$ e obtém-se um monólito transparente e flexível. A Figura 1.2 ilustra esquematicamente a estrutura da ormolita Tipo II. Nesta figura ilustramos o fato de que, com o procedimento utilizado, as ormolitas do Tipo II apresentam-se com a estrutura de sílica no formato de aglomerados, com o polímero interagindo com a fase inorgânica através de ligações covalentes em ambas extremidades. 


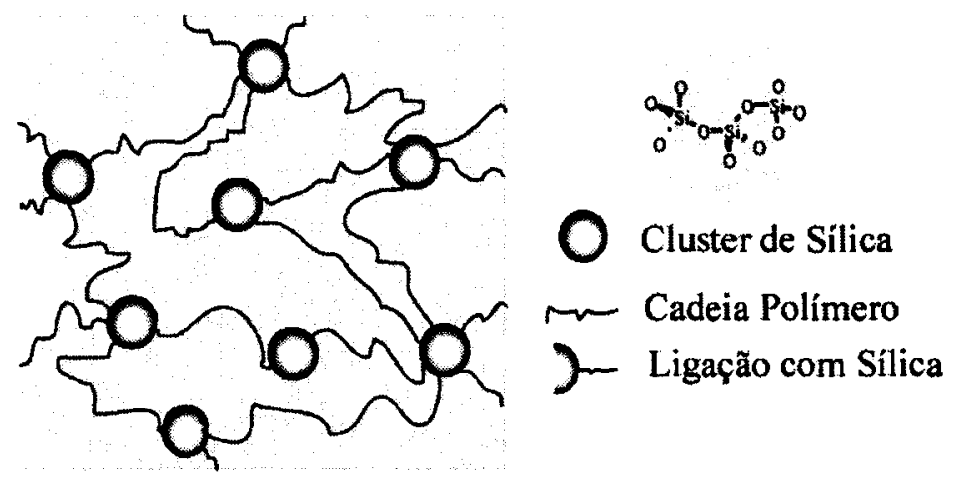

Figura 1.2: Ormolita Tipo II apresenta as fases orgânicas e inorgânicas unidas por ligaç̃es químicas covalentes. $O$ polímero utilizado possui grupos nas extremidades do tipo ...-( $\left(\mathrm{CH}_{2}\right)_{3}-\mathrm{NH}-$ $\mathrm{CO}-\mathrm{NH}-. .$. , que estão ligadas quimicamente ao aglomerado de sílica.

Portanto, no processo de formação dos híbridos orgânico-inorgânicos pode-se obter dois Tipos de Ormolitas: a não ligada, Tipo I (menos estável quimicamente) e a Ligada, Tipo II (mais estável quimicamente). Devido à ligação covalente, as ormolitas do Tipo II apresentam temperaturas de transição vítrea maiores que as do Tipo I, quando preparadas em condições $[\mathrm{X}],[\mathrm{Y}]$ e $n$ semelhantes. 


\subsection{Referências:}

1. Fenton, D.E., J.M. Parker, and P.V. Wright, Polymer, 1973. 14: p. 589.

2. MacCallum, J.R. and C.A. Vincent, Polymer Electrolyte Reviews. Vol. 2. 1989, New York: Elsevier.

3. Berthier, C., Gorecki, W., Minier, M., Armand, M., Chabagno, J., Rigaud, P., Solid State Ionics, 1983. 11: p. 91.

4. Minier,M. Berthier, C., Gorecki, W., J. Phys, 1984. 45: p. 739.

5. Lightfoot, P., A. Mehta, and P. Bruce, J. Mater Chem, 1992. 2: p. 379.

6. Donoso, J.P., Bonagamba, T. J. Panepucci, H., Oliveira, L.N., Gorecky, W., Berthier, C., Armand, M. NMR Study of Poly(Ethylene Oxide) - Lithium Salt Based Electrolyte. Jounal Chemical Physics, 1993. 98(12): p. 10026-10036.

7. Gadjourova, Z. Andreev, Y.G. Tnstall, D.P. Bruce, P. G., Nature, 2001: p. 412-520.

8. MacCallum, J.R. and C.A. Vincent, Polymer Electrolyte Reviews. Vol. 1. 1987, New York: Elsevier.

9. Judeinstein, P. Titman, J., Stamm, M., Schmidt, H., Chem. Mater, 1994. 6: p. 127.

10. Dahmouche, K. Atik, M. Mello, N. C. Bonagamba, T. J. Panepucci, H. Aegerter, M. A.., Judeinstein, P., J. Sol-Gel Sci. Technol., 1997. 8: p. 711715.

11. Dahmouche, K. Souza, P. H. Bonagamba, T. J. Panepucci, H. Judeinstein, P. Pulcinelli, S. H. Santilli, C. V., J. Sol-Gel Sci. Technol., 1998. 13: p. 909913.

12. Dahmouche, K. Atik, M. Mello, N. C. Bonagamba, T. J. Panepucci, H. Judeinstein, P. Aegerter, M. A., New Li+ ion-conducting Ormolytes. Sol. Energy Mater. Sol. Cells, 1998. 54: p. 1-8.

13. Mello,N. C. Bonagamba,T.J. Panepucci, H. Dahmouche, K. Judeisten, P. Aegerter M. A., et al., NMR Study of Ion-Conducting Organic-Inorganic Nanocomposites Poly(ethylene glycol)-Silica-LiClO4. Macromolecules, 2000. 33(4): p. $1280-1288$.

14. Souza, P. H. Bianchi, R. F. Dahmouche, K. Judeisten, P. Faria, R. M. Bonagamba, T.J., Solid-State NMR, Ionic Conductivity, and Thermal Studies of Lithium-doped Siloxane-Poly(propylene glycol) Organic-Inorganic Nanocomposites. Chem. Mater., 2001. 13(10): p. 3685-3692.

15. Mello, N.C., Estudo de Polimeros e Compostos Hibridos OrgânicosInorgânicos Condutores Iônicos Utilizando-se Espectroscopia de Alta Resolução e Relaxação em Sólidos por RMN., in Instituto de Física de São Carlos. 1998, Universidade de São Carlos: São Carlos. p. 178.

16. Judeinstein, P., http://patoo.hope.free.fr/english/hybrids.php. 2003. 


\section{Capítulo 2: Ressonância Magnética Nuclear Convencional.}

\section{Ressonância Magnética Nuclear.}

As técnicas de RMN convencionais utilizadas neste trabalho foram: Desacoplamento Dipolar (DD, do termo em inglês Dipolar Decoupling) e Polarização Cruzada (CP, do termo inglês Cross Polarization), as quais são utilizadas para a obtenção de espectros $d e{ }^{13} \mathrm{C}$ com maior intensidade e melhor resolução $[1,2]$.

\subsection{Princípios Básicos de Ressonância Magnética Nuclear.}

A Ressonância Magnética Nuclear (RMN), como todas as formas de espectroscopia, trata-se da interação da radiação eletromagnética com a matéria[3]. Sendo que o efeito de RMN ocorre para núcleos que possuem momentos magnéticos e angulares, $\vec{\mu}$ e $\vec{J}$, respectivamente. Os núcleos apresentam momentos magnéticos e angulares paralelos entre si, respeitando a expressão $\vec{\mu}=\gamma \vec{J}$, onde $\gamma$ é o fator giromagnético. O momento angular $\vec{J}$ é definido, quanticamente, por $\vec{J}=\hbar \vec{I}$, onde $\vec{I}$ é um operador adimensional, também denominado de momento angular ou spin, cujos valores podem ser somente números inteiros ou semi-inteiros $0,1 / 2,1,3 / 2$, 2.... A separação entre os níveis de energia $\Delta E=\gamma \mathrm{I} h B_{0}$ é um resultado da interação do momento magnético $\vec{\mu}$ do núcleo atômico com o campo magnético $\vec{B}_{0}$ aplicado. $\mathrm{Na}$ espectroscopia de RMN é possível controlar a radiação eletromagnética (faixa de radiofreqüência ou $R F$ ) e descrever a interação desta radiação com os spins nucleares 
do sistema. Isto contribui em grande parte para o desenvolvimento do grande número de técnicas utilizadas em RMN. Quase todos os elementos químicos têm ao menos um isótopo com um núcleo atômico que possui momento magnético $\vec{\mu}$, e quando este é colocado em um campo magnético externo, e a ele for aplicada uma excitação com freqüência igual a sua freqüência de precessão $\left(v_{o}\right)$, tal núcleo é retirado de seu estado de equilíbrio. Após a retirada do campo de RF, este núcleo tende a voltar ao seu estado fundamental de equilíbrio através dos processos de relaxação spin-rede $\left(T_{1}\right)$ e relaxação spin-spin $\left(T_{2}\right)$.

\subsection{Interações de spin nuclear ( $(\mathrm{=}=1 / 2)$ no estado sólido.}

Experimentos de Ressonância Magnética Nuclear com amostras no estado sólido apresentam resultados diretamente relacionados com as propriedades físicas dos sistemas estudados. A representação da energia dos spins nucleares em experimentos de Ressonância Magnética Nuclear é expressa pelo operador Hamiltoniano[4, 5]. Assim, o Hamiltoniano de spin nuclear descreve as interações que definem a posição e a forma da linha espectral pode ser decomposta em uma soma de várias interações e assume a seguinte forma:

$$
\mathrm{H}_{R M N}=\mathrm{H}_{Z}+\mathrm{H}_{R F}+\mathrm{H}_{D}+\mathrm{H}_{D Q}
$$

Sendo $H_{z}$ e $H_{R F}$ as interações Zeeman e de radiofrequeência (RF) respectivamente, consideradas interações externas, pois são definidas pelos campos magnéticos estático, gerado pelo magneto supercondutor, e de RF, gerado pelas bobinas onde é inserida a amostra. As interações externas associadas ao acoplamento 
do momento magnético de spin $\vec{\mu}=\gamma \hbar \vec{I}$ com o campo magnético estático $\vec{B}_{0}=B_{0} \hat{z}$ (efeito Zeeman) e com a oscilação da radiofreqüência aplicada perpendicularmente ao campo magnético estático $\vec{B}_{R F}=B_{1}(t)[\cos (\omega t+\phi(t)) \hat{i}+\sin (\omega t+\phi(t)) \hat{j}]$, causa transições entre os níveis adjacentes. As demais interações são consideradas internas, visto que elas estão intrinsecamente associadas às características microscópicas da amostra, as quais alteram a distribuição dos níveis de energia definidos pela interação Zeeman, modificando o espectro. Através destas interações, principalmente a de deslocamento químico anisotrópico, estudaremos a dinâmica molecular da fase polimérica das ormolitas.

\subsubsection{Interação Zeeman.}

O Hamiltoniano Zeeman, representa o acoplamento do momento magnético nuclear $\vec{\mu}=\xi \hbar \vec{I}$ com o campo magnético externo estático $\vec{B}_{0}=\vec{B}_{0} \hat{z}$, é dada por[6]:

$$
\begin{gathered}
E=-\vec{\mu} \cdot \vec{B}_{0}=-\hbar\left(\gamma \vec{B}_{0}\right) I_{z}=-\hbar \omega_{0} I_{z} \\
H=-\hbar \omega_{0} I_{z}
\end{gathered}
$$

Como resultado deste hamiltoniano encontram-se os possíveis níveis de energia,

$$
E=-m \gamma \hbar B_{0}=-m \hbar \omega_{0}
$$

onde $m=-I,-I+1, \ldots I-1, I$ e $\omega_{0}=\gamma B_{0}$ é denominada Freqüência de Larmor. Tal desdobramento nos níveis de energia é denominado Efeito Zeeman[7]. 
A Figura 2.1 ilustra os níveis de energia para o caso de um spin $I=1 / 2$, onde pode-se observar que a diferença de energia entre os dois níveis é dada por $\Delta E=\hbar \gamma B_{0}=\hbar \omega_{0}$.

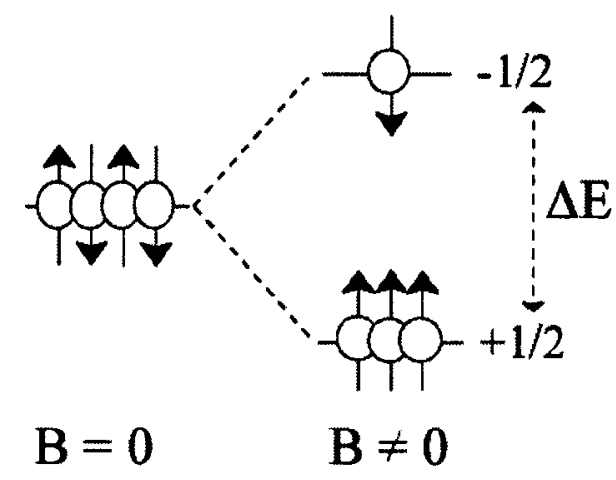

Figura 2.1. Autovalores da energia de um núcleo com momento magnético $\vec{\mu}$ em um campo magnético $\overrightarrow{\mathrm{B}}$.

$\mathrm{Na}$ realidade, quando uma amostra é colocada na presença de um campo magnético estático $\vec{B}_{0}$, há na ordem de $10^{23}$ núcleos atômicos precessionando em torno dele. Para os núcleos com $m=1 / 2$, possuem menor energia e precessionam em torno do campo magnético externo $\left(\vec{B}_{0}\right)$, orientados a favor do campo, e outros núcleos com $m=-1 / 2$, possuem maior energia e precessionam na direção oposta ao campo magnético externo, sendo estas populações $\mathrm{N}^{-}$e $\mathrm{N}^{+}$, respectivamente. A partir da Mecânica Estatística tem-se que a razão entre estas populações é dada pela distribuição de Boltzmann:

$$
\frac{N^{+}}{N^{-}}=\exp \left[\frac{\not \hbar B_{o}}{k T}\right]
$$

Tomando a intensidade do campo magnético da ordem de 1 Tesla, a temperatura da amostra em torno da temperatura ambiente, $\mathrm{T} \approx 300 \mathrm{~K}$, e o fator 
giromagnético do núcleo do átomo de Hidrogênio, $\gamma_{\mathrm{H}}=42,394 \mathrm{MHz} \cdot \mathrm{T}^{-1}$, da expressão acima obtém-se que $\mathrm{N}^{-}=1,000007 \mathrm{~N}^{+}$para temperatura ambiente.

Como $\mathrm{N}^{-}+\mathrm{N}^{+}=6,02 \times 10^{23}$, conseqüentemente determina-se que a diferença de população é de $\Delta \mathrm{N}=2,11 \times 10^{18}$ spins, implicando no fato de que $\mathrm{N}^{+}=3,0099894 \times 10^{23}$ spins precessionam no sentido oposto ao campo magnético externo e $\mathrm{N}^{-}$ $=3,01001106 \times 10^{23}$ spins precessionam em torno do campo. Desta forma, $\Delta \mathrm{N} / \mathrm{N}=3,5 \times 10^{-6}$, ou seja, a diferença de população entre os dois níveis é da ordem de partes por milhão (ppm) com relação ao número total de spins da amostra. Devido à precessão aleatória dos spins em torno da direção $\mathrm{z}$, a magnetização transversal ao campo é nula, e a magnetização longitudinal, ao longo da direção do campo magnético aplicado, é dada por $\overrightarrow{\mathrm{M}}_{0}=\Delta \mathrm{N} \vec{\mu}_{\mathrm{i}}$. Logo, $\overrightarrow{\mathrm{M}}_{0}$ é a magnetização resultante que surge na amostra quando a mesma é colocada sob a ação de um campo magnético, a qual é normalmente denominada por magnetização de equilíbrio[7].

\subsubsection{Excitação dos Sistemas de Spins com RF.}

Para que haja transições entre níveis de energias de um sistema de spins, é necessário excitar os núcleos de um dado sistema por meio da aplicação de um campo magnético oscilante com freqüência adequada (faixa de $\mathrm{MHz}$ ou RF). Promover assim, transições de spins entre os níveis de energia Zeeman. Sendo $\omega_{1}$ a freqüência de oscilação do campo $\vec{B}_{1}$, temos que $\mathrm{H}_{\mathrm{RF}}$ é dado por:

$$
\mathrm{H}_{\mathrm{RF}}=-\vec{\mu} \cdot \overrightarrow{B_{1}}
$$


O efeito de $H_{R F}$ é induzir transições entre os auto-estados de $\alpha \rightarrow \beta$, com probabilidades por unidade de tempo dada pela "regra de ouro de Fermi", a qual define a probabilidade de transição entre dois níveis de energia :

$$
P_{\alpha \rightarrow \beta}=P_{\beta \rightarrow \alpha} \cong \gamma^{2} B_{1}^{2}\left|\left\langle\alpha\left|\mathrm{I}_{x}\right| \beta\right\rangle\right|^{2} \delta\left(\omega-\omega_{L}\right)
$$

A expressão da probabilidade é tanto maior quanto maiores forem o fator giromagnético do núcleo em questão e a intensidade do campo da RF de excitação; a função $\delta$, centrada na freqüência de Larmor, garante que o campo $\vec{B}_{1}$ deve oscilar com freqüência exatamente igual ao espaçamento, em freqüência, dos níveis zeeman, para que ocorra a absorção de energia pelo sistema de spins.

\subsubsection{Interação Dipolar}

Em amostras sólidas há possibilidades de ocorrer interação direta entre núcleos, na qual os spins nucleares interagem magneticamente através do espaço. Este tipo de interação, é chamada de acoplamento dipolar[8]. Para comentarmos a respeito da interação dipolar magnética nuclear, tomaremos como exemplo uma amostra sólida, constituída basicamente por um núcleo do grupo I e outro do grupo II, onde queremos medir o sinal de RMN do núcleo do grupo II. Neste caso, a interação dipolar magnética que os núcleos do grupo II sofrem é devida, predominantemente, à presença dos núcleos do grupo I, sempre naturalmente $100 \%$ abundantes na amostra e de intenso fator giromagnético $[6,9,10]$. O núcleo II pode 
experimentar, além do campo $\vec{B}_{0}$ aplicado, um campo magnético dipolar também ao longo da direção z, $\vec{B}_{d i p}$, produzido pelo momento magnético nuclear, $\vec{\mu}_{I}$, do núcleo I, situado a uma distância $\vec{r}$. A intensidade do campo magnético dipolar, $\vec{B}_{\text {dip }}$, depende da distância internuclear, $\vec{r}$, do ângulo $\theta$ entre o vetor internuclear e o campo externo, $\vec{B}_{0}$, e do momento magnético do núcleo atômico I, $\vec{\mu}_{I}$ na forma $\vec{B}_{d i p}=\mu_{I}\left(3 \cos ^{2} \theta-1\right) / r^{3}$. Deste modo, é de costume observar alargamento da linha por interação dipolar de amostras sólidas policristalinas, pois os pares podem estar a todas as distâncias internucleares e orientações $\theta$ possíveis e, portanto teremos várias freqüências de ressonância e uma larga linha espectral[6]. O acoplamento entre os spins nucleares através dos seus momentos dipolares magnéticos, é representado pelo hamiltoniano dipolar que é expresso pela seguinte equação[6, 10]:

$$
H_{D}=\frac{1}{2} \gamma_{1} \gamma_{2} \hbar^{2} \sum_{j=1}^{N} \sum_{k=1}^{N}\left[\frac{\vec{I}_{j} \cdot \vec{I}_{k}}{r_{j k}^{3}}-\frac{3\left(\vec{I}_{j} \cdot \vec{r}_{j k}\right)\left(\vec{I}_{k} \cdot \vec{r}_{j k}\right)}{r_{j k}^{5}}\right]
$$

Esta interação é removida do espectro com a utilização da técnica de desacoplamento dipolar a ser apresentada na sessão 2.3 .

\subsubsection{Interação de Deslocamento Químico.}

A posição da linha de RMN para alguns tipos de núcleo depende estritamente do ambiente eletrônico [11]. Sabe-se que o movimento dos elétrons na nuvem eletrônica induzida pelo campo estático $\vec{B}_{0}$ do espectrômetro pode alterar o campo 
local do núcleo $B_{\text {eff }}=(1-\sigma) \vec{B}_{0}$ [12], onde $\sigma$ é o tensor proteção magnética. Este efeito de proteção nuclear produzida pode ser descrito pelo Hamiltoniano:

$$
\widehat{H}_{D Q}=-\vec{\mu} \cdot\left(\tilde{\sigma} \cdot \vec{B}_{0}\right)=-\gamma \hbar \vec{I} \cdot \tilde{\sigma} \cdot B_{0}
$$

onde $\tilde{\sigma}^{i}$ representa um tensor simétrico de segunda ordem, denominado tensor de deslocamento químico que caracteriza a blindagem do i-ésimo sítio nuclear por sua nuvem eletrônica. As constantes $\vec{I}^{i}, \vec{B}_{0}$ e $\gamma^{i}$ representam, respectivamente, o operador de spin nuclear, o vetor campo magnético e o fator giromagnético nuclear. Considerando ambas interações zeeman e deslocamento químico o Hamiltoniano resultante é:

$$
H=H_{z}+H_{D Q}=-\hbar\left(\gamma B_{0}\right)\left(1-\sigma_{z z}\right) I_{z}
$$

e o espectro será definido pela contribuição de ambas interações. Mas para o caso de moléculas é mais complicado. A presença de vários núcleos impede uma precessão livre dos elétrons no campo magnético e para moléculas sem simetria esférica, a blindagem também depende da orientação da molécula no campo magnético. Gerando uma forma anisotrópica no deslocamento químico, sendo para este caso o hamiltoniano produz um desvio na freqüência de ressonância $v$ que depende da orientação de $\vec{B}_{0}$ em relação aos eixos principais do tensor $\sigma$. Como há um desvio de freqüências de ressonância podemos citar uma distribuição de freqüências composta por todas as possiveis orientações entre o grupo C-H e o campo estático $\vec{B}_{0}$. 


$$
\omega_{D Q}(\theta, \varphi)=\omega_{i s o}+\frac{1}{2} \delta\left[3 \cos ^{2} \theta-1+\eta \sin ^{2} \theta \cos 2 \varphi\right]
$$

onde,

$$
\omega_{D Q A}(\theta, \phi)=\frac{1}{2} \delta\left[3 \cos ^{2} \theta-1+\eta \sin ^{2} \theta \cos 2 \phi\right]
$$

de maneira que o Hamiltoniano de desvio químico torna-se

$$
\hat{H}_{D Q A}=\hbar \sigma_{z z} \hat{\mathrm{I}}_{z}\left\{\omega_{i s o}+\frac{1}{2} \delta\left[3 \cos ^{2} \theta-1+\eta \sin ^{2} \theta \cos 2 \varphi\right]\right\}
$$

onde $\omega_{i s o}$ representa a parte isotrópica da interação de deslocamento químico e $\omega_{D Q A}$ a parte anisotrópica, a qual mostra que a frequência de $\mathrm{RMN}$ (frequência de precessão de spins) sob a interação de deslocamento químico depende da orientação do campo magnético no sistema de eixos principais do tensor de deslocamento químico. Como a orientação do sistema de eixos principais muda com a orientação do segmento molecular, pode-se dizer que a frequência de $\mathrm{RMN}$ reflete diretamente a orientação relativa entre campo magnético e segmento molecular. Portanto, cada segmento molecular específico contribui para uma linha específica com uma frequência de $\mathrm{RMN} \omega(\theta, \phi)$. Na Figura 2.2 podemos ver a vasta distribuição de freqüências que pode assumir as interações de desvio químico anisotrópico[10]. 

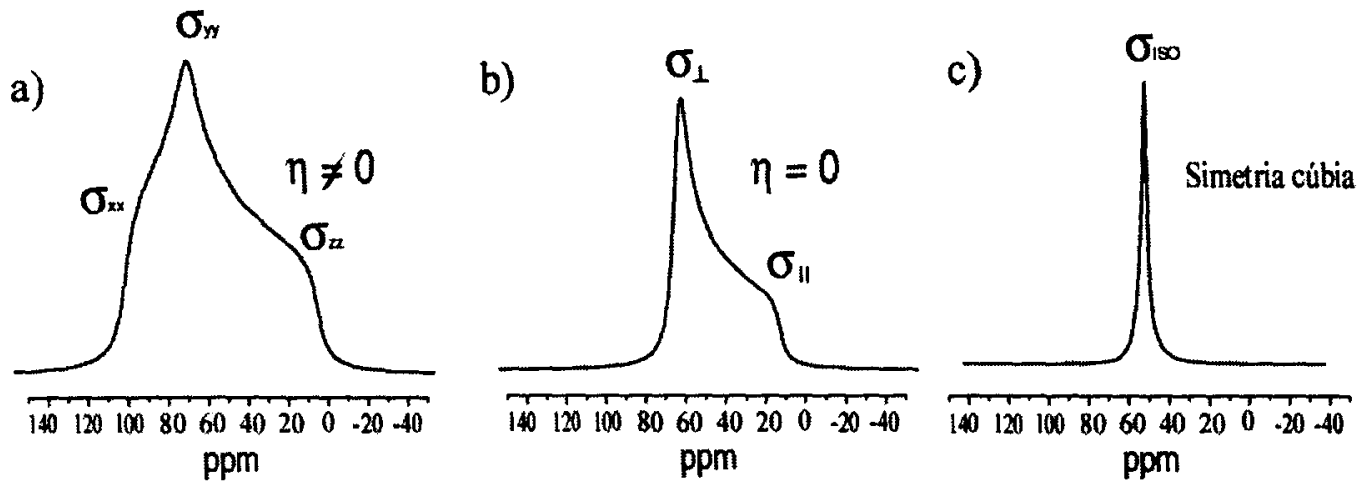

Figura 2.2: Formato da linha de RMN do estado sólido: a) simetria não-axial, b) simetria axial, c) simetria cúbica.

As formas de linha apresentadas na Fgura 2.2 traduzem os espectros típicos do padrão de pó para interações de deslocamento químico com a) $\eta=0$, b) $\eta \neq 0$, sendo $\sigma_{\square}=\sigma_{11}, \sigma_{\perp}=\sigma_{22}=\sigma_{33}$ e c) simetria cúbica, onde as formas de linha podem ser definidas pelos parâmetros de anisotropia (largura) $\delta$ e de simetria $\eta$, sendo o parâmetro de anisotropia definido por[13, 14]:

$$
\delta=\sigma_{33}-\sigma_{\text {iso }}
$$

e o parâmetro de assimetria é:

$$
\eta=\frac{\left(\sigma_{22}-\sigma_{i s o}\right)}{\delta}
$$




\subsection{Métodos utilizados para a intensificação do sinal e para o aumento da resolução dos espectros de $\mathrm{RMN}$ em amostras sólidas.}

A combinação das duas técnicas abaixo permite obter espectros de alta resolução de RMN em estado sólido:

1. Polarização Cruzada (Cross Polarization - CP)

2. Desacoplamento (Decoupling - DEC)

Estas técnicas se baseiam na distribuição das interações de spin nuclear que alargam os espectros de RMN. Para solucionar os problemas de baixa sensibilidade e longos tempos de relaxação longitudinal para núcleos de pequeno fator giromagnético e baixa abundância natural e um único experimento, é necessário a combinação destas duas técnicas.

\subsubsection{Polarização Cruzada.}

Em 1973 Pines, Gibby e Waugh divulgaram um trabalho no Journal of Chemical Physics 59, o qual tratava em relatar o ganho de sensibilidade de um dado núcleo raro $S$ através da transferência de polarização de um núcleo abundante $I$ [15]. A técnica Polarização Cruzada - $\mathrm{CP}$, consiste em otimizar os problemas relacionados com baixa abundância natural de núcleos raros. $\mathrm{O}$ efeito do $\mathrm{CP}$ é provocar um aumento da magnetização de núcleos raros do tipo ${ }^{13} \mathrm{C}$ em favor de núcleos abundantes, ${ }^{1} \mathrm{H}$, facilitando (diminuindo) a relaxação spin-rede $\left(T_{l}\right)$ e melhorando (aumentando) a relação sinal/ruído num fator $\gamma_{H} / \gamma_{C} \approx 4 \quad[1,2,9,14,16-19]$. Neste 
caso os núcleos abundantes $I$ comportam-se como um reservatório térmico, e a sua transferência de polarização para o núcleo raro $S$ se dá por processo favorável, de natureza termodinâmica. Favorecendo um sistema de alta magnetização alinhada a um baixo campo magnético $\vec{B}_{0}[1,17]$. Este contato térmico é estabelecido no chamado sistema girante de coordenadas, quando a condição de Hartmann-Hahn, $\gamma_{H} B_{1 H}=\gamma_{C} B_{1 C}$ é satisfeita através da aplicação de campos de RF para o núcleo $I \mathrm{e}$ $\boldsymbol{S}$ simultaneamente [20]. A Figura 2.3 apresenta uma demonstração esquemática deste reservatório térmico.

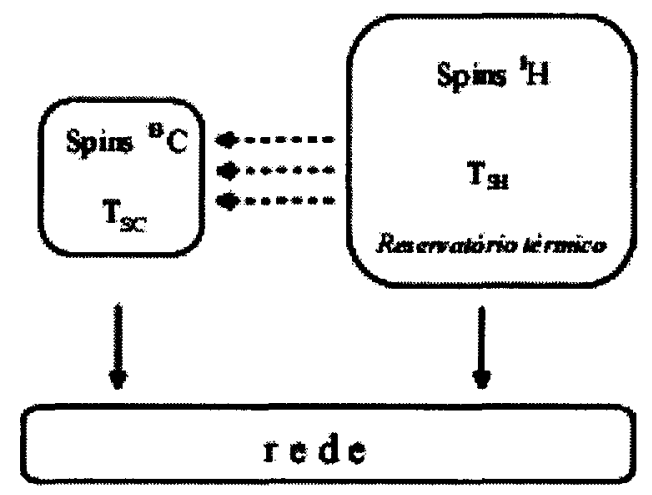

Figura 2.3: Representação de um reservatório térmico.

Quando ambos os sistemas de spins apresentarem as mesmas frequiências angulares $\omega_{1}\left(=\gamma B_{1}\right)$, obtidas através do ajuste da intensidade $B_{1}$ no sistema de coordenadas girantes, a condição de Hartmann-Hahn é satisfeita[21], e a transferência de polarização é permitida[20]. O sistema girante de coordenadas é um sistema que gira com a freqüência de ressonância de cada núcleo em particular em torno de $\vec{B}_{0}$. Em tal sistema, a frequiência de precessão de Larmor $\gamma B_{0}$ é eliminada, o que significa o desaparecimento de $\vec{B}_{0}$. O único campo magnético que age sobre cada spin é o campo de RF estático, neste referencial, e tem o mesmo papel de $\vec{B}_{0}$ no sistema de referência do laboratório. Neste caso, pode-se observar que a condição de 
Hartmann-Hahn significa que os dois núcleos terão a mesma freqüência de Larmor em seus respectivos sistemas girantes de coordenadas, $\omega_{1 H}=\omega_{1 C}$. Veja a ilustração da seqüência de pulso do processo na Figura 2.4.

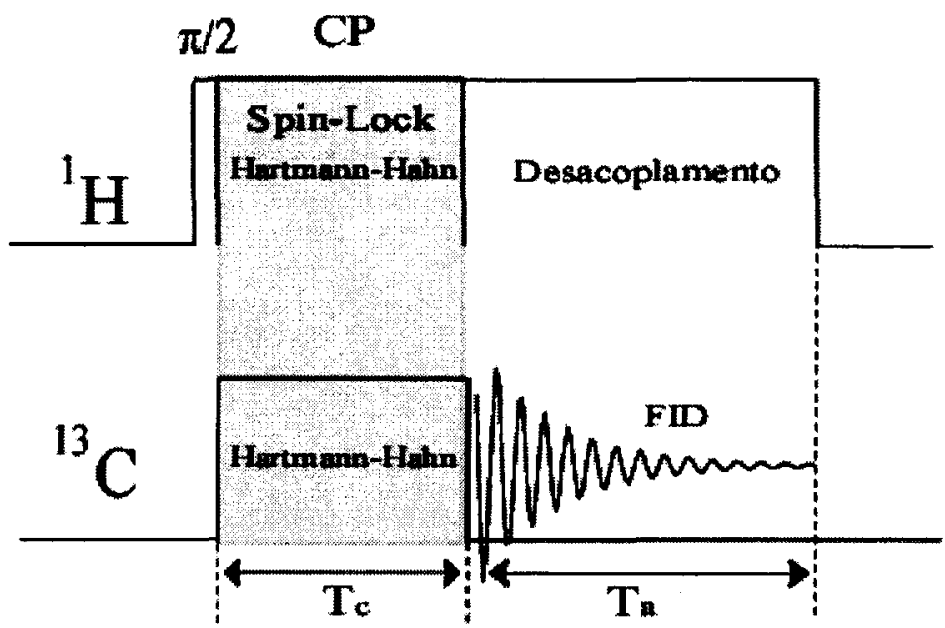

Figura 2.4: Sequência de pulso Polarização cruzada estabelecimento da condição de Hartmann-Hahn $\omega_{1 H}=\omega_{1 C}$. Tc é o tempo de contato térmico, Ta é o tempo de aquisição.

\subsubsection{Desacoplamento Dipolar.}

Para núcleos com spin $1 / 2$, as interações de spin nuclear relevantes são o deslocamento químico e as interações dipolares homo e heteronuclear. No caso específico de ${ }^{13} \mathrm{C}$, cuja abundância natural é de $\sim 1 \%$, a interação dipolar homonuclear pode ser desprezada, restando o deslocamento químico e a interação dipolar heteronuclear ${ }^{1} \mathrm{H}-{ }^{13} \mathrm{C}$. Geralmente, a interação dipolar heteronuclear predomina no espectro, tornando-se impossível à observação de padrões de pó de deslocamento químico para ${ }^{13} \mathrm{C}$ quando a interação dipolar ${ }^{1} \mathrm{H}^{13} \mathrm{C}$ está presente. No entanto, existem técnicas tradicionais capazes de eliminar ou reduzir drasticamente os efeitos 
da interação dipolar ${ }^{1} \mathrm{H}-{ }^{13} \mathrm{C}$. Dentre essas técnicas, a mais utilizada é o método de desacoplamento heteronuclear por irradiação contínua.

A técnica de Desacoplamento Dipolar Heteronuclear (DEC) foi proposta originalmente por Sarles e Cotts [22]. O desacoplamento é feito através da redução

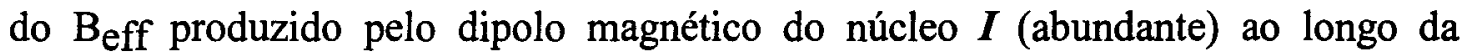
direção $\mathrm{z}$, a partir da aplicação de uma RF. A interação para o caso do ${ }^{13} \mathrm{C}$ (abundância 1\%) é do tipo heteronuclear ${ }^{1} \mathrm{H}^{-13} \mathrm{C}$ diretamente ligados ou próximos. O desacoplamento de núcleos diretamente ligados ${ }^{1} \mathrm{H}-{ }^{13} \mathrm{C}$ (da ordem de $100 \mathrm{kHz}$ ) é incompleta, mas é total para núcleos separados (da ordem de 1-10 Hz).
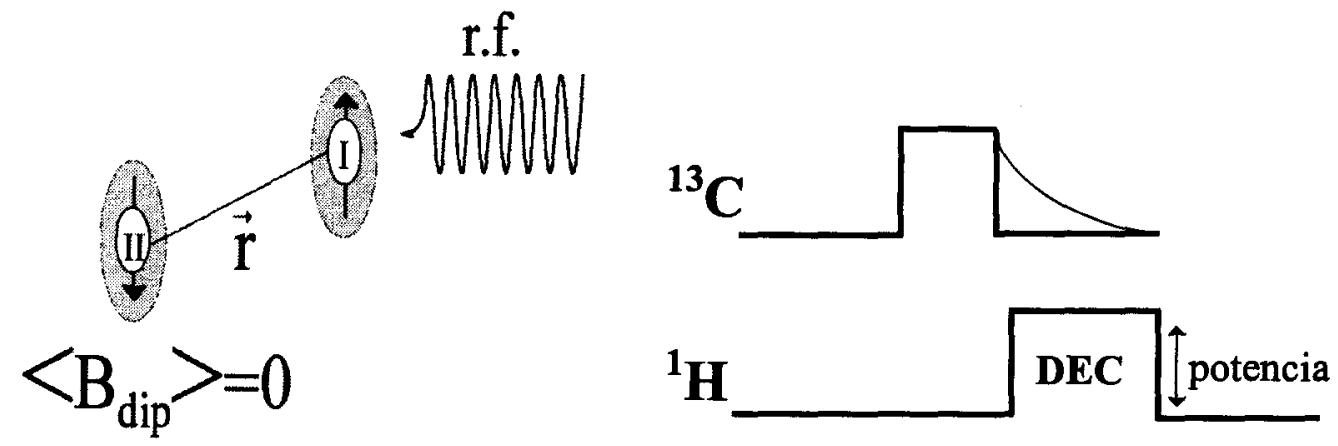

Figura 2.5: $O$ efeito do desacoplamento heteronuclear. Devido à rápida rotação do momento magnético do núcleo $\mathrm{I}$, o seu campo dipolar local, $\vec{B}_{\text {dip }}$, na direção do campo $\vec{B}_{0}$ (direção z), é em média reduzido a zero no sítio do núcleo II. 


\subsection{Referências:}

1. Stejskal, E.O. and J.D. Memory, High Resolution NMR in the Solid State. 1994, New York. 189.

2. Silvestri, R.L. and J.L. Koenig, Applications of Nuclear Magnetic Resonance Spectrometry to Solid Polymers. Analytica Chimica Acta, 1993. 283: p. $997-$ 1005.

3. Teixeira Dias, J.J.C., Espectroscopia Molecular: Fundamentos, Métodos e Aplicações. Vol. unico. 1986, Lisboa: Fundação Calouste Gulbenkian. 162.

4. Smith, S.A., W.E. Palke, and J.T. Gerig, The Hamiltonians of NMR: Part I. Concepts in Magnetic Resonance, 1992. 4: p. 107-144.

5. Smith, S.A., W.E. Palke, and J.T. Gerig, The Hamiltonians of NMR: Part II. Concepts in Magnetic Resonance, 1992. 4: p. 181-204.

6. Bonagamba, T.J., Supressão de Bandas Laterais em Experimentos de RMN com Rotação em Torno do ângulo Mágico, in Departamento de Física e Informática, Universidade de São Paulo: São Carlos. p. 82.

7. Zucchi, M.R., Implementação da técnica de espectroscopia in vivo por RMN e sua aplicacao na fisiologia do exercício, in Departamento de Física. 1997, Universidade de São Paulo: Sao Carlos. p. 69.

8. Figueroa Villar, J.D., Aspectos Quânticos da Ressonância Magnética Nuclear. Fundamentos e Aplicações da Ressonância Magnética Nuclear. Vol. 2. 2000, Rio de Janeiro: AUREMN. 85.

9. Bonagamba, T.J., Espectroscopia de Alta Resolução em Sólidos por Ressonância Magnética Nuclear, in Instituto de Física de São Carlos. 1991, Universidade de São Paulo: São Carlos.

10. deAzevedo, E.R., Novas Metodologias de Ressonância Magnética Nuclear para o Estudo da Dinâmica Lenta em Materiais Orgânicos no Estado Sólido: Aplicações em Polímeros e Proteínas, in Instituto de Física de São Carlos. 2001, Universidade de São Paulo: São Carlos. p. 197.

11. McWeeny, R., Spins in Chemistry. 1970, New York: Academic Press.

12. Lamb, W.E., Internal Diamagnetic Fields. Physical Review, 1941. 60: p. 817-819.

13. Duncam, T.M., 13C Chemical Shielding in Solids. Journal Physics Chemical Ref. Data, 1987. 16(1): p. 125-137.

14. Koenig, J.L., Spectroscopy of Polymer. 1992, Washington: American Chemical Society. 328.

15. Bathista, A.L.B.S. and J.S. Nogueira. Elementos Históricos da Ressonância Magnética Nuclear. in VII Jornada Brasileira de Ressonância Magnética Nuclear. 2002. Maringá-PR.

16. Stejskal, E.O., J. Schaefer, and J.S. Waugh, Magic-Angle Spinning and Polarization Transfer in Proton-Enhanced NMR. Journal of Magnetic Resonance, 1977. 28: p. 105-112.

17. Gil, V.M.S. and C.F.G.C. Geraldes, Ressonância Magnética Nuclear: Fundamentos, Métodos e Aplicações. 1987, Lisboa: Fundação Calouste Gulbenkian. 1012. 
18. Freitas, J.C.C., Espectroscopia de Alta Resolução por Ressonância Magnética Multinuclear aplicada ao Estudo de Zeólitas, in Instituto de Física de São Carlos. 1994, Universidade de São Paulo: São Carlos.

19. Chandrakumar, N. and S. Subramanian, Modern Techniques in HighResolution FT-NMR. 1987, New York: Springer-Verlag. 388.

20. Hartmann, S.R. and E.L. Hahn, Nuclear Double Resonance in the Rotating Frame. Physical Review, 1962. 128(5): p. 2042-2053.

21. Mehring, M., Principles of High Resolution NMR in Solids. 2nd ed. 1983, New York: Springer-Verlag. 342.

22. Sarles, L.R. and R.M. Cotts, Double Nuclear Magnetic Resonance and the Dipole Interacations in Solids. Physical Review, 1958. 111(3): p. 853-859. 


\section{Capítulo 3: Técnicas de Ressonância Magnética Nuclear destinadas ao Estudo da Dinâmica Molecular.}

\subsection{Introdução.}

A dinâmica molecular apresenta importantes efeitos nas propriedades mecânicas e físico-químicas de moléculas, tais como no comportamento de materiais amorfos[1], condução em polímeros [2-5], na contribuição da classificação de alimentos naturais[6], na classificação de resinas[7], na caracterização de amidos[8], etc. Os processos de relaxação da magnetização são causados devido ao movimento molecular[9], e as taxas de relaxação medidas podem ser relacionadas com o tempo de correlação característico do movimento, $\tau_{c}$. A medida da taxa de relaxação provê informações sobre a dinâmica molecular em vários regimes de frequiência[10, 11], onde pode-se medir os tempos de relaxação $\left(T_{1}, T_{2}\right.$ e $\left.T_{1 \mathrm{p}}\right)$, e com isso, consegue-se estudar diferentes movimentos que ocorrem com uma distribuição de freqüências. Em RMN podemos classificar o estudo da dinâmica do estado sólido em três etapas: rápida, intermediária e lenta. Movimentos rápidos, com freqüências da ordem de $\mathrm{MHz}$, podem ser detectados por meio de experimentos de relaxação spin-rede $\left(\mathrm{T}_{1}\right) . \mathrm{A}$ dinâmica intermediária, com taxas entre $10-100 \mathrm{kHz}$, pode ser caracterizada por experimentos de análise de largura de linha, técnicas de relaxação como $T_{1 \rho}$ (relaxação spin-rede no referencial rotante). Sistemas que envolvem processos dinâmicos lentos $(0.1-1000 \mathrm{~Hz})$, as informações podem ser obtidas através de experimentos de RMN de Exchange, onde os movimentos moleculares lentos são 
observados em termos de mudanças na freqüência de RMN, a qual reflete diretamente mudanças na orientação dos segmentos moleculares.

\subsection{Cálculo do Espectro de RMN sob a ação de Movimentos Moleculares.}

Em uma análise mais detalhada as informações sobre a dinâmica molecular são geralmente obtidas utilizando simulações numéricas dos espectros que contem modelos dinâmicos específicos. Deste modo, é importante estabelecer parâmetros adequados que liguem a dinâmica molecular e as simulações espectrais. Na ausência de dinâmica molecular o sinal de RMN pode ser calculado com base nas interações de spin nuclear sentidas pelo núcleo. No caso de núcleos de ${ }^{13} \mathrm{C}(\mathrm{S}=1 / 2)$ em sistemas orgânicos se o sinal é adquirido com o uso de desacoplamento de ${ }^{1} \mathrm{H}$ as interações presentes na amostras são a interação Zeeman e a de deslocamento químico. Como já discutido, em sólidos a interação de deslocamento químico depende da orientação do sistema de eixos principais da interação em relação ao campo magnético $\mathbf{B}_{\mathbf{0}}$. Deste modo, localmente esta interação é definida pela orientação de cada molécula em relação ao campo $\mathbf{B}_{0}$, já que o sistema de eixos principais é fixo para cada molécula. Como a freqüência de RMN é definida pela interação de spin nuclear, pode-se dizer que em um sólido amorfo ou policristalino cada ${ }^{13} \mathrm{C}$ em uma dada molécula possui uma freqüência de ressonância que depende da orientação da molécula e da vizinhança local. Como resultado disso, podemos imaginar que em um sólido existe um conjunto de magnetizações que possuem diferentes freqüências de ressonância, sendo a magnetização total a soma dessas magnetizações. É interessante notar que cada uma das magnetizações individuais desse conjunto é constituída pela soma de 
todos os momentos magnéticos de núcleos de ${ }^{13} \mathrm{C}$ que estão localizados em moléculas que possuem a mesma orientação (isocromatas) em relação ao campo $\mathbf{B}_{0}$. Podemos então denominar por $\boldsymbol{M}_{\boldsymbol{i}}$ a magnetização correspondente ao conjunto de núcleos cuja orientação do campo magnético $\mathbf{B}_{0}$ no sistema de eixos principais da interação de deslocamento químico é $\left(\theta_{i}, \phi_{i}\right)$ e cuja correspondente freqüência de RMN é $\Omega\left(\theta_{i}, \phi_{i}\right)$. Após um esquema de excitação (que pode ser um pulso de $\pi / 2$ ou um esquema de polarização cruzada) a magnetização transversal correspondente evolui com a sua freqüência característica resultado no sinal de RMN. Portanto, contribuição de cada isocromata para o sinal de RMN, ou seja, a evolução pode ser calculada usando a equação de Bloch, que na ausência de relaxação fica:

$$
\frac{d M_{i}}{d t}=i \Omega\left(\theta_{i}, \phi_{i}\right) M_{i} \quad \text { onde } \quad M_{i}=M_{x}^{i}+i M_{y}^{i}
$$

Para considerar todos os sítios moleculares $\left(\theta_{i}, \phi_{i}\right)$ esta equação pode ser escrita de forma vetorial, ou seja:

$$
\frac{d \vec{M}}{d t}=i \tilde{\Omega} \vec{M} \text { com } \vec{M}=\left(\begin{array}{c}
M_{1} \\
M_{2} \\
\vdots \\
M_{n}
\end{array}\right) \text { e } \tilde{\Omega}=\left(\begin{array}{cccc}
\Omega_{1}\left(\theta_{1}, \phi_{1}\right) & \cdots & 0 & 0 \\
0 & \Omega_{2}\left(\theta_{2}, \phi_{2}\right) & \cdots & 0 \\
\vdots & \vdots & \vdots & \vdots \\
0 & 0 & \cdots & \Omega_{3}\left(\theta_{n}, \phi_{n}\right)
\end{array}\right)
$$

Note a definição da matriz real $\tilde{\Omega}$, conhecida como matriz das freqüências. Neste caso a solução desta equação é trivial resultando em:

$$
\vec{M}=\vec{M}_{i 0} e^{i \ddot{\Omega} t}
$$

onde $\vec{M}_{i 0}$ é um vetor que contém as magnetizações iniciais de cada sítio. Para obter o sinal de RMN é necessário somar sobre todas as possíveis orientações $\left(\theta_{i}, \phi_{i}\right)$ (média sobre todas as orientações) com o peso probabilístico de cada uma, ou seja. 


$$
S(t)=\langle M(\theta, \phi, t)\rangle=\frac{1}{4 \pi} \int_{0}^{2 \pi} d \phi \int_{0}^{\pi} M(\theta, \phi, t) \operatorname{sen} \theta d \theta
$$

Em termos do formalismo vetorial anterior isto significa somar sobre todos os elementos com os respectivos pesos angulares.

No caso de haver movimento molecular durante a aquisição do sinal de RMN o tratamento a ser feito é bastante parecido. Basta notar que se há movimento molecular durante a evolução da magnetização a freqüência de uma dada isocromata não é mais constante em todos os instantes de tempo, já que durante a evolução a orientação de um dado segmento molecular varia de acordo com o processo dinâmico. Para levar este efeito em consideração devemos introduzir um novo termo na equação de precessão matricial que se encarregue de conectar as freqüências dos vários sítios. Intuitivamente podemos dizer que as características deste novo termo devem ser as seguintes: 1) deve ser uma matriz imaginária, pois será simplesmente um termo de conexão entre as várias freqüências e não deve mudar as freqüências de precessão individuais do sistema; 2) Os elementos diagonais dessa matriz devem estar associados com as populações de cada sítio individual. 3) Deve possuir termos não diagonais, já que só assim pode fazer com que os diversos elementos da matriz de freqüência possam ser interconectados durante a evolução. Deste modo, a equação matricial de precessão pode ser reescrita como:

$$
\frac{d \vec{M}(t)}{d t}=i(\tilde{\Omega}+i \tilde{\Pi}) \vec{M}(t)
$$

Esta equação é conhecida como equação de Bloch-MacDowell [12-14]. A 
matriz $\tilde{\Pi}$ é conhecida como matriz de Exchange, e seus elementos não diagonais $\Pi_{i j}$ representam o probabilidade por unidade de tempo (taxa), de que ocorra uma mudança na frequiência, ou equivalentemente na orientação molecular, de $\Omega\left(\theta_{i}, \phi_{i}\right)$ para $\Omega\left(\theta_{j}, \phi_{j}\right)$. Já os elementos diagonais $\Pi_{i i}$ representam a taxa de probabilidade de que haja uma reorientação molecular do sítio I para qualquer outro sítio acessível, isto é $\Pi_{i j}=\sum_{i(i \neq j)}^{N} \Pi_{i j}$. Finalmente, uma outra propriedade da matriz de Exchange é que se a distribuição inicial de magnetização é tal que a população de cada sítio é $P_{i}$, então a equação de balanço detalhado deve-ser satisfeita, isto é, $P_{i} \Pi_{i j}=\Pi_{i j} P_{j}$. Como exemplo de matrizes de Exchange representado processos dinâmicos, considere um movimento molecular que envolva saltos entre dois sítios específicos com uma taxa $k=1 /\left(2 \tau_{C}\right)$, onde $\tau_{C}$ é o tempo de correlação do movimento. Neste, caso a matriz de Exchange é dada pela equação [3.6] Já no caso em que a reorientação ocorre como saltos aleatórios entre $\mathrm{N}$ sítios (random jumps) a matriz de Exchange é dada pela equação [3.7]. Este último modelo é comumente usado em processos onde não existe memória reorientacional, como é o caso de processos de transição vítrea.

$$
\begin{gathered}
\tilde{\Pi}=\left(\begin{array}{cc}
-k & k \\
k & -k
\end{array}\right) \\
\tilde{\Pi}=\left(\begin{array}{cccc}
(1-N) k & \cdots & -k & -k \\
-k & (1-N) k & \cdots & -k \\
\vdots & \cdots & \cdots & \vdots \\
-k & -k & \cdots & (1-N) k
\end{array}\right)
\end{gathered}
$$

Portanto, conhecendo-se a matriz de Exchange correspondente a um dado processo de reorientação molecular a solução da equação de Bloch-MacDowell provê 
o vetor magnetização transversal sob a ação do movimento molecular, isto é:

$$
\vec{M}=\vec{M}_{i 0} e^{i(\widetilde{\Omega}+i \bar{\Pi}) t}
$$

Com isso o sinal de RMN e o espectro correspondente podem ser calculados da mesma forma que ilustrado anteriormente. Na Figura 3.1 está mostrado um conjunto de espectros simulados para diferentes tempos de correlação e modelos dinâmicos. É facilmente visto que a forma do espectro depende fortemente do tempo de correlação, o que possibilita a determinação deste parâmetro através da comparação entre espectros experimentais simulados $[15,16]$.
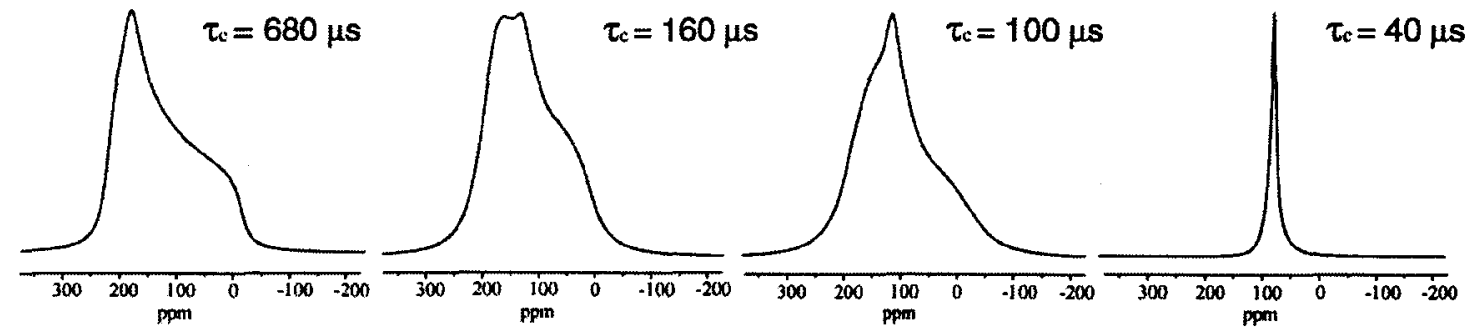

Figura 3.1: conjunto de espectros simulados para diferentes tempos de correlação do núcleo de ${ }^{13} \mathrm{C}$.

\subsection{Experimentos de Exchange.}

A dinâmica molecular representa um aspecto importante em materiais, como por exemplo polímeros sólidos, a qual influencia as propriedades macroscópicas dos materiais[17]. As técnicas de Exchange podem ser aplicadas para caracterizar em 

Molecular.

detalhes a dinâmica e a conformação molecular, tais como relaxações $\alpha, \beta$ e $\gamma$ em polímeros, onde os tempos de correlação, $\tau_{c}$, alcançam valores entre $1 \mathrm{~ms}$ a $1 \mathrm{~s} . \mathrm{O}$ princípio básico da técnica de Exchange é a medida da freqüência de RMN de um dado segmento molecular em dois tempos distintos, de maneira a se detectar a existência de processos dinâmicos lentos que podem produzir mudanças na freqüência de RMN $[17,18]$. O propósito de se fazer os experimentos de RMN de Exchange é o monitoramento da freqüência de precessão dos spins localizados num dado sítio, ou num segmento molecular, em diferentes instantes de tempo. Os intervalos de tempos em que ocorrem as perturbações de RF, são separados por um tempo de espera, denominado tempo de mistura, $\mathrm{t}_{\mathrm{m}}$ (Figura 3.2). Este tempo de mistura é adicionado à sequiência de pulsos justamente para que haja mudanças de orientação num dado sítio molecular ou num segmento molecular. Normalmente, este tempo de mistura é maior que os intervalos de tempo evolução. A reorientação dos movimentos moleculares implica numa mudança da freqüência de precessão de um spin nuclear localizado em uma molécula. Isto significa que a observação da freqüência de RMN em diferentes instantes de tempo representa o monitoramento em tempo real das orientações sucessivas de um dado segmento molecular durante o movimento molecular[19]. Explicitando a dependência da freqüência de ressonância com a orientação dos segmentos moleculares, $\omega(\theta, \phi)$, e quando esta dependência muda em relação à orientação do segmento molecular, deriva-se uma nova freqüência de precessão $\omega_{0}[17]$ como mostrado na Figura 3.2.

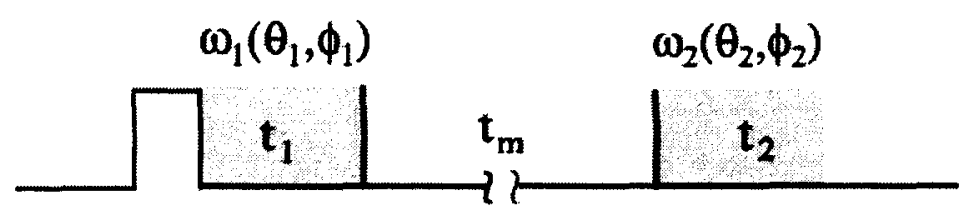


Figura 3.2: Princípio do experimento 2D Exchange para detecção de movimentos reorientacionais. As frequêencias dependentes dos ângulos em dois instantes de tempo distintos, os quais são separados por um tempo de mistura $t_{\mathrm{m}}$. Uma reorientação (mudança dos ângulos $(\theta, \phi)$ ) é detectada através da mudança concomitante das freqüências $\omega_{1}\left(\theta_{1}, \phi_{1}\right)$ para $\omega_{2}\left(\theta_{2}, \phi_{2}\right)$. Figura adaptada da referência [17].

Devido a esta mudança de $\omega_{1}$ para $\omega_{2}$ há um diferente ordenamento da freqüência de ressonância em instantes de tempos distintos. Esta dependência da freqüência de RMN com a orientação de um dado segmento molecular relativo a $\vec{B}_{0}$, em geral, causa uma mudança da freqüência que pode ser detectada através de um experimento de Exchange. Veja Figura 3.3.

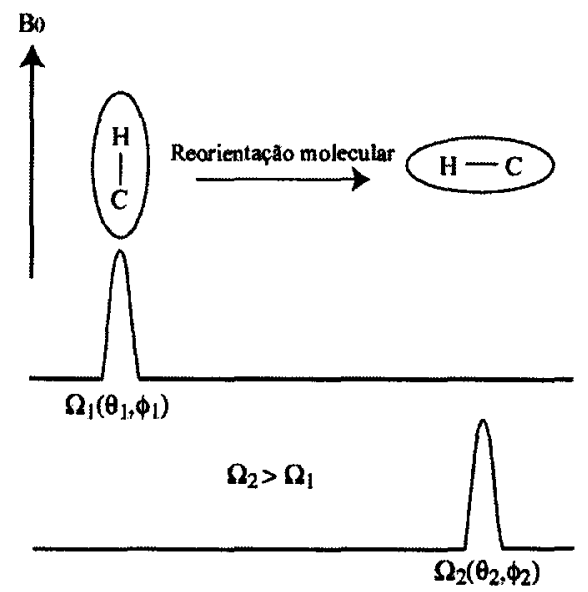

Figura 3.3: Esquema da reorientação molecular de $\omega_{1}\left(\theta_{1}\right.$, $\left.\phi_{1}\right)$ para $\omega_{2}\left(\theta_{2}, \phi_{2}\right)$, devido ao processo de Exchange do movimento lento.

A reorientação durante $t_{m}$ envolve mudança dos ângulos $(\theta, \phi)$, os quais são detectados como mudança de frequiência $\omega(\theta, \phi)$ no experimento de Exchange. Ocorrendo a reorientação molecular durante o tempo de mistura $t_{m}$, uma nova freqüência irá aparecer, tal que $\omega_{2} \neq \omega_{1}$, e a linha selecionada perderá sua intensidade correspondente. A partir da intensidade dos picos integrados, a população relativa do segmento molecular móvel pode ser determinada. $\mathrm{O} \mathrm{t}_{\mathrm{m}}$ depende do conteúdo do tempo de correlação do processo de movimento que produz o Exchange. Estas 
intensidades são proporcionais as probabilidades $S\left(\omega_{2} ; t_{\mathrm{m}} / \omega_{1}\right)$ de parecer um segmento com $\omega_{2}$, sobre a condição imposta pela de seqüência de pulsos que tem a freqüência $\omega_{1}$ há um tempo $t_{m}[17]$.

A interpretação do espectro de Exchange 2D tem caráter probabilístico devido a reorientação dos segmentos moleculares ao longo das freqüências de ressonância durante o tempo de mistura $t_{m}$, com os tempos de espera $t_{1}$ e $t_{2}$ diferentes, causando o aparecimento de picos não diagonais $\left(\omega_{1} \neq \omega_{2}\right)$. Para entendermos a natureza probabilística dos espectros de 2D Exchange, podemos considerar um sistema idealizado onde existam apenas duas orientações possíveis, e conseqüentemente duas freqüências de RMN para os diversos segmentos moleculares da amostra. Neste caso particular, os demais movimentos moleculares se restringem apenas a duas orientações, as quais possuem dois sítios moleculares distintos denominados A e B. Considerando que as populações destes sítios moleculares sejam iguais para $t_{m}=0$, a probabilidade de encontrarmos um spin localizado no sítio $A$ antes de $t_{m}$ em um sítio B depois de $\mathrm{t}_{\mathrm{m}}$ será nula, $S\left(\omega_{2}=\omega_{1}\right)=0$, e o espectro de 2D Exchange será diagonal, $\omega_{1}=\omega_{2}$ (Figura 3.4.a). A medida da evolução de $t_{m}$ aumenta a probabilidade $S\left(\omega_{1}, \omega_{2}\right.$; $\left.t_{m}\right)$ de que $\omega_{1} \neq \omega_{2}$, fazendo com que picos com freqüências $\left(\omega_{A}, \omega_{B}\right)$ e $\left(\omega_{B}, \omega_{A}\right)$ apareçam no espectro (Figura 3.4.b). Para visualizar os picos não diagonais, $t_{m}$ precisa ser grande o suficiente para que os dois sítios moleculares sejam acessados com igual probabilidade, fazendo com que a intensidade dos picos fora da diagonal sejam iguais a dos picos diagonais, Figura 3.4.c, tendo uma maior razão ( $\left.\mathrm{S}_{\text {Exchange }} / \mathrm{S}_{\text {Total }}\right)$ no espectro 2D. 
a)

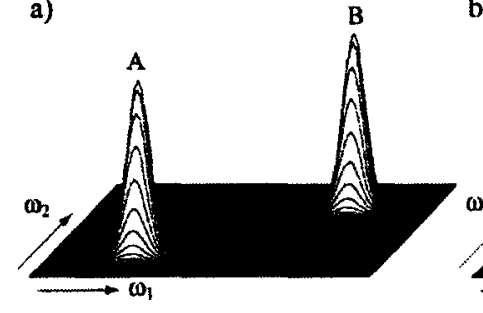

b)

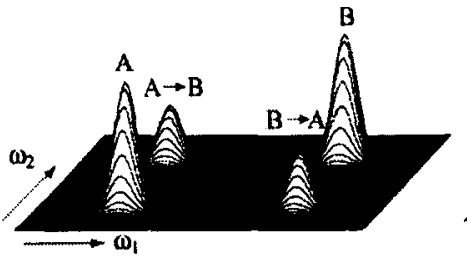

b)

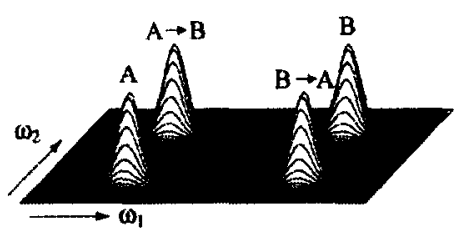

Figura 3.4: Sequiência da evolução do espectro Exchange 2D com função de $t_{m}$ para o processo de reorientação molecular entre os sítios A e B. (a) $t_{m}=0, b$ ) $t_{m}=$ intermediário e c) $t_{m}=$ indeterminado.

No entanto, a informação gerada pelo espectro 2D Exchange em estado sólido em amostras de diversas naturezas, tais como, cristalinas, policristalinas, semicristalinas, amorfas, com irregularidades eventuais, microestruturas e interfaces, está relacionada exclusivamente aos processos de reorientação molecular. Neste caso, o estudo dos ângulos de reorientação pode ser obtido através de simulações dos espectros 2D Exchange utilizando-se métodos padrões[17, 19].

\subsection{RMN de Exchange Bidimensional - Exchange 2D.}

RMN de Exchange bidimensional é uma técnica de RMN do estado sólido que estuda as freqüências dos spins de um dado segmento molecular que são medidas em dois instantes de tempo distintos e correlacionados através de um mapa bidimensional (espectro 2D). A seqüência de pulsos utilizada no experimento de $\mathrm{RMN}$ de Exchange bidimensional para $0{ }^{13} \mathrm{C}$ está ilustrada na Figura 3.5. 


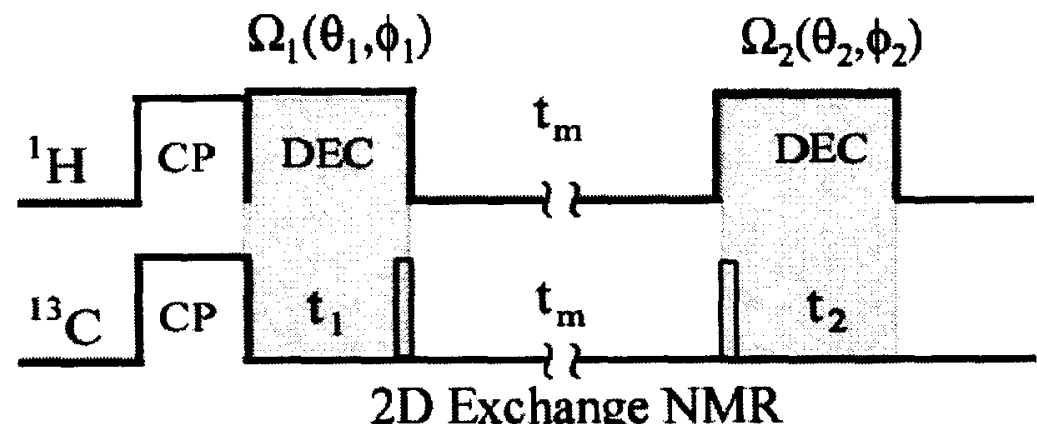

Figura 3.5 Seqüência de pulsos utilizada para obtenção do espectro de 2D Exchange NMR através do deslocamento químico anisotrópico. A evolução nos tempos $t_{1}$ e $t_{2}$ é feita sob desacoplamento heteronuclear. Na primeira parte da sequiência de pulso, aumento da sensibilidade do ${ }^{13} \mathrm{C}$ para que haja uma melhor magnetização como também a relação sinal ruído a partir da Polarização Cruzada. $E m t_{1}$ temos a decodificação de fase, $t_{m}$ temos a reorientação molecular (informação em $t_{1}$ é transferida para $t_{2}$ ). E detecção do sinal com amplitude modulada através da informação contida em $t$.

Após a perturbação, $(\pi / 2)_{-x}$, os spins evoluem no plano transversal somente sob a ação da interação de deslocamento químico, $\delta$, devida ao processo de desacoplamento heteronuclear (Figura 3.5). Depois de um tempo $t_{1}$, a magnetização é armazenada na direção $\mathrm{z}$ de modo que não executa movimento de precessão durante o tempo de mistura $t_{m} e$, finalmente, a magnetização é então colocada para evoluir novamente no plano transversal, onde o sinal é detectado.

\subsubsection{Padrões de Intensidade para Espectros de Exchange 2D: $\eta=0$ e $\eta \neq 0$.}

A intensidade dos espectros bidimensionais de 2D-Exchange depende fortemente da simetria do segmento molecular estudado. há duas possibilidades de Exchange em amostras com $\eta=0$ e $\eta \neq 0$. Para o caso em que o sistema possui simetria axial $\eta=0$, o tensor de deslocamento químico depende unicamente da reorientação do eixo z do Sistema de Eixos Principais, SEP. 


$$
\omega(\theta)=\omega_{i s o}+\frac{\delta}{2}\left[\left(3 \cos ^{2} \theta-1\right)-\eta \operatorname{sen}^{2} \theta \cos ^{2} \phi\right]
$$

Aqui o interesse é somente a componente em freqüência que dependente da orientação do SEP (parte anisotrópica) e a parte isotrópica é omitida. Neste caso, a dependência da freqüência com a orientação do SEP relacionado a $\vec{B}_{0}$ é dado por:

$$
\omega(\theta)=\frac{\delta}{2}\left(3 \cos ^{2} \theta-1\right)
$$

logo, a reorientação do $\mathrm{SEP}$, e conseqüentemente do segmento molecular em relação ao campo magnético externo $\vec{B}_{0}$, induz mudanças na freqüência de desvio químico. Fazendo a primeira consideração que a reorientação do eixo $\mathrm{z}$ do SEP tenha mudado de $\theta_{1}$ para $\theta_{2}$ durante $\mathrm{t}_{\mathrm{m}}$, o ângulo de reorientação será $\beta_{R}$.

Depois de haver a reorientação molecular, o espectro na freqüência $\omega_{2}\left(\theta_{2}, \phi_{2}\right)$ consiste de um espectro de pó, o qual possui uma forma que é definida pelos fatores geométricos de reorientação molecular. Para ilustrar esta discussão sobre a reorientação molecular, devemos considerar uma expressão que descreve as freqüências de $\mathrm{RMN} \omega_{1}$ e $\omega_{2}$ correspondentes às singularidades (intensidade máxima) do espectro de pó. Quando a singularidade ocorre em $\theta_{1}$ e $\theta_{2}=\theta_{1} \pm \beta_{R}$ tem-se:

$$
\left(\begin{array}{l}
\omega_{1} \\
\omega_{2}
\end{array}\right)=\frac{\delta}{2}\left(\begin{array}{c}
3 \cos ^{2} \theta_{1}-1 \\
3 \cos ^{2}\left(\theta_{1} \pm \beta_{R}\right)-1
\end{array}\right)
$$


Capítulo 3 - Técnicas de Ressonância Magnética Nuclear destinadas ao Estudo da Dinâmica Molecular.

As expressões correspondentes às singularidades, representando a equação paramétrica de uma elipse, onde os semi-eixos a, b, e c são definidos como:

$$
a=\left|\frac{3}{4} \delta \sqrt{2} \cos \beta_{R}\right| ; b=\left|\frac{3}{4} \delta \sqrt{2} \operatorname{sen} \beta_{R}\right| \mathrm{e} \frac{b}{a}=\tan \beta_{R}
$$

logo, o padrão do espectro de pó 2D Exchange é uma elipse, cuja excentricidade está diretamente relacionada com o ângulo de reorientação.

$$
\text { Excentricidade }=\frac{b}{a}=\tan \beta_{R}
$$

Na Figura 3.6 podemos ver um conjunto de espectros 2D Exchange simulados para as singularidades entre os ângulos de $0^{\circ}$ a $90^{\circ}$. Os espectros são distintos, mesmos para a variação do ângulo de reorientação.

a)

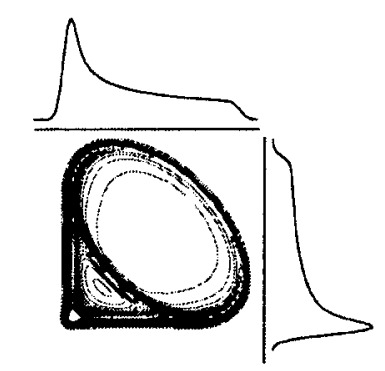

b)

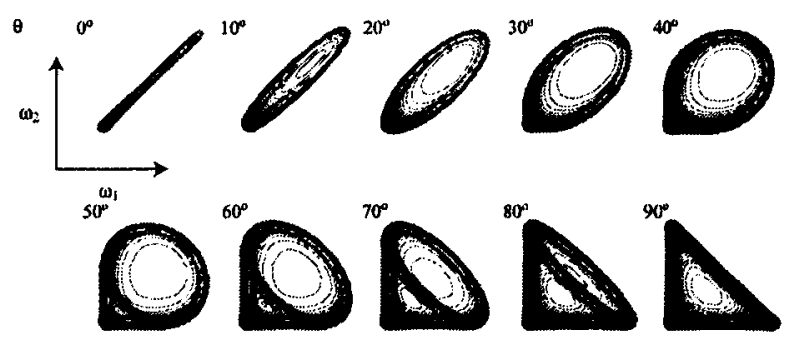

Figura 3.6 Conjunto de espectros de Exchange 2D simulados para vários ângulos de reorientação para $\eta=0$. Figura adaptada das referências $[17,19]$. 
Para o caso de simetria não axial, $\eta \neq 0$, os três ângulos de Euler $(\alpha, \beta, \gamma)$ que definem a reorientação do sistema de eixos principais devem ser considerados, o que torna o cálculo do espectro mais complexo. Aqui os diferentes SEP's são superpostos, isto é, unificados para que seja representada por uma distribuição de orientação dos campos magnéticos. Em um experimento de Exchange 2D a freqüência de precessão antes de $t_{m}$ calculada no SEP unificado depende basicamente do tensor de deslocamento químico e da orientação do campo magnético $\vec{B}_{0}$ neste sistema de coordenadas, sendo dada por:

$$
\omega_{1}=\vec{b}_{0}^{S E P} \cdot \tilde{\sigma} \cdot \vec{b}_{0}^{S E P}
$$

a freqüência apresentada é a frequiência de precessão unificada, e esta é diagonal, onde $\vec{b}_{o}^{S E P}=\frac{\vec{B}_{0}^{S E P}}{B_{0}}$ é o vetor unitário que representa a orientação do campo magnético no SEP unificado e $\widetilde{\sigma}$ é tensor de deslocamento químico no mesmo sistema de coordenadas. Quando ocorre o movimento, obtemos uma segunda matriz depois do movimento, associada a mudança da freqüência de $\omega_{1}$ para $\omega_{2}$ :

$$
\omega_{2}=\vec{b}_{0}^{S E P} \cdot \tilde{\sigma}_{2} \cdot \vec{b}_{0}^{S E P}
$$

A matriz $\sigma_{2}$ que representa o tensor de deslocamento químico e pode ser obtida pela matriz de rotação que envolve os ângulos de Euler $(\alpha, \beta, \gamma)$ : 


$$
\sigma_{2}=\boldsymbol{R}(\alpha, \beta, \gamma) \sigma \boldsymbol{R}^{-1}(\alpha, \beta, \gamma)
$$

a matriz de rotação $R(\alpha, \beta, \gamma)$ é definida de acordo com a convenção de Mehring[20]. O procedimento discutido acima foi utilizado em muitos programas para simular espectros de 2D Exchange mostrados neste trabalho. Para maiores detalhes sobre os procedimentos utilizados nas simulações consultar as referências $[17,19,21]$ e os apêndice $I$.

\subsubsection{Movimento Molecular em RMN do Estado Sólido.}

O movimento molecular em RMN de sólidos orgânicos pode ser classificado em três tipos de movimentos, devido o regime em que se encontra o sólido. Portanto estes regimes possuem escalas de tempo ou freqüências próprias. A classificação dos regimes é a seguinte ordem: a) Regime rápido - $\mathrm{MHz}$; b) Regime intermediário $\mathrm{kHz}$ e c) Regime lento - $\mathrm{Hz}$. $\mathrm{O}$ regime rápido do movimento molecular se encontra na escala de freqüências da ordem de $\mathrm{MHz}$. Sendo que as freqüências desses movimentos são superiores à anisotropia das interações internas de RMN $\left(H_{D}, H_{C S A}, H_{Q}\right)$, onde esses movimentos podem ser observados por experimentos de $T_{1}$. No regime intermediário, a freqüência dos movimentos moleculares dos sólidos orgânicos é da ordem de $\mathrm{kHz}$. Nesta faixa de freqüências o movimento molecular promedia parcialmente as interações internas de RMN, sendo possível realizar estudos que adquirem informações de tais movimentos através da análise da forma da linha, como também obter os tempos de relaxação transversal e longitudinal no sistema de coordenadas girante, $T_{2}$ e $T_{1 \rho}$ respectivamente. Já para o regime lento, o 

Molecular.

movimento molecular ocorre com freqüências inferiores a $\mathrm{kHz}$ e geralmente só podem ser observados por RMN de Exchange.

Os movimentos moleculares em sólidos orgânicos geralmente variam ao longo da molécula devido aos grupos químicos presentes, substituintes, ou até mesmo pela sua complexidade molecular. Devido a estes fatores, o movimento molecular em tais sólidos orgânicos não pode ser caracterizado por um único tempo de correlação, tempo este em que ocorre uma mudança de orientação molecular. Em resumo, o movimento molecular ocorre segundo uma distribuição de tempos de correlação. Considerando movimentos termicamente ativados, a temperatura possui um papel fundamental, pois pode ser ajustada para obter certas freqüências de modo que o movimento molecular ocorra dentro de uma faixa do regime do movimento de interesse. Seguindo o raciocínio em que podemos ter uma distribuição de tempos de correlação do movimento molecular, a uma dada temperatura pode haver ao mesmo tempo grupos químicos, ou segmentos moleculares, se movendo no regime intermediário e lento, dependendo da distribuição do tempo de correlação.

Para o experimento de Exchange, movimentos moleculares que ocorrem no regime intermediários possuem tempos de correlação comparáveis aos períodos de evolução $t_{1}$ e $t_{2}$. Esse fato implica na existência de movimento durante estes períodos de evolução, necessitando fazer uma consideração do efeito deste movimento sobre o experimento de Exchange. Apesar desses fatores ocorrerem no experimento de Exchange, pode-se extrair informações interessantes da amostra.

\subsection{Experimento PUREX: Pure Exchange.}

\subsubsection{Conceito do Experimento PUREX.}


PUREX é uma técnica de eco-estimulado, com supressão de segmentos moleculares não móveis na escala de tempo de milisegundos a segundos (ms-s) [19, 22]. Seu objetivo é suprimir o sinal proveniente dos segmentos rígidos no espectro de Exchange 2D como também para Exchange 1D. Esta supressão é obtida pela modulação do espectro de Exchange através de uma função de modulação $\operatorname{sen}^{2}\left(\left(\Omega_{1}-\Omega_{2}\right) \tau / 2\right)$, obtendo assim o espectro PUREX com supressão dos segmentos rígidos na escala de tempo ms-s.

$$
S_{P U R E X}\left(\omega_{1}, \omega_{2}\right)=2\left\langle\operatorname{sen}^{2}\left(\left(\Omega_{1}-\Omega_{2}\right) \frac{\tau}{2}\right)\right) S_{E X C}\left(\omega_{1}, \omega_{2}\right)
$$

onde $S_{E X C}\left(\omega_{1}, \omega_{1}\right)$ é o espectro de Exchange, $<>$ é a média sobre todas as possíveis orientações dos segmentos moleculares do sólido referente ao SEP. $\Omega_{1}$ e $\Omega_{2}$ são as freqüências de precessão dos spins antes e depois de $t_{m}$. A informação obtida pelo experimento de Exchange é a mesma do experimento PUREX, porém com a supressão dos segmentos rígidos para o caso de PUREX 1D. A função de modulação $\operatorname{sen}^{2}\left(\left(\Omega_{1}-\Omega_{2}\right) \tau / 2\right)$, pode ser representada também pela igualdade trigonométrica:

$\operatorname{sen}^{2}\left(\left(\Omega_{1}-\Omega_{2}\right) \frac{\tau}{2}\right) S_{E X C}\left(\omega_{1}, \omega_{2}\right)=\frac{1}{2}\left(1-\cos \left(\Omega_{1}-\Omega_{2}\right) \tau\right) S_{E X C}\left(\omega_{1}, \omega_{2}\right)$

onde

$\left.\cos \left(\Omega_{1}-\Omega_{2}\right) \tau\right) S_{E X C}\left(\omega_{1}, \omega_{2}\right)=\left[\cos \left(\Omega_{1} \tau\right) \cos \left(\Omega_{2} \tau\right)+\operatorname{sen}\left(\Omega_{1} \tau\right) \operatorname{sen}\left(\Omega_{2} \tau\right)\right] S_{E X C}\left(\omega_{1}, \omega_{2}\right)$ 
Observando este propósito podemos combinar três espectros, um deles nãomodulado e os demais modulados por $\cos \left(\Omega_{1} \tau\right) \cos \left(\Omega_{2} \tau\right)$ e $\operatorname{sen}\left(\Omega_{1} \tau\right) \operatorname{sen}\left(\Omega_{2} \tau\right)$. Os termos correspondentes a $\operatorname{sen}^{2}, \cos \left(\Omega_{1} \tau\right) \cos \left(\Omega_{2} \tau\right)$ e $\operatorname{sen}\left(\Omega_{1} \tau\right) \operatorname{sen}\left(\Omega_{2} \tau\right)$ (equação [3.19]), podem ser inseridos na seqüência de pulso Exchange, através da introdução de dois períodos de evolução extra com duração $\tau$, sendo estes dois períodos de evolução referentes aos tempos antes e depois de $t_{m}$, conforme mostrado na Figura 3.7 A seleção dos termos $\cos \left(\Omega_{1} \tau\right) \cos \left(\Omega_{2} \tau\right)$ e $\operatorname{sen}\left(\Omega_{1} \tau\right) \operatorname{sen}\left(\Omega_{2} \tau\right)$ é feita da escolha adequada dos pulsos entre o tempo $t_{z}$. Para se obter o sinal modulado por $\cos \left(\Omega_{1} \tau\right) \cos \left(\Omega_{2} \tau\right)$, a magnetização transversal, criada na direção y pela seqüência $\mathrm{CP}$, evolui durante o primeiro tempo de evolução $\tau$, antes de $\mathrm{t}_{\mathrm{m}}$.

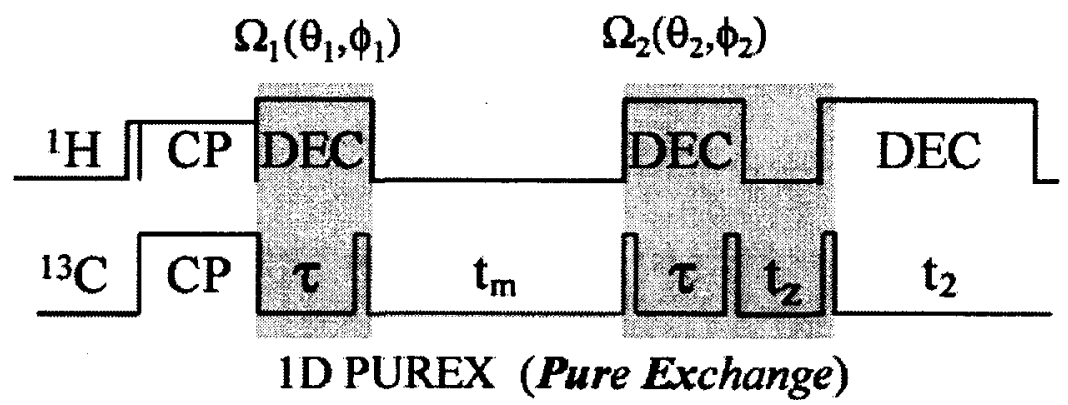

Figura 3.7 Seqüência de pulsos utilizada para obtenção do espectro de 1D Purê Exchange NMR (PUREX) através do deslocamento químico anisotrópico. A evolução dos dois períodos $\tau$ é feita sob desacoplamento heteronuclear. Na primeira parte da seqüência de pulso, enriquecemos $0{ }^{13} \mathrm{C}$ para que haja uma melhor magnetização como também a relação sinal ruído a partir da Polarização Cruzada.

O sinal detectado terá um fator de modulação que é definido pelas fases dos pulsos entre $t_{z}$ e através da escolha apropriada dessas fases, é possível adquirir um sinal com amplitude modulada por $\cos \left(\Omega_{1} \tau\right) \cos \left(\Omega_{2} \tau\right)$ ou $\operatorname{sen}\left(\Omega_{1} \tau\right) \operatorname{sen}\left(\Omega_{2} \tau\right)$. Através da escolha adequada dos pulsos, na Figura 3.7 podem-se obter os sinais: 


$$
\begin{aligned}
& S_{c c}\left(t_{1}, t_{2}\right)=e^{-\frac{2 \tau}{T_{2}}} \cos \left(\Omega_{1} \tau\right) \cos \left(\Omega_{2} \tau\right) \cos \left(\Omega_{1} t_{1}\right) e^{i \Omega_{2} t_{2}} \\
& S_{s s}\left(t_{1}, t_{2}\right)=e^{-\frac{2 \tau}{T_{2}}} \operatorname{sen}\left(\Omega_{1} \tau\right) \operatorname{sen}\left(\Omega_{2} \tau\right) \operatorname{sen}\left(\Omega_{1} t_{1}\right) e^{i \Omega_{2} t_{2}} \\
& S_{1}\left(t_{1}, t_{2}\right)=e^{-\frac{2 \tau}{T_{2}}} \operatorname{sen}\left(\Omega_{1} t_{1}\right) e^{i \Omega_{2} t_{2}}
\end{aligned}
$$

\subsubsection{Função de modulação PUREX.}

A função de modulação PUREX $\operatorname{sen}^{2}\left(\left(\Omega_{1}-\Omega_{2}\right) \tau / 2\right)$ inseridas nos espectros de Exchange também pode ser representada como uma expansão, onde os valores de $\tau$ são diferentes. Isso promove uma combinação de espectros PUREX com modulações minimizadas, de modo que o espectro de PUREX seja,

$$
S_{P U R E X}\left(\omega_{1}, \omega_{2}\right)=2\left\langle\sum_{m=1,2,3 \ldots}^{N} \operatorname{sen}^{2}\left(\left(\Omega_{1}-\Omega_{1}\right) \frac{m \tau}{2}\right)\right) S_{E X C}\left(\omega_{1}, \omega_{2}\right)
$$

e a expansão da função de modulação é dada por

$$
W(\Delta \Omega)=\sum_{m=1,2,3 \ldots}^{N} \operatorname{sen}^{2}\left(\left(\Omega_{1}-\Omega_{2}\right) \frac{m \tau}{2}\right)
$$

Na Figura 3.8 mostra o comportamento da função de modulação PUREX, onde o período $\mathrm{N}=1,2,3,4 \mathrm{e} \tau=250 \mu \mathrm{s}$. 

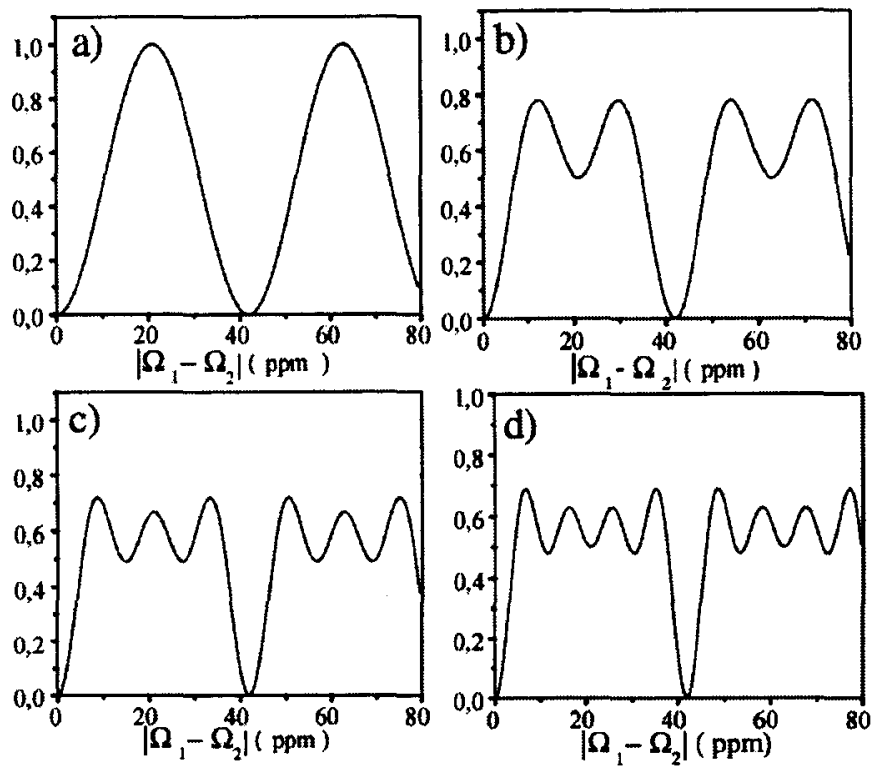

Figura 3.8 Funções de modulação do experimento PUREX obtidas somando $N$ funções de modulação com $\tau_{1}=250 \mu$ s. a) $N=1$, b) $N=2$, c) $N=3$, d) $N=4$. A função de modulação aproxima-se de uma constante na faixa de $0 \leq\left|\Omega_{1}-\Omega_{2}\right| \leq 2 \pi / \tau$, mas permanece igual a zero em $\left|\Omega_{1}-\Omega_{2}\right|=0$.

Figura adaptada da referência [19]

\subsubsection{Informações Sobre a escala de tempo do movimento molecular.}

A técnica PUREX 1D pode ser utilizada com eficiência para a obtenção de tempos e funções de correlação de movimentos moleculares com escala de tempo típica entre $1 m s$ a $1 s[19,22]$. As informações sobre a escala de tempo do movimento $(m s-s)$ podem ser obtidas a partir da análise da intensidade do espectro PUREX 1D como função do tempo de mistura, $t_{m}$, do experimento. Quanto a geometria do movimento, analisamos a intensidade do espectro PUREX 1D como função do tempo de evolução $\tau$. A amplitude normalizada do espectro 1D PUREX como função de $t_{m}$, e $\tau$ fixo, está relacionado com a função de correlação $\phi\left(t_{m}, \tau_{c}\right)$ do movimento molecular, pela seguinte expressão. 
Molecular.

$$
\begin{gathered}
E\left(t_{m}, \delta \tau_{c}\right)=\frac{S-S_{0}}{S_{0}}=\frac{f_{m}(M-1)}{M} C\left(t_{m},<\tau_{c}>\right)\left\langle 2 \operatorname{sen}^{2}\left[\left(\Omega_{1}-\Omega_{2}\right) \tau\right]\right\rangle \\
E\left(t_{m}, \delta \tau_{c}\right)=f\left(t_{m}\right) G(\tau)
\end{gathered}
$$

onde $E\left(t_{m}, \delta \tau_{c}\right)=\frac{f_{m}(M-1)}{M} C\left(t_{m},<\tau_{c}>\right)$ e $G(\tau)=\left\langle 2 \operatorname{sen}^{2}\left[\left(\Omega_{1}-\Omega_{2}\right) \tau\right]\right\rangle$. O termo $f_{m}$ representa a fração móvel dos sítios que participam do movimento molecular, ou seja, o número de sítios magneticamente não equivalentes acessíveis. Os termos $S \mathrm{e}$ $S_{0}$ são as intensidades dos espectros PUREX $1 \mathrm{D}$, modulado e de referência respectivamente. $\mathrm{O}$ termo de referência $S_{0}$ contém os efeitos da relaxação transversal ( $\left.T_{2}\right)$ durante $\tau$ e longitudinal $\left(T_{1}\right)$ durante $t_{\mathrm{m}}$. Deste modo, os gráficos da razão $\left(S_{0}-S\right) / S_{0}$ (normalizados) em função de $\mathrm{t}_{\mathrm{m}}$ ou $\tau$ podem ser utilizados para caracterizar, respectivamente a dinâmica e a geometria dos movimentos, porém sem os efeitos de relaxação. A função $C\left(t_{m},<\tau_{c}>\right)$ está relacionada com a função de correlação do movimento molecular, $\phi\left(t_{m}, \tau_{c}\right)$, onde $C\left(t_{m},<\tau_{c}>\right)=1-\phi\left(t_{m}, \tau_{c}\right)$. A amplitude do movimento $E\left(t_{m}, \tau_{c}\right)$ pode ser obtida como função do tempo de mistura $t_{m}$, gerando informações sobre o tempo de correlação médio $\left\langle\tau_{c}\right\rangle$ do movimento molecular lento. Na Figura 3.9 podemos ver o comportamento da função $C\left(t_{m},<\tau_{c}>\right)$ e notar as distinções entre as curvas com os seus tempo de correlação característico. 


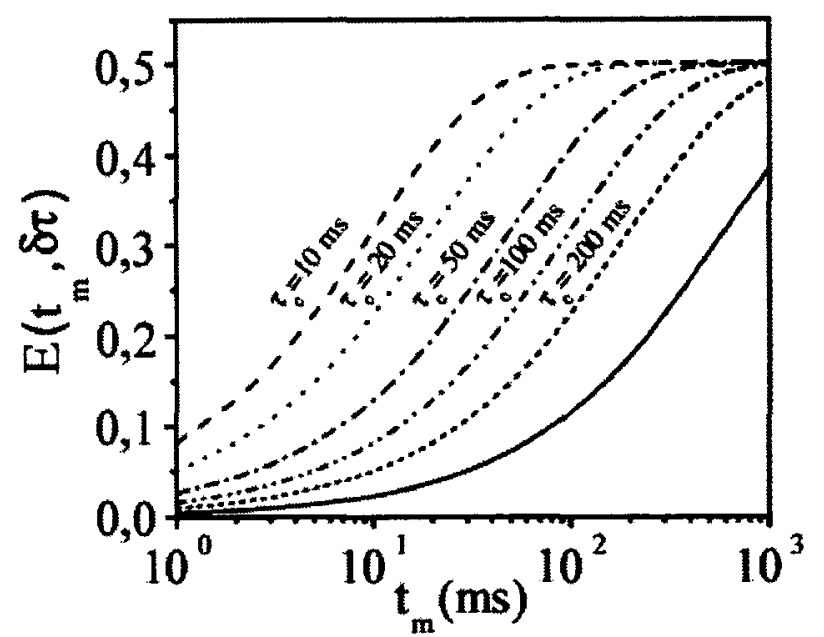

Figura 3.9: Simulações da intensidade $E\left(t_{m}, \delta \tau\right)$ versus $t_{m}$. Podemos ver que, quanto maior for o tempo de correlação, maior é o $\mathrm{t}_{\mathrm{m}}$ dado ao experimento. Através desta análise aparente podemos construir uma Janela Dinâmica do Sistema onde envolve movimentos na escala de $1 \mathrm{~ms}$ a $1 \mathrm{~s}$.

Quanto aos parâmetros PUREX, o tempo de mistura deve ser tal que $t_{m} \gg \tau_{c}$ para englobar os movimentos moleculares lentos que ocorrem dentro da janela dinâmica PUREX e $\tau \gg 1 / \Delta \Omega$ para conseguir obter todas as freqüências envolvidas no processo de PUREX. Na Figura 3.10 mostra a dependência de $E\left(t_{m}, \delta \tau\right)$ versus $t_{m}$ para diversos tempos de correlação no regime lento e intermediário, onde engloba movimentos com tempos de correlação entre $1 \mu \mathrm{s}$ a $1 \mathrm{~s}$. Neste caso, pode-se obter informações importantes do experimento PUREX 1D, onde parte do movimento dos segmentos moleculares podem estar realizando reorientaç̃̃es moleculares neste curto intervalo de tempo. É importante argumentar que a amplitude $E\left(t_{m}, \delta \tau\right)$ decai à medida que o tempo de correlação diminui até se anular totalmente $\tau_{c} \sim 10 \mu \mathrm{s} . \mathrm{E}$ enfatizar que este decaimento resulta somente da promediação do deslocamento químico anisotrópico durante $\tau$, já que neste caso $t_{z}$ é muito menor que os tempos de correlação utilizados. O limite experimental mínimo de $\mathrm{t}_{\mathrm{z}}$ é da ordem de $100 \mu \mathrm{s}$. 


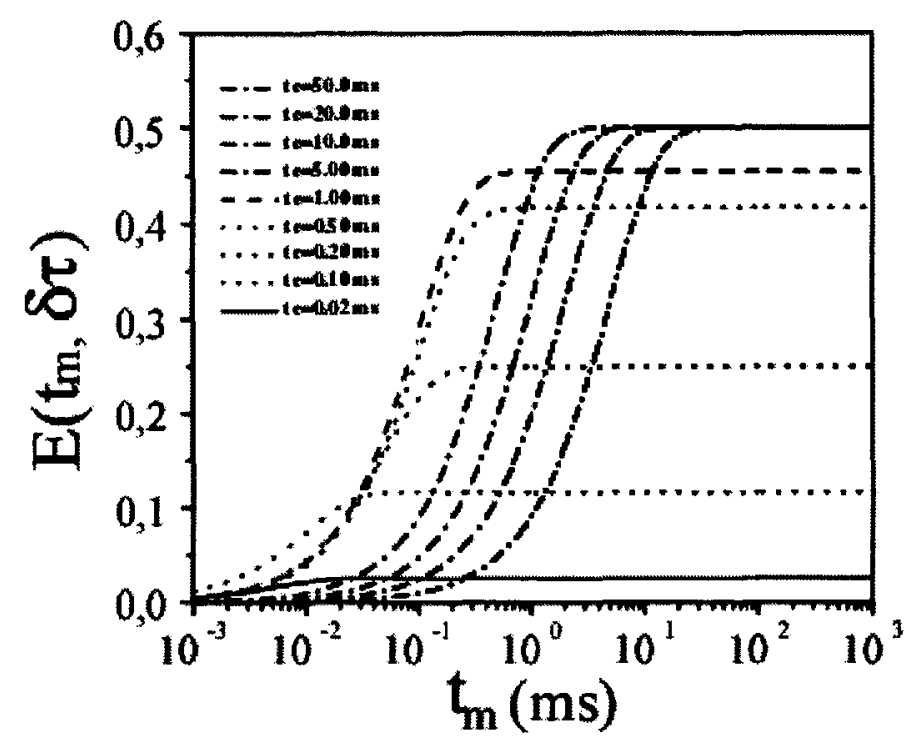

Figura 3.10 Curvas obtidas por simulações da intensidade $E\left(t_{m}, \delta \tau\right)$ versus $t_{\mathrm{m}}$. Para regimes intermediários de movimentos moleculares.

\subsubsection{Distribuição de tempos de correlação.}

Sistemas com heterogeneidades na estrutura molecular apresentam regimes de movimentos lentos, intermediários e rápidos. A pluralidade destes regimes de movimentos num sistema com heterogeneidades define notavelmente que não há somente um tempo de correlação, mas sim uma distribuição de tempos de correlação. Isso é devido aos diferentes sítios magneticamente não equivalentes nas heterogeneidades e devido a sua vizinhança. Isso faz com que esses sítios se movam com tempos de correlação distintos. Um aspecto importante da análise do movimento molecular por RMN de Exchange é sensibilidade do mesmo à distribuição de tempos de correlação. Uma vez que a janela dinâmica observável neste experimento está entre $0,1 \mathrm{~ms}$ e $1 s$, se o movimento molecular envolve distribuições de tempos de correlação com largura superior a essa janela, segmentos que se movem com tempos de correlação mais curtos $\sim 0,1 \mathrm{~ms}$ que aparecem como se fossem rígidos no experimento. Com respeito aos segmentos que se movem com tempos de correlação 

Molecular.

dentro da janela dinâmica observável, alguns estarão no regime intermediário, enquanto que outros se moverão no regime de movimentos lentos. Na Figura 3.11 há uma demonstração desta distribuição de tempos de correlação em função dos regimes de movimentos[5], onde se pode ver a janela dinâmica do experimento PUREX para movimentos lentos, bem como a forma pela qual a distribuição destes tempos de correlação variam em função da temperatura.

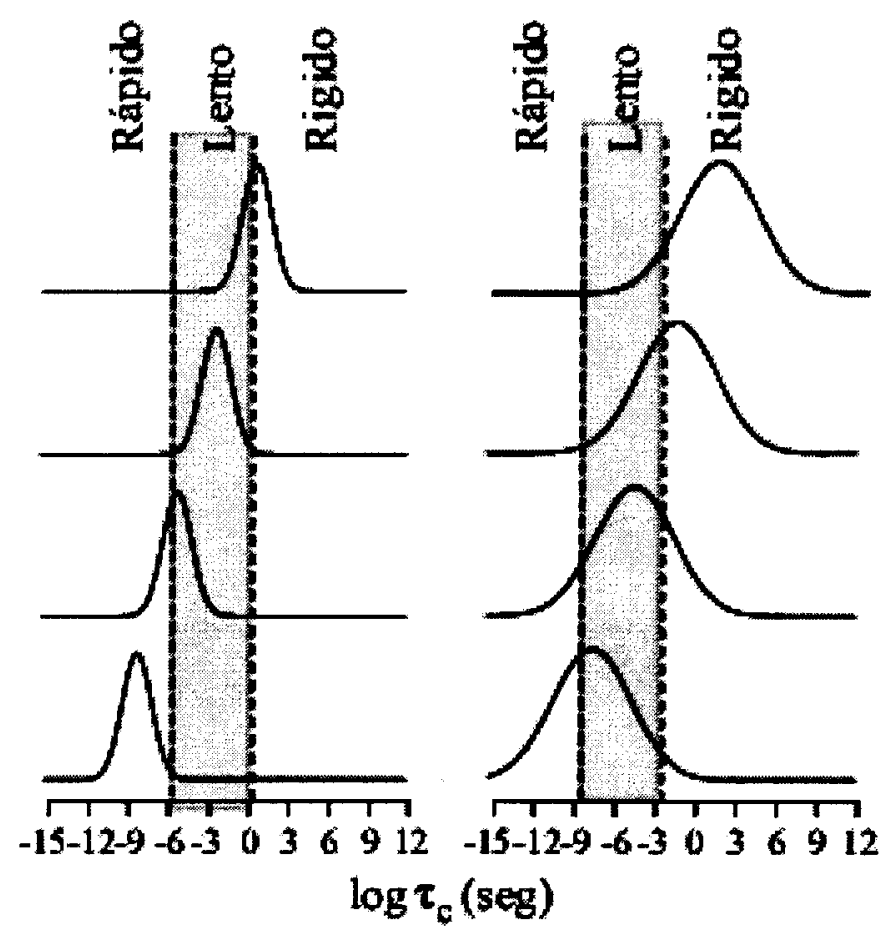

Figura 3.11: Distribuição de tempos de correlação em função da temperatura: rápido, lento e rígido [5].

Restringindo a discussão para o regime de movimentos lentos (1ms-1s), se o movimento molecular apresentar somente um único tempo de correlação, $\tau_{\mathrm{c}}>5 \mathrm{~ms}$, a função $C\left(t_{m},<\tau_{c}>\right)$, torna-se $C\left(t_{m}, \tau_{c}\right)$ e pode ser representada por uma função exponencial da seguinte forma: 
Molecular.

$$
C\left(t_{m}, \tau_{c}\right)=\left(1-e^{-\frac{t_{m}}{t_{c}}}\right)
$$

Considerando a quantidade

$$
E\left(t_{m}, \delta \tau_{c}\right)=E_{\infty}\left(1-e^{-\frac{t_{m}}{\tau_{c}}}\right)
$$

onde

$$
E_{\infty}=f_{m}\left(1-\frac{1}{M}\right)
$$

como mencionado, o tempo de correlação neste caso é único e por isso podemos considerar o processo do tipo Arrhenius e os tempos de correlação descritos em função da variável termodinâmica, temperatura, são dados por[19]:

$$
\tau_{c}=\tau_{0} \exp \left(\frac{E_{a}}{K T}\right)
$$

onde $E_{a}$, a energia de ativação aparente do sistema, juntamente com $\tau_{0}$, formam os parâmetros da curva de Arrhenius. Inserindo [3.29] em [3.27] temos,

$$
E\left(t_{m}, \delta \tau_{c}\right)=E_{\infty}\left(1-\exp \left(-\frac{t_{m}}{\tau_{0}} e^{-E_{a}} \frac{K T}{K T}\right)\right.
$$

através desta aproximação podemos calcular a curva $E\left(t_{m}, \delta \tau_{c}\right)$ em função da temperatura para o regime de movimentos lentos. A curva obtida da equação [3.30] 
dependerá de $\mathrm{E}_{\mathrm{a}} \mathrm{e} \tau_{0}$, os quais poderão ser determinados por meio do ajuste da curva com os resultados experimentais. Veja na Figura 3.12 a simulação da dependência de $E\left(t_{m}, \delta \tau_{c}\right)$ versus da temperatura para diferentes de $\mathrm{E}_{\mathrm{a}}$ e $\tau_{0}$.
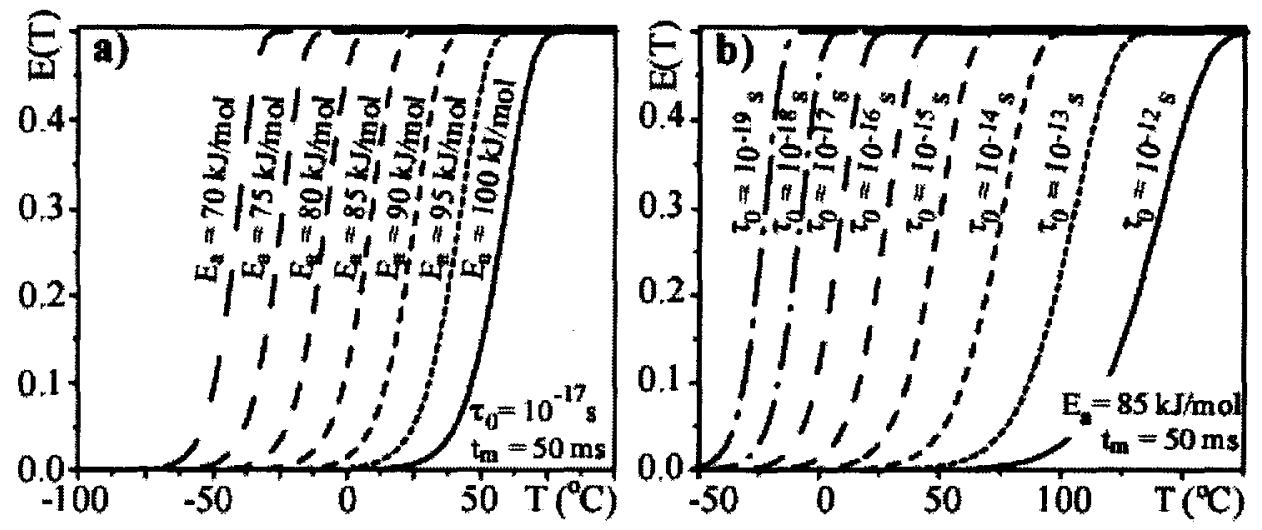

Figura 3.12: Simulação das curvas $E\left(t_{m}, \delta \tau_{c}\right)$ versus temperatura como função dos parâmetros de Arrhenius $\mathrm{E}_{\mathrm{a}}$ e $\tau_{0}$. a) $E\left(t_{m}, \delta \tau_{c}\right)$ versus $\mathrm{T}$ como função da energia de ativação: Somente um deslocamento da curva em temperatura é observado. b) $E\left(t_{m}, \delta \tau_{c}\right)$ versus $\mathrm{T}$ como função de $\tau_{0}$ : além do deslocamento em temperatura, uma variação na taxa de crescimento da curva é observado.

Na Figura 3.12a observa-se que o efeito da variação da energia de ativação nestas curvas é um deslocamento das mesmas em temperatura. Por outro lado, além de um deslocamento em temperatura, a variação de $\tau_{0}$ implica também na mudança da taxa de crescimento da mesma.

No caso anterior, os cálculos das curvas $E$. vs. $T$ foi realizado considerando a aproximação de movimentos lentos. No entanto, é possivel calcular das curvas no caso de movimentos no regime intermediário utilizando o procedimento da matriz de Exchange discutido anteriormente. Neste caso basta considerar que durante os períodos de evolução $\tau$, onde a magnetização é transversal, o sistema de spins evolui simultaneamente de acordo com a matriz de Exchange e a matriz de freqüências, mas durante os períodos $t_{m}$ e $t_{z}$ o sistema evolui somente de acordo com a matriz de 

Molecular.

Exchange. Deste modo, o vetor de magnetizações complexas após a evolução de acordo com a seqüência de pulsos PUREX-1D é,

$$
\vec{M}=\vec{M}_{i 0}\left\{\begin{array}{l}
\operatorname{Re}\left[e^{i(\tilde{\Omega}+(\tilde{\Pi}) t}\right] e^{-\tilde{\Pi} t_{m}} \operatorname{Re}\left[e^{i(\tilde{\Omega}+\tilde{\Pi}) t}\right] e^{-\tilde{\Pi} t_{t}} e^{i(\tilde{\Omega}+\tilde{\Pi}) t} \\
+\operatorname{Im}\left[e^{i(\tilde{\Omega}+\tilde{\Pi}) \tau}\right] e^{-\tilde{\Pi} t_{m}} \operatorname{Im}\left[e^{i(\tilde{\Omega}+\tilde{\Pi}) \tau}\right] e^{-\tilde{\Pi} t_{z}} e^{i(\tilde{\Omega}+\tilde{\Pi}) t}
\end{array}\right\}
$$

Note a combinação entre as partes reais e imaginárias utilizadas para selecionar as componentes cosseno.cossseno e seno.seno da magnetização como necessário no experimento PUREX1D. Com essa expressão o sinal pode ser então calculado para qualquer regime de movimento, mesmo que o tempo de correlação do mesmo seja comparável à duração do período de evolução $\tau$.

Portanto, utilizando o mesmo tratamento anterior o sinal PUREX 1D no regime intermediário, é possível calcular a curva de $E$. vs. $T$ para diferentes energias de ativação tal como mostrado a seguir para um modelo de saltos entre dois sítios.

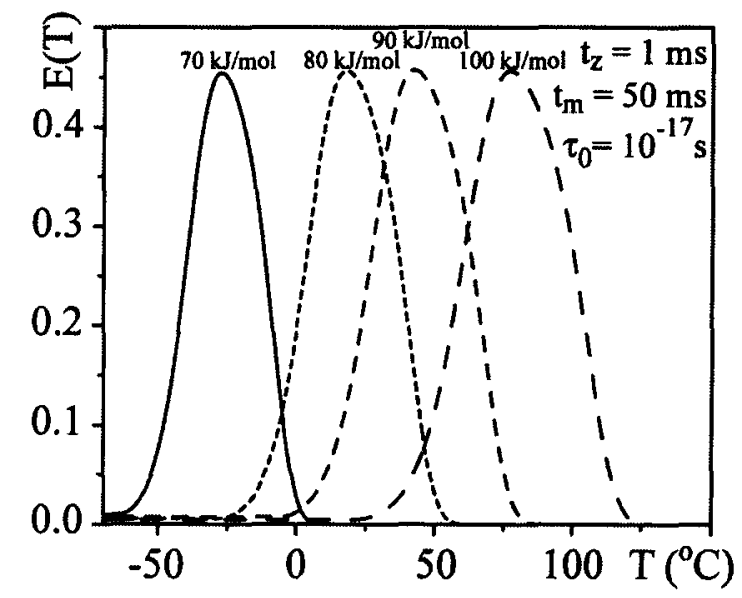

Figura 3.13: Curvas $E\left(t_{m}, \delta \tau_{c}\right)$ versus temperatura obtidas por meio de simulação do sinal PUREX 1D no regime intermediário. 
Pode-se notar na figura que o sinal decai novamente a zero após passar por um máximo, o que se deve a promediação da anisotropia deslocamento químico devido ao movimento molecular que ocorre durante o período de evolução $\tau$. Nota-se ainda que a posição do máximo define a energia de ativação do processo.

Um aspecto interessantes das curvas $E\left(t_{m}, \delta \tau_{C S A}\right)$ diz respeito a presença de heterogeneidades dinâmicas, isto é, distribuição de tempos de correlação. Neste caso, para uma dada distribuição $g\left(\tau_{C}\right)$ a amplitude $E\left(t_{m}, \delta \tau_{C S A}\right)$ pode ser calculada pela seguinte expressão:

$$
E\left(t_{m}, \delta \tau_{C S A}\right)=\int_{0}^{\infty} g\left(\tau_{C}\right) E_{\tau_{C}}\left(t_{m}, \delta \tau_{C S A}\right) d \tau_{C}
$$

Neste caso, $E_{\tau_{C}}\left(t_{m}, \delta \tau_{C S A}\right)$ representa a amplitude correspondente a um dado tempos de correlação $\tau_{C}$. Com essa expressão e com o resultado anterior pode-se calcular o comportamento das curvas $E$ versus $T$ considerando que há distribuição de tempos de correlação. Na Figura 3.14 apresenta uma série de curvas $E$ versus $T$ para um processo de saltos aleatórios, juntamente com as respectivas distribuições de tempos de correlação. Neste caso foram consideradas distribuições de tempos de correlação log-Gaussian (gaussianas em escala logarítmica) as quais também estão mostradas na Figura 3.14. A característica mais importante da figura é que a amplitude máxima da curva depende exclusivamente da largura da distribuição de tempos de correlação, sendo, portanto este parâmetro um indicativo direto do grau de heterogeineidade dinâmica. De fato, a amplitude máxima da curva decresce proporcionalmente ao crescimento da largura da distribuição de tempos de correlação, e a comparação de resultados experimentais com essas simulações pode permitir uma estimativa quantitativa deste parâmetro. 


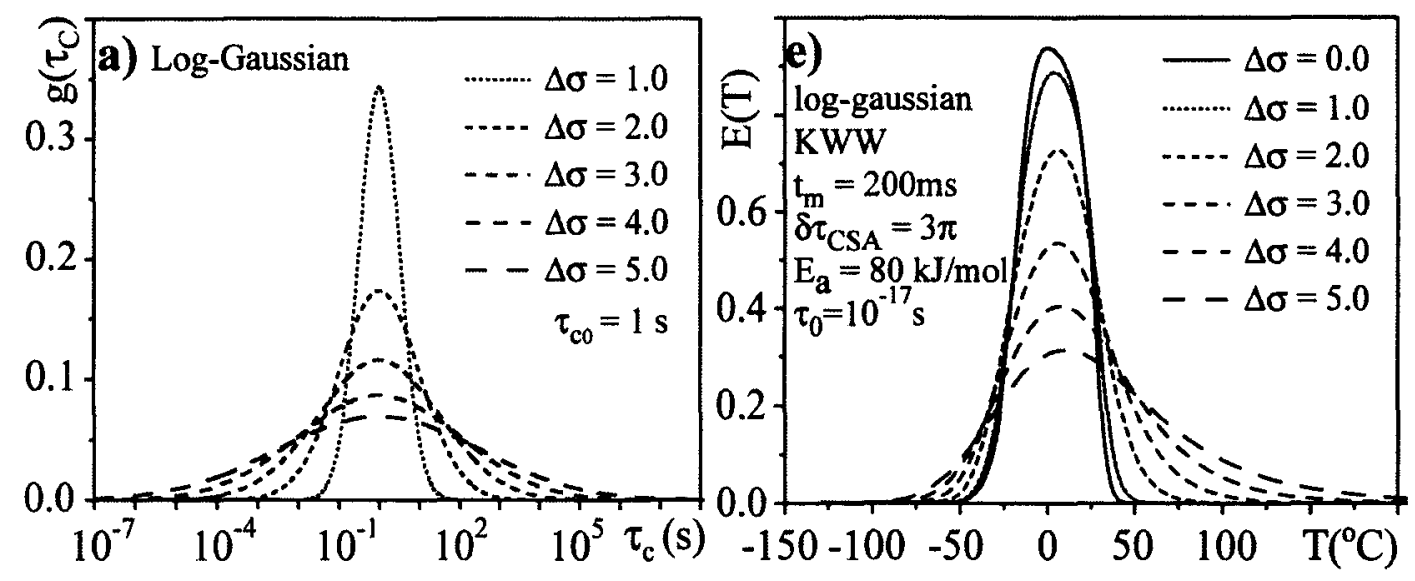

Figura 3.14: a) Conjunto de funções distribuição de tempos de correlação do tipo log-Gaussian. b) Curvas $E\left(t_{m}, \delta \tau_{c}\right)$ versus temperatura obtidas por meio de simulação do sinal PUREX 1D no regime intermediário considerando diferentes distribuições de tempos de correlação. 


\subsection{Referências:}

1. Costa, P.M., Tavares, M. I.B., Silva, E. O., Bathista, A. L. B. S., Luetkmeyer, L, Nogueira, J. S., Filho, N. P.Solution and Solid State NMR Characterization of Fruit Seed Starches. in LX Encontro de Usuários de Ressonância Magnética Nuclear. 2003. Angra dos Reis: AUREMN.

2. Bathista, A.L.B.S., Bloise, A. C. deAzevedo, E. R. Dahmouche, K. Bonagamba, T. J. Correlation between slow carbon and lithium dynamics in lithium doped-Siloxane/Poly(Ethylene Glycol) Nanocomposites. in XXVII Encontro Nacional de Física da matéria Condensada. 2004. Poços de Caldas.

3. Bathista, A.L.B.S., Bloise, A. C., Mantovani, G. L., deAzevedo, E. R.,Dahmouche, K., Bonagamba, T. J.. Estudo de Compostos Hibridos Orgânicos-Inorgânicos Condutores iônicos por RMN de Estado Sólido. in III Encontro do Instituto do Milênio de Materiais Poliméricos. 2004. Atibaia.

4. Bathista, A.L.B.S., deAzevedo, E. R. Dahmouche, K. Bonagamba, T. J. Estudo de Compostos Hibridos Orgânico-Inorgânicos Condutores Iônicos por RMN do Estado Solido. in VI Simpósio em Ciência e Engenharia de Materiais. 2003. São Carlos.

5. deAzevedo, E.R., Reichert, D., Vidoto, E. L. G., Dahmouche, K., Judeinstein, P., Bonagamba, T. J., Motional Heterogeneities in Siloxane/Poly(ethylene glycol) Ormolyte Nanocomposites Studied by ${ }^{13}$ CNMR Solid-State Exchange NMR. Chem. Mater., 2003. 15(10): p. 2070-2078.

6. Tavares, M.I.B., Bathista, A. L. B. S., Silva, E. O., Filho, N. P., Nogueira, J. S., A molecular dynamic study of the starch obtained from the Mangifera indica $C v$. Bourbon and Espada seeds by ${ }^{13} C$ solid state NMR. Carbohydrate Polymers, 2003. 53(2): p. 213-216.

7. Tavares, M.I.B., Bathista, A. L. B. S., Silva, E. O., Filho, N. P., Nogueira, J. S., High-Resolution Carbon-13 Nuclear Magnetic Resonance Study of Natural Resins. Journal of Applied Polymer Science, 2002. 86(8): p. 18481854.

8. Tavares, M.I.B., Bathista, A. L. B. S., Silva, E. O., Costa, P. M., Filho, N. P., Nogueira, J. S., ${ }^{13}$ C NMR Study of Dipteryx Alata Vogel Starch. Journal Applied Polymer Science, 2004. 93(4): p. 2151-2154.

9. Bloembergen, N., E.M. Purcell, and R.V. Pound, Relaxation Effects in Nuclear Magnetic Resonance Absorption. Physical Review, 1948. 73(7): p. 679-711.

10. Silvestri, R.L. and J.L. Koenig, Applications of Nuclear Magnetic Resonance Spectrometry to Solid Polymers. Analytica Chimica Acta, 1993. 283: p. 9971005.

11. Koenig, J.L., Spectroscopy of Polymer. 1992, Washington: American Chemical Society. 328.

12. Schmidt A, Smith SO, Raleigh DP, Roberts JE, Griffin RG, Vega S, Chemical-Exchange Effects In The NMR-Spectra Of Rotating Solids. Journal Of Chemical Physics, 1986. 85(8): p. 4248-4253.

13. Schmidt A and Vega S, Nmr Line-Shape Analysis For 2-Site Exchange In Rotating Solids. Journal Of Chemical Physics, 1987. 87(12): p. 6895-6907. 
14. Luz Z, Poupko R, and Alexander. S, Theory Of Dynamic Magic-AngleSpinning Nuclear-Magnetic-Resonance And Its Application To C-13 In Solid Bullvalene. Journal Of Chemical Physics, 1993. 99(10): p. 7544-7553.

15. Leo, G.C., Colnago, L. A., Valentine, K. G., Opella, S. J.., Dynamics of FdCoat Protein in Lipid Bilayers. Biochemistry, 1987. 26(3): p. 854-862.

16. Shon, K.J., Kim, Y. G., Colnago, L. A., Opella, S. J., NMR-Studies of the Structure and Dynamics of Membrane-Bound Bacteriophage-Pfl Coat Protein. Science, 1991. 252(5010): p. 1303-1304.

17. Schmidt-Rohr, K. and H.W. Spiess, Multidimensional Solid-State NMR and Polymers. 1994, San Diego CA: Academic Press. 478.

18. Chmelka, B.F., K. Schmidt-Rohr, and H.W. Spiess, Molecular Dynamics in Polymers Studied by Multidimensional Solid-State NMR, in Nuclear Magnetic Resonance Probes of Molecular Dynamics, R. Tycko, Editor. 1994, Kluwer Academic Publishers: Netherlands. p. 113-153.

19. deAzevedo, E.R., Novas Metodologias de Ressonância Magnética Nuclear para o Estudo da Dinâmica Lenta em Materiais Orgânicos no Estado Sólido: Aplicações em Polímeros e Proteínas, in Instituto de Física de São Carlos. 2001, Universidade de São Paulo: São Carlos. p. 197.

20. Mehring, M., Principles of High Resolution NMR in Solids. 2nd ed. 1983, New York: Springer-Verlag. 342.

21. Wefing, S. and H.W. Spiess, Two-Dimensional Exchange Nmr of Powder Samples .1. 2-Time Distribution-Functions. Journal of Chemical Physics, 1988. 89(3): p. 1219-1233.

22. deAzevedo, E.R., T.J. Bonagamba, and K. Schmidt-Rohr, Pure-Exchange Solid-State NMR. Jounal of Magnetic Resonance, 2000. 142: p. 86-89. 


\section{Capítulo 4: Resultados Experimentais e Discussões.}

\subsection{Materiais e Métodos.}

As amostras utilizadas neste trabalho foram preparadas no Departamento de Química da UNESP de Araraquara pelo Prof. Karim Dahmouche. Os métodos de síntese das ormolitas do Tipo II podem ser encontrados no Capítulo 1 e nas referências[1-3]. Relembrando, a seguinte nomenclatura será usada para descrever os nanocompósitos: $[\mathrm{X}]_{\mathrm{n}}[\mathrm{Y}]-\mathrm{Z}$, onde $\mathrm{X}$ representa a porcentagem em massa de polímero, n o grau de polimerização, aproximadamente o número médio de monômeros que formam a cadeia polimérica, e $\mathrm{Z}$ igual a $\mathrm{I}$ e II, indica respectivamente o tipo de ormolita, não ligada e ligada quimicamente.

Para entender o efeito do comprimento da cadeia do nanocomposto na dinâmica do polímero, as seguintes amostras foram preparadas, $[50]_{47}[08]-\mathrm{II},[50]_{47}[30]-\mathrm{II}$, $[50]_{11}[08]-$ II e $[50]_{11}[30]-\Pi$.

Dentro das possibilidades experimentais envolvidas na preparação, tentou-se manter constante a percentagem de polímero e variar o tamanho da cadeia para este tipo de híbrido. Lembrando que o híbrido aqui escolhido para estudo foi o do Tipo II, em função de sua estabilidade química e, principalmente, pela heterogeneidade da dinâmica molecular induzida pela ligação covalente entre as fases orgânica e inorgânica do nanocomposto. O objetivo deste procedimento foi a obtenção de amostras com quantidades similares de polímero e tamanho de cadeias bem diferentes, aproximadamente quatro vezes de diferença entre os tamanhos da cadeia polimérica. Já que um dos objetivos é estudar o efeito do tamanho das cadeias 
poliméricas na dinâmica do polímero. É interessante observar que a constituição química do polímero utilizado é ligeiramente modificado, com grupos contendo $\mathrm{NH}$ no final da cadeia polimérica, $\left\{3 / 2 \mathrm{OSi}-\mathrm{NH}-\mathrm{CO}-\mathrm{NH}-\left(\mathrm{CH}_{2}\right)_{3}-(\mathrm{PEG})-\left(\mathrm{CH}_{2}\right)_{3}-\mathrm{NH}-\mathrm{CO}-\right.$ $\left.\mathrm{NH}-\mathrm{SiO}_{3 / 2}\right\}$ para que haja ligação química entre o polímero e a sílica.

\subsection{Parâmetros experimentais de RMN.}

Os experimentos foram realizados em um espectrômetro VARIAN INOVA com freqüência de ${ }^{13} \mathrm{C}$ de $100 \mathrm{MHz}$ localizado no Instituto de Física de São Carlos. Foi utilizada uma sonda de dupla ressonância DOTY com bobina de $10 \mathrm{~mm}$ equipada com sistema de variação de temperatura. Pulsos de $90^{\circ}$ com duração entre 3 a $5 \mu$ s foram utilizados para o ${ }^{13} \mathrm{C}$ e ${ }^{1} \mathrm{H}$. A amplitude do campo de desacoplamento de ${ }^{1} \mathrm{H}$ utilizado foi de aproximadamente de $65 \mathrm{KHz}$. Tempo de polarização cruzada de 1 ms, e tempos de repetição entre 3 a 64 segundos devido a variação da temperatura. Nos experimentos de Exchange 2D, o tempo de mistura $t_{m}$ para todos os experimentos foi de $t_{m}=200 \mathrm{~ms}, t_{z}=2$ ms. Para o experimento PUREX 1D, foi realizado Curvas versus tempo de mistura obtidas por meio de integração dos sinais $S$ e $S_{0}$, com variação do tempo de mistura de 2 a $600 \mathrm{~ms}$. Para os experimentos versus Temperatura, o tempo de mistura foi fixado em $200 \mathrm{~ms}$. Para ambos os casos $t_{m} \gg$ $t_{z}$ para que não haja movimento durante a detecção do sinal. 


\subsection{Introdução.}

Vários estudos envolvendo eletrólitos poliméricos mostraram que há uma forte correlação entre a dinâmica da matriz polimérica e mobilidade iônica[1-9]. Em particular, estudos envolvendo Ormolitas do Tipo I e Tipo II utilizando metodologias convencionais de $\operatorname{RMN}[9,10]$ confirmaram este comportamento também para este tipo de material. Em resumo, foi mostrado que a mobilidade iônica é assistida pelo movimento do segmento molecular do polímero, havendo uma restrição maior ao movimento da cadeia polimérica em Ormolitas do Tipo II, devido à forte interação entres as fases orgânica e inorgânica neste tipo de material. Recentemente, estudos mais detalhados sobre a dinâmica da cadeia polimérica em Ormolitas do Tipo I e II não dopadas foram realizados utilizando metodologias de RMN de Exchange[11]. Utilizando experimentos de 2D Exchange e 1D PUREX, os movimentos lentos das cadeias poliméricas que ocorrem em temperaturas próximas à temperatura de transição vítrea desses materiais foram caracterizados. Estes estudos mostraram claramente o efeito dos impedimentos estéricos introduzidos pela presença das estruturas de sílica no comportamento dinâmicos das cadeias nestes dois tipos de Ormolitas e confirmaram a maior restrição ao movimento molecular para os materiais do Tipo II. Além disso, no caso das Ormolitas do Tipo II, foi possível distinguir entre segmentos mais rígidos, localizados próximos as ligações com a estrutura de sílica, e segmentos com maior mobilidade localizados em regiões mais afastadas destas estruturas. Isto está mostrado na Figura 4.1, onde o espectro de 2D Exchange é diagonal na região correspondente ao sinal dos grupos ligantes, e possui um padrão característico de movimentos isotrópicos na região correspondente ao segmentos mais afastados das estruturas de sílica. 


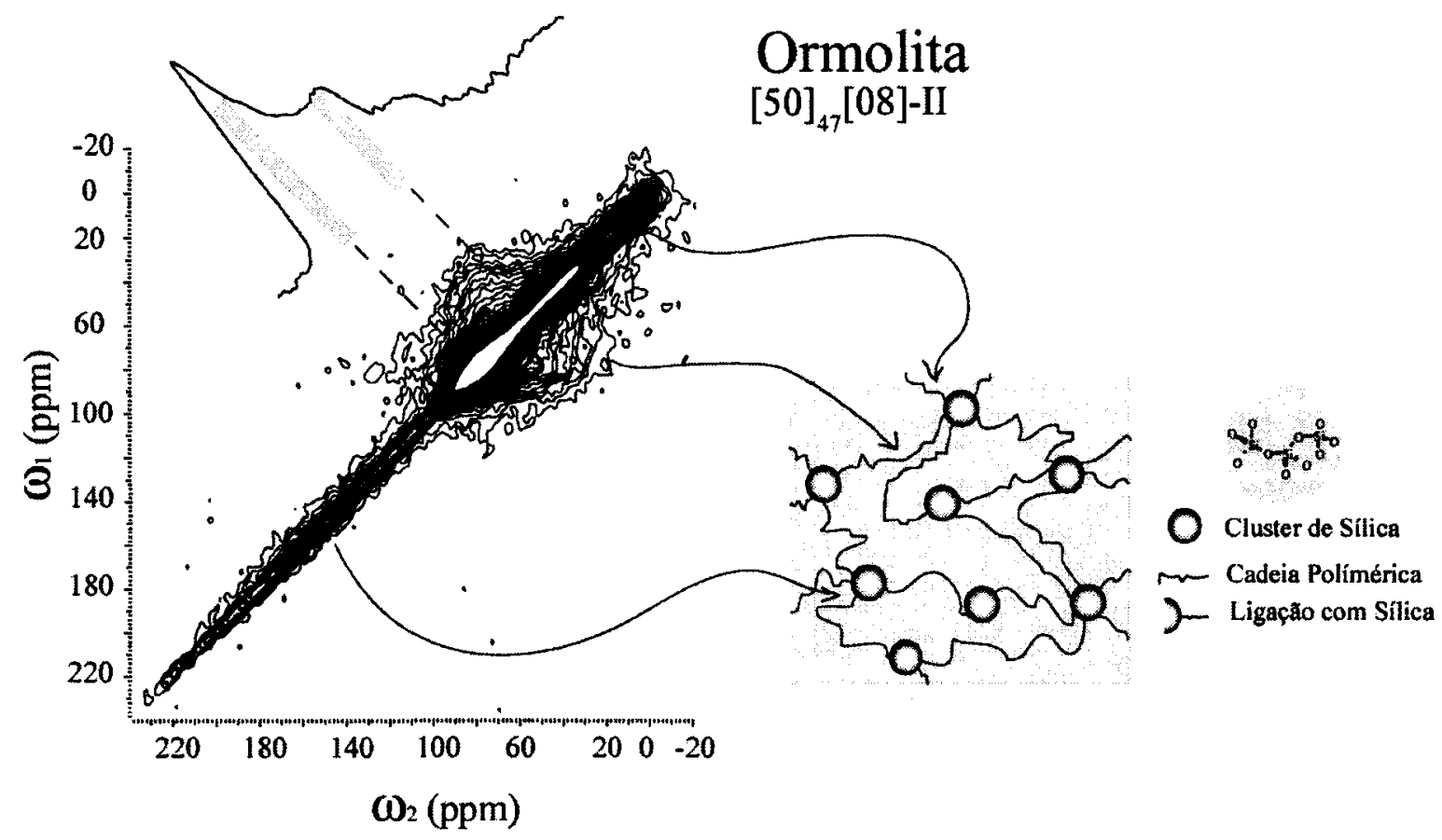

Figura 4.1: Presença de heterogeneidades dinâmicas na amostra [50 ${ }_{47}[08]-$ II: a parte diagonal no espectro indica a restrição do movimento enquanto que porção não-diagonal do espectro indica o movimento molecular do polímero. Espectro obtido pelo experimento $2 \mathrm{D}$ Exchange.

Este comportamento aponta para presença de heterogeneidades dinâmicas na amostra, o que implica em uma distribuição de tempos de correlação para os movimentos moleculares, detectado através de experimentos PUREX 1D[12, 13]. Neste trabalho, experimentos de RMN convencional e de Exchange foram utilizados afim de obter informações sobre as propriedades dinâmicas de Ormolitas do Tipo II dopadas com diferentes concentrações de Lítio. Aspectos como a presença de heterogeneidades dinâmicas na amostra, bem como o efeito da concentração de Lítio e do tamanho da cadeia nessa heterogeneidade serão abordados. Além disso, será mostrada uma interessante aplicação da técnica 1D PUREX na quantificação dessas heterogeneidades. 


\subsection{Espectros de Carbono em função da Temperatura.}

O estudo da dependência da forma de linha com a temperatura pode levar a informações importantes sobre a dinâmica do polímero na escala de tempo de microsegundos a milissegundos. Isto é possível devido à dependência do deslocamento químico anisotrópico (CSA) com a orientação de um dado segmento molecular em relação ao campo magnético $B_{0}$. Nas Figuras 4.2a-e estão mostrados os espectros de pó de ${ }^{13} \mathrm{C}$ obtidos com as técnicas de Polarização Cruzada (CP), Figura 4.2d-e e Polarização Direta (DP). Na Figura 4.2a. no regime de rede rígida, a baixa temperatura, pode-se observar, na região de 50 a 100 ppm, um espectro de pó típico do PEG $\left(\sigma_{\mathrm{xx}}=93 \mathrm{ppm}, \sigma_{\mathrm{yy}}=82 \mathrm{ppm}\right.$ e $\left.\sigma_{\mathrm{zz}}=33 \mathrm{ppm}\right)$. Com o aumento da temperatura, observa-se o início do movimento molecular a partir da promediação do deslocamento químico anisotrópico, $\delta_{C S A}$, o que se manifesta através da distorção e posterior estreitamento do padrão de pó observado, Figuras $4.2 \mathrm{~b}$ e $4.2 \mathrm{f}$. Esta distorção aumenta até que um máximo da largura de linha é obtido, e daí em diante um estreitamento pronunciado da linha como função da temperatura é observado, Figuras 4.2c e 4.2g. Para altas temperaturas a taxa de movimento, $k \approx\left(\tau_{c}\right)^{-1}$, tornase maior que a anisotropia de deslocamento químico, $\Delta \sigma=\left|\sigma_{x x}-\sigma_{z z}\right|=60 \mathrm{ppm} \approx 6 \mathrm{kHz}$, produzindo uma promediação completa da interação de deslocamento químico e gerando uma linha gaussiana estreita, Figura 4.2d e 4.5h. Geralmente, a transição da largura de linha observada para as Ormolitas está associada com o aumento do movimento da cadeia que ocorre para o polímero na transição vítrea [9]. A linha em $67 \mathrm{ppm}$ para $\mathrm{T}=45^{\circ} \mathrm{C}$ é um sinal típico do grupo $\left[\mathrm{CH}_{2} \mathrm{CH}_{2} \mathrm{O}\right]_{\mathrm{n}}$, podendo ser associada segmentos do polímero não pertencentes ao 
grupo de ligação à estrutura de sílica [11]. Além disso, é observado um segundo sinal na região de -20 a 20 ppm, o qual é atribuído a carbonos pertencentes a segmentos nos grupos químicos $-\mathrm{Si}-\mathrm{NH}-\mathrm{CO}-\mathrm{NH}-\left(\mathrm{CH}_{2}\right)_{3}-(\mathrm{PEG})_{\mathrm{n}}$ responsáveis pela ligação da cadeia polimérica com as estruturas de sílica. $\mathrm{O}$ fato de as linhas observadas à temperatura de $45^{\circ} \mathrm{C}$ não possuírem nenhum estrutura particular parecida com os padrões de pó, i.e., são simplesmente linhas gaussianas, indicam que os segmentos moleculares do grupo $\left[\mathrm{CH}_{2} \mathrm{CH}_{2} \mathrm{O}\right]_{\mathrm{n}}$ executam movimentos isotrópicos à temperatura ambiente.

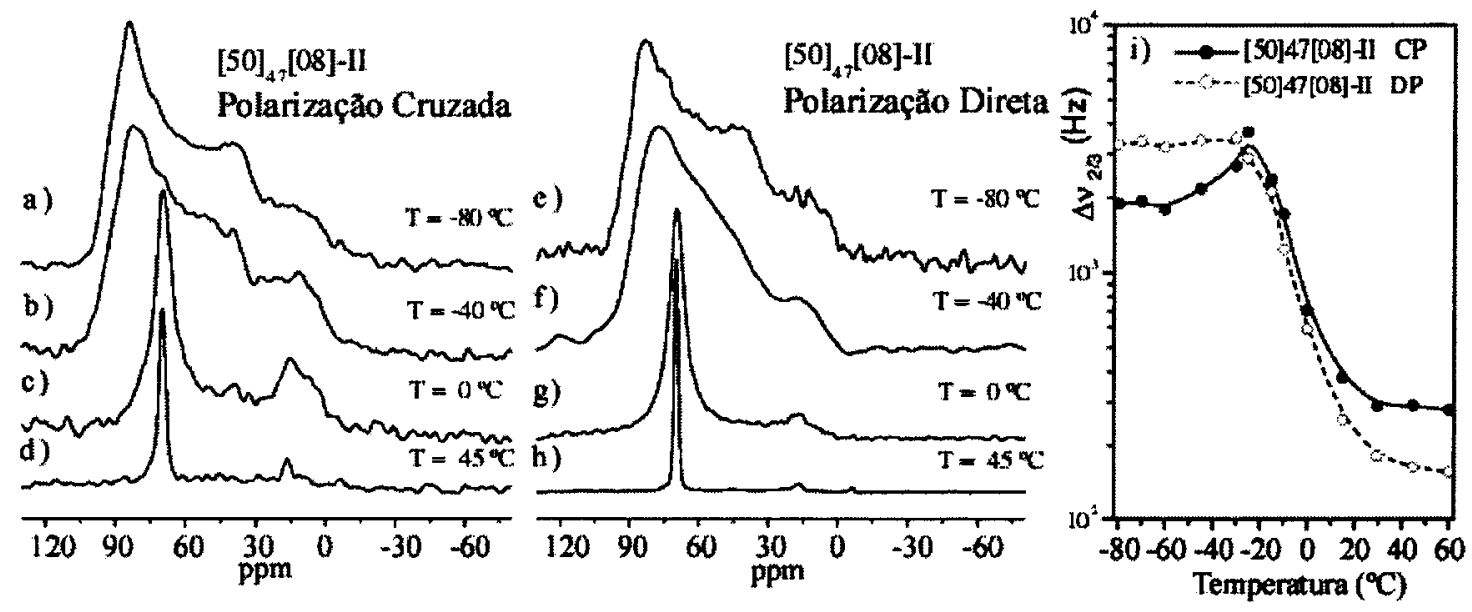

Figura 4.2: as Figuras 4.2a-d) mostram as formas de linha do espectros de ${ }^{13} \mathrm{C}$, utilizando a técnica de Polarização Cruzada em função da temperatura para a Ormolita do Tipo II, [50] ${ }_{47}[08]-$ II. 4.2e-h) mostram as formas de linha do espectros de ${ }^{13} \mathrm{C}$, utilizando a técnica de Polarização Direta em função da temperatura para a mesma Ormolita. A Figura 4.2-i) apresenta as curvas obtidas à partir da largura de linha espectral à dois terços da altura, $\Delta v_{(2 / 3)}$, do experimento de Polarização Cruzada e Polarização Direta.

O comportamento das larguras dos espectros de ${ }^{13} \mathrm{C}$ como função da temperatura está mostrado na figura 4.2-i. Neste caso estão mostradas as curvas de ${ }^{13} \mathrm{C}$ para as larguras de linhas medidas a $2 / 3$ da altura máxima dos espectros, $\Delta v_{(2 / 3)} \cdot$ O estreitamento de linha com função da temperatura é geralmente quantificado pela medida da largura de linha a meia altura em função da temperatura [13]. Porém, como a distorção do padrão de pó não pode ser detectado pela medida a meia altura, neste caso optou-se por medir esta grandeza a 2/3 da altura máxima, 
afim de evitar a contribuição dos grupos de conexão, cujos sinais se superpõem consideravelmente ao padrão de pó principal. Além disso, medindo-se $\Delta v_{(2 / 3)}$ é possível observar um alargamento inicial que precede o estreitamento de linha, o qual é resultado da distorção do padrão de pó. Uma vez que esta distorção no padrão de pó acontece devido à presença de movimento molecular com freqüências da ordem de unidades de $\mathrm{kHz}[13]$, a medida da largura de linha à ${ }^{13} \mathrm{C} \Delta v_{(2 / 3)}$ provê uma boa indicação da temperatura onde a taxa do movimento, $k$, torna-se menor que kHz. Com o propósito de auxiliar as técnicas de Exchange, a análise da evolução da forma de linha dos espectros de ${ }^{13} \mathrm{C}$ como função da temperatura provê informações sobre a dinâmica intermediária. A mudança na forma de linha com a temperatura, acontece basicamente devido a promediação da anisotropia de deslocamento químico, CSA, pelo movimento molecular. No entanto, para se obter informações quantitativas sobre tais movimentos é necessário simular os espectros sob a ação dos mesmos. Esta simulação também pode ser feita utilizando a equação de BlochMacdowell [14-16], que permite calcular a evolução da magnetização sob a ação de movimentos moleculares, onde podemos obter mais detalhes nas referências $[13,17]$. $\mathrm{Na}$ ausência de movimento molecular e desprezando os efeitos da relaxação transversal, o sinal de RMN em função do tempo, $S(t)$, após a perturbação de $90^{\circ}$ ou por uma seqüência de polarização cruzada, pode ser calculado utilizando a expressão $S(t)=M_{0} e^{i \omega t}$ e tomando-se a média sobre todas as possíveis orientações dos segmentos moleculares $[13,17]$. De maneira análoga, sob a ação do movimento o mesmo procedimento pode ser utilizado, mas deve-se acrescentar o termo de Exchange entre os vários sítios acessíveis, já que as reorientações moleculares ocorrem simultaneamente e na mesma escala de tempo do tempo de aquisição. O 
sinal de RMN sob a ação de movimentos moleculares pode ser calculado através da seguinte expressão[13]:

$$
\tilde{S}(t)=\left\langle M_{0} e^{(\tilde{\Pi}+i \bar{\omega}) t}\right\rangle
$$

onde $\mathrm{M}_{0}$ representa a magnetização transversal gerada logo após a perturbação e $<\ldots>$ representa a média sobre todas as possiveis orientações dos segmentos. $\mathrm{O}$ resultado da transformada de Fourier da expressão [4.1] é o espectro de pó sob a ação do movimento molecular. Na Figuras 4.3a-d, estão mostrados os espectros de pó em função da temperatura e suas respectivas simulações (Apêndice I), enquanto que na Figura 4.3i está mostrada a largura de linha em função da temperatura e a respectiva simulação.
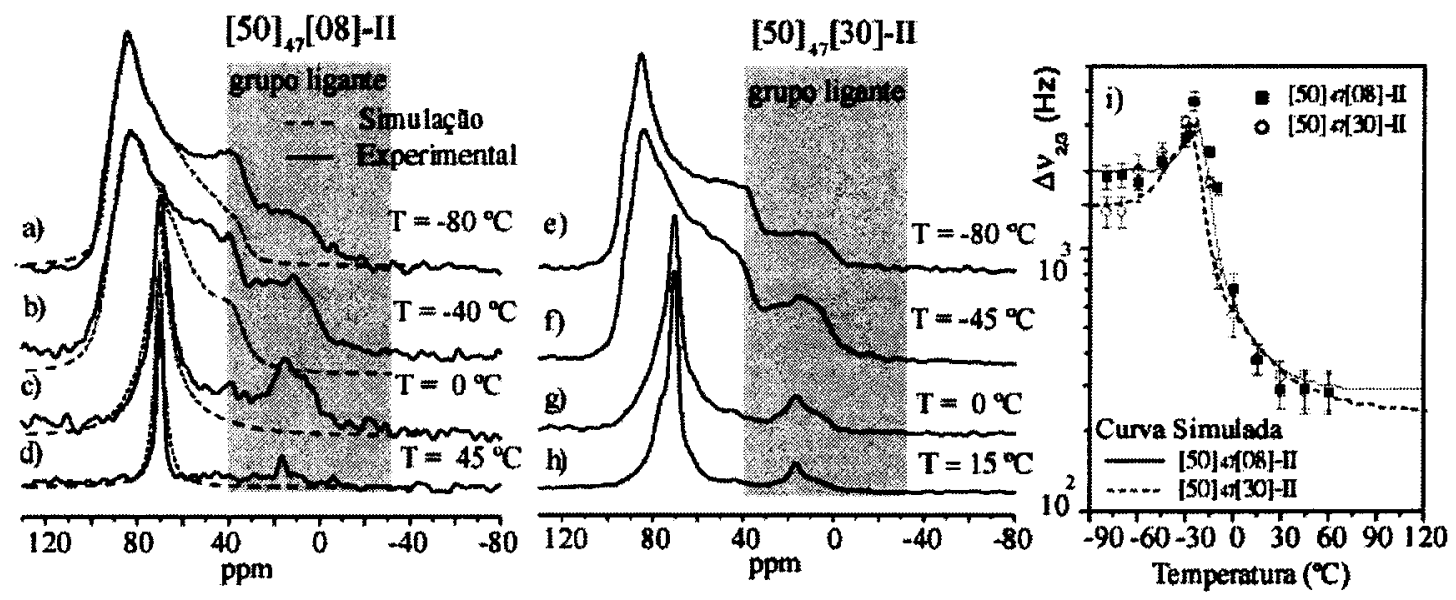

Figura 4.3: As Figuras 4.3a-d) mostram as formas de linhas do espectros de ${ }^{13} \mathrm{C}$, utilizando a técnica de Polarização Cruzada, em função da temperatura, onde a linha contínua representa o espectro experimental e a linha pontilhada o espectro simulado, para a amostra [50] ${ }_{47}$ [08]-II. As Figuras 4.3e-h) mostram as formas de linha do espectros de ${ }^{13} \mathrm{C}$ para a amostra [50 ${ }_{47}[30]$-II. A Figura 4.3-i) apresenta a curva obtida a partir da largura de linha espectral à dois terços da altura, $\Delta v_{2 / 3}$, do experimento de Polarização Cruzada, onde os pontos são as larguras de linhas à $\Delta v_{2 / 3}$ experimentais e a linha contínua é a simulação.

A partir das simulações dos espectros de ${ }^{13} \mathrm{C}$, utilizando a equação [4.1], e comparado-as aos resultados experimentais (como mostrado na Figura 4.3), é possível determinar o tempo de correlação médio $\left\langle\tau_{c}\right\rangle$ do movimento molecular. 
haja uma melhor comparação dos resultados experimentais e as simulações. Uma outra informação que pode ser obtida à partir de espectros do tipo mostrado nas Figuras $4.3 \mathrm{i}$ e $4.4 \mathrm{i}$ é a temperatura em torno da qual o movimento molecular atinge o regime de movimentos lentos, isto é, a faixa de temperatura em que o experimento de Exchange deve ser realizado, pois isso pode ser extraído da curva diretamente, e para conseguirmos uma curva simulada de linha contínua como apresentada nas referentes figuras, necessitamos de fazer uma interpolação de pontos para que se obter uma melhor comparação com a curva experimental. Enfatizando que o processo de estreitamento por movimento molecular é do tipo de Arrhenius, logo se pode calcular a energia de ativação aparente de cada amostra a partir dos dados experimentais, isto é, comparando a curva simulada com a adquirida experimentalmente, seguindo a equação $(1 / T)=\left(k / E_{a}\right) \ln \left(\tau_{c} / \tau_{0}\right)$, podemos ajustar a energia de ativação conforme chegamos próximos à curva experimental.
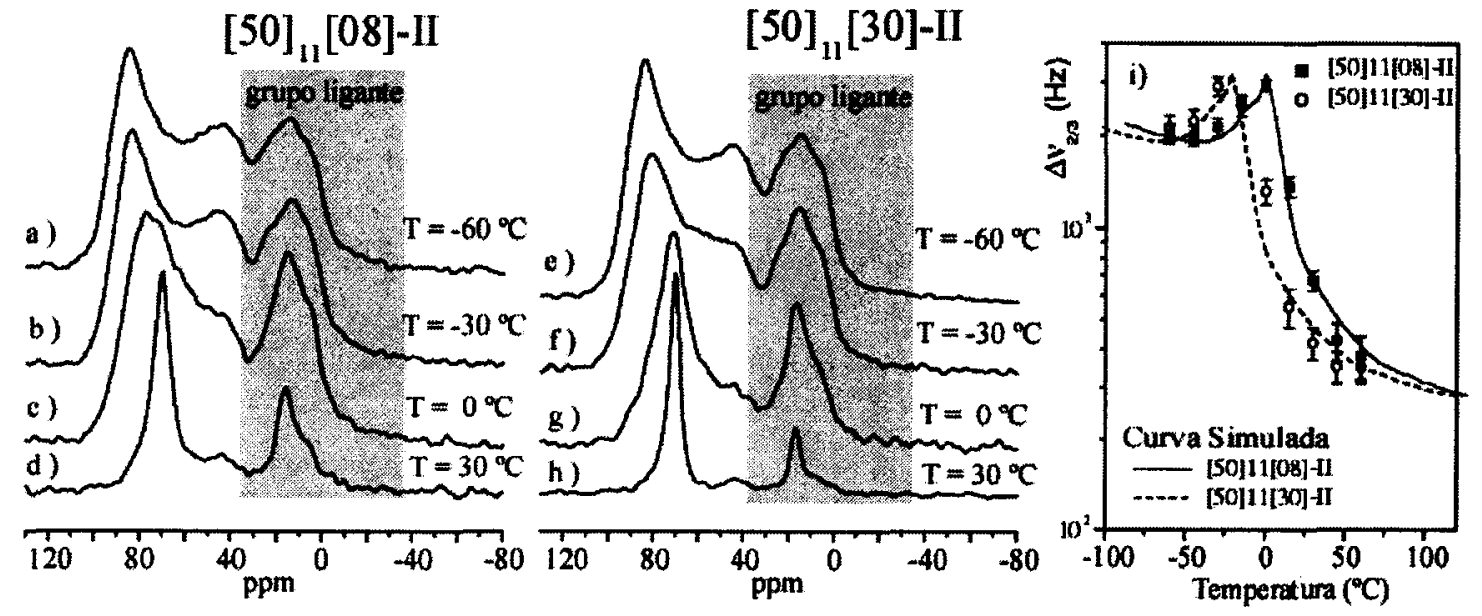

Figura 4.4: As Figuras 4.4a-d) mostram as formas de linhas do espectros de ${ }^{13} \mathrm{C}$, utilizando a técnica de Polarização Cruzada em função da temperatura, onde a linha contínua corresponde ao espectro experimental e a linha pontilhada ao espectro simulado da amostra [50 ${ }_{11}$ [08]-II. As Figuras 4.4e-h) mostram as formas de linha do espectros de ${ }^{13} \mathrm{C}$, para Ormolitas do Tipo II, [50 $]_{11}[30]$-II. A Figura 4.4-i) Curva referente a largura de linha $\Delta v_{(2 / 3)}$, onde os pontos representam os dados experimentais e a linha contínua corresponde a simulação.

$\mathrm{Na}$ Figura 4.4 está mostrado o comportamento das amostras [50 $]_{11}[08]-\mathrm{II}$ e $[50]_{11}[30]-$ II em função da temperatura, o qual apresenta uma ligeira diferença na 
região espectral de 20 a $60 \mathrm{ppm}$, onde aparece um sinal referente ao carbono ligado ao átomo de nitrogênio, indicando a sensibilidade do experimento em relação ao comprimento da cadeia polimérica. A diferença entre as figuras $4.3 \mathrm{i}$ e $4.4 \mathrm{i}$, amostras $[50]_{47}[\mathrm{Y}]-$ II e $[50]_{11}[\mathrm{Y}]-$ II respectivamente, está no deslocamento do estreitamento de linha pelo movimento molecular (motional narrowing) das curvas de $\mathrm{CP}$, devido a variação do parâmetro $[\mathrm{Y}]=[\mathrm{O}] /[\mathrm{Li}]$ (razão oxigênio-lítio) e do parâmetro $n$,comprimento da cadeia. Um outro fato importante observado, é quanto a distorção espectral do grupo de conexão $-\left(\mathrm{CH}_{2}\right)_{3}-(\mathrm{PEG})_{\mathrm{n}}$ mostrado nas Figuras 4.3c-g, referentes a temperatura de $0^{\circ} \mathrm{C}\left(\right.$ acima da $T_{\mathrm{g}}$ ) este grupo ainda se mantém aparentemente imóvel em relação ao segmento molecular $\left\{\mathrm{CH}_{2}-\mathrm{CH}_{2}-\mathrm{O}\right\}_{\mathrm{n}}$. Da mesma forma observamos este fato para as amostras $[50]_{11}[08]$-II e [50 $]_{11}[30]-\Pi$, relativamente de maior intensidade em relação a $[50]_{47}[08]$-II. isso é devido à influência do movimento do segmento estar intimamente relacionado com o comprimento da cadeia.

Na Tabela 4.1 estão mostradas as temperaturas do início da estreitamento de linha das ormolitas $[50]_{47}[08]-$ II, $[50]_{47}[30]-$ II, $[50]_{11}[08]-$ II e $[50]_{11}[30]-$ II para o estudo de Exchange 2D.

Tabela 4.1 : Temperaturas selecionadas para o experimento

2D Exchange, obtidas das larguras de linha $\Delta v_{(2 / 3)}$ do

experimento $\mathrm{CP}$, versus temperatura.

\begin{tabular}{lcc}
\hline Amostra & $\begin{array}{c}\text { Temperatura de } \\
\text { Exchange }\left({ }^{\circ} \mathrm{C}\right)\end{array}$ & $\begin{array}{c}\text { Tempo de } \\
\text { correlação }(\mu \mathrm{s})\end{array}$ \\
\hline$[50]_{11}[08]-$ II & -5 & 265 \\
{$[50]_{11}[30]-$ II } & -23 & 300 \\
{$[50]_{47}[08]-$ II } & -25 & 200 \\
{$[50]_{47}[30]-$ II } & -30 & 280 \\
\hline
\end{tabular}

$\mathrm{Na}$ tabela 4.2 estão mostradas as energias de ativação obtidas pela simulação das curvas $4.3 \mathrm{i}$ e $4.4 \mathrm{i}$. 
Tabela 4.2 : Energia de ativação das ormolitas obtidas a partir do experimento de $\mathrm{CP}$.

\begin{tabular}{lccc}
\hline Amostra & $\mathrm{E}_{\mathrm{a}}(\mathrm{eV})$ & $\mathrm{E}_{\mathrm{a}}(\mathrm{kJ} / \mathrm{mol})$ & $\mathrm{E}_{\mathrm{a}}(\mathrm{Kcal} / \mathrm{mol})$ \\
\hline$[50]_{11}[08]-\mathrm{II}$ & 0,50 & 48,24 & 11,52 \\
{$[50]_{11}[30]-\mathrm{II}$} & 0,41 & 39,56 & 9,45 \\
{$[50]_{47}[08]-\mathrm{II}$} & 0,51 & 49,20 & 11,75 \\
{$[50]_{47}[30]-\mathrm{II}$} & 0,40 & 38,59 & 9,22 \\
\hline
\end{tabular}

\subsection{Espectros de 2D Exchange NMR de ${ }^{13}$ C estático.}

Nesta sessão de resultados serão apresentados espectros 2D Exchange para as três temperaturas distintas: $\mathrm{T}_{\mathrm{g}}-10^{\circ} \mathrm{C}, \mathrm{T}_{\mathrm{g}}$ e $\mathrm{T}_{\mathrm{g}}+8^{\circ} \mathrm{C}$ para as amostras $[50]_{47}[08]-\Pi$ (Figura 4.6) e $\mathrm{T}_{\mathrm{g}}-5^{\circ} \mathrm{C}, \mathrm{T}_{\mathrm{g}}$ e $\mathrm{T}_{\mathrm{g}}+5^{\circ} \mathrm{C}[50]_{11}[08]-\mathrm{II}$ (Figura 4.8). Estas temperaturas selecionadas tiveram como objetivo detectar os movimentos dentro da escala de tempo de observação do experimento de Exchange, os quais ocorrem em temperaturas próximas à transição vítrea do polímero. De forma a complementar o estudo da dinâmica da amostra $[50]_{47}[08]-$ II por 2D Exchange foram realizados as suas respectivas simulações (Figura 4.7), utilizando-se o modelo de difusão rotacional isotrópica[18,19], obtendo assim a distribuição de ângulos de reorientação adequada como sugerido nas referencias $[13,17]$.

A amplitude do movimento da cadeia polimérica pode ser observada em duas regiões distintas no espectro 2D Exchange da Ormolita [50 $]_{47}[08]-$ II, como mostrado na Figura 4.6 em três temperaturas distintas próximas de $T_{\mathrm{g}}$. Na temperatura de $-33^{\circ} \mathrm{C}$ o espectro 2D apresenta uma região diagonal em uma faixa de -10 a $20 \mathrm{ppm}$, indicando uma baixa amplitude do movimento molecular, devido ao movimento não se encontrar na escala de tempo de $m s-s$. Como discutido antes, este sinal é atribuído ao núcleo de ${ }^{13} \mathrm{C}$ do grupo de conexão com a sílica $\mathrm{PEG}\left(\mathrm{CH}_{2}\right)_{3} \mathrm{NH}$. O mesmo fato ocorre para a outra conexão $\mathrm{NH}-\mathrm{CO}-\mathrm{NH}$, cujo espectro encontra-se em uma região 
espectral também diagonal entre 100 a 230 ppm. Nesta Figura podemos ver claramente um forte impedimento do movimento molecular devido a ligação covalente com a sílica, enquanto que muito dos segmentos mais afastados da ligação se comportam como cadeias praticamente livres, revelando um comportamento distinto da dinâmica do segmento molecular próximo a sílica. De fato, a presença da diagonal tanto pode indicar que alguns segmentos se movem mais lentamente ou mais rapidamente que a escala de tempo do experimento de Exchange, quanto pode ser atribuída a segmentos executando reorientações por pequenos ângulos, que dão origem a um padrão quase diagonal.
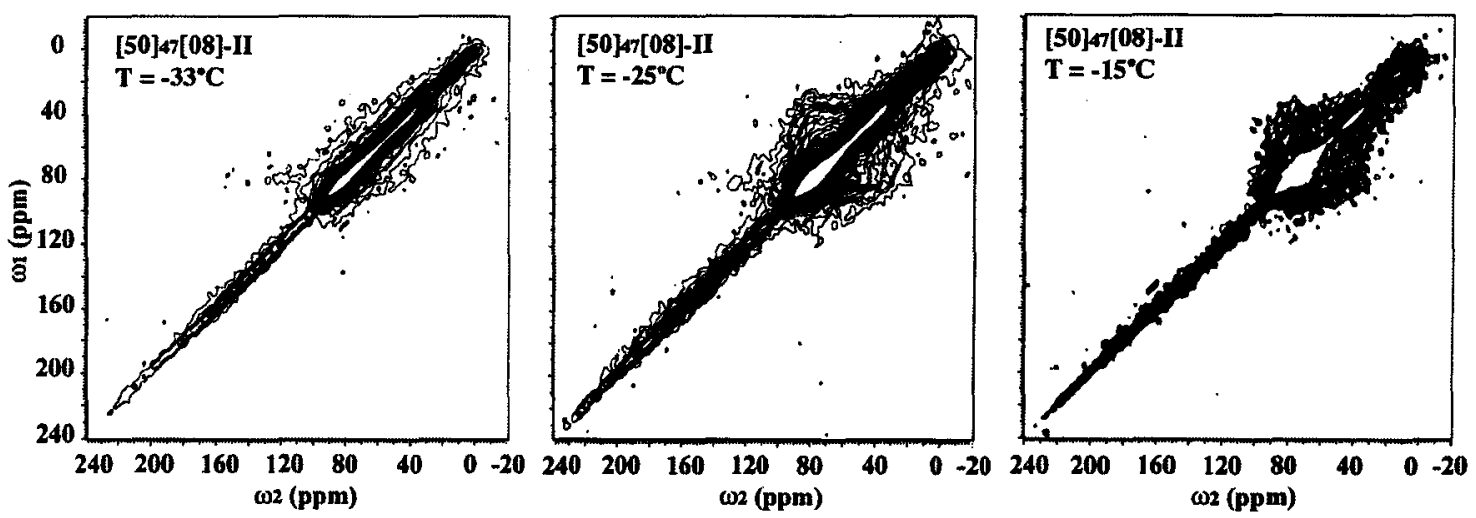

Figura 4.6: Espectro de Exchange 2D realizado $8^{\circ} \mathrm{C}$ abaixo da $T_{\mathrm{g}}\left(-25^{\circ} \mathrm{C}\right)$ da Ormolita $[50]_{47}[08]-\mathrm{II}$. Podemos ver a pequena mobilidade do segmento molecular $\left\{\mathrm{CH}_{2}-\mathrm{CH}_{2}-\mathrm{O}\right\}_{\mathbf{n}}$ na região de 10 a 90 ppm devido a este fato, e na região da conexão Sílica-NH-CO-NH o espectro é puramente diagonal. $O$ tempo de mistura $t_{m}$ foi fixado em $200 \mathrm{~ms}$. Na temperatura de $15^{\circ} \mathrm{C}$ a amplitude do movimento do segmento molecular no espectro de 2D Exchange, já não é mais diagonal devido à promediação dos tensores do deslocamento químico anisotrópico. $O$ incremento da figura foi de 0,5 e o contorno foi de $30 \%$ do máximo da altura.

Por outro lado, a região entre 32 a $95 \mathrm{ppm}$, referente ao segmento molecular $\left\{\mathrm{CH}_{2}-\mathrm{CH}_{2}-\mathrm{O}\right\}_{\mathrm{n}}$, é composta tanto por intensidades diagonal quanto não-diagonal, indicando a presença de segmentos rígidos e móveis, prevalecendo neste caso o segmento móvel, deduzido a partir da larga amplitude do espectro 2D na escala de tempo de $m s-s$. Isto é confirmado a partir da simulação do espectro 2D Exchange, como mostrado na Figura 4.7. Este espectro foi calculado usando a superposição dos 
segmentos rígidos (diagonal) e segmentos móveis (não-diagonal) utilizando os procedimentos descritos nas referências 13 e 17. A partir da simulação podemos também determinar o tempo de correlação para que seja possível comparar o espectro obtido experimentalmente com o espectro simulado.
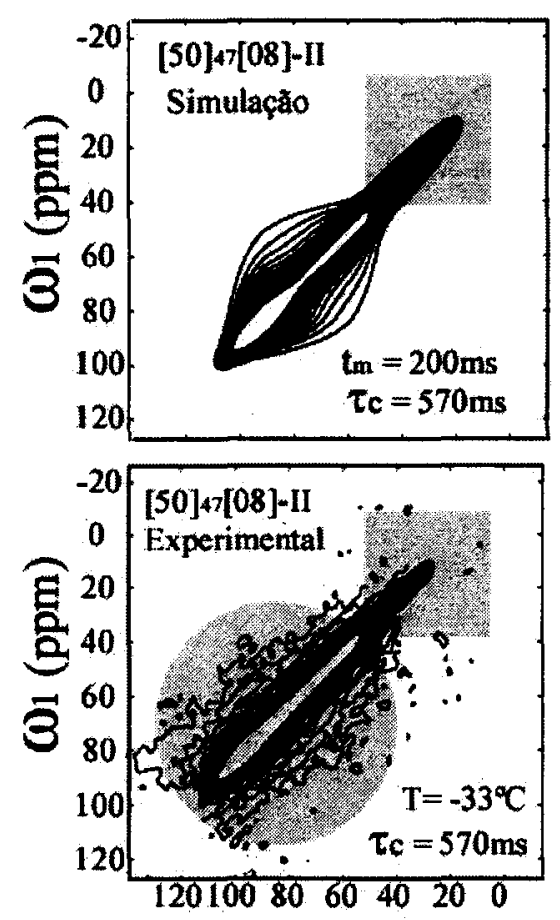

$\omega_{2}(\mathrm{ppm})$
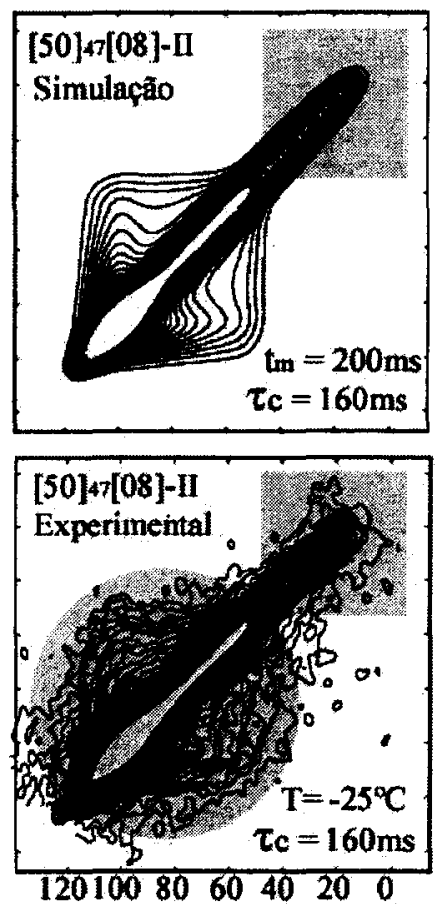

$\omega_{2}(\mathrm{ppm})$
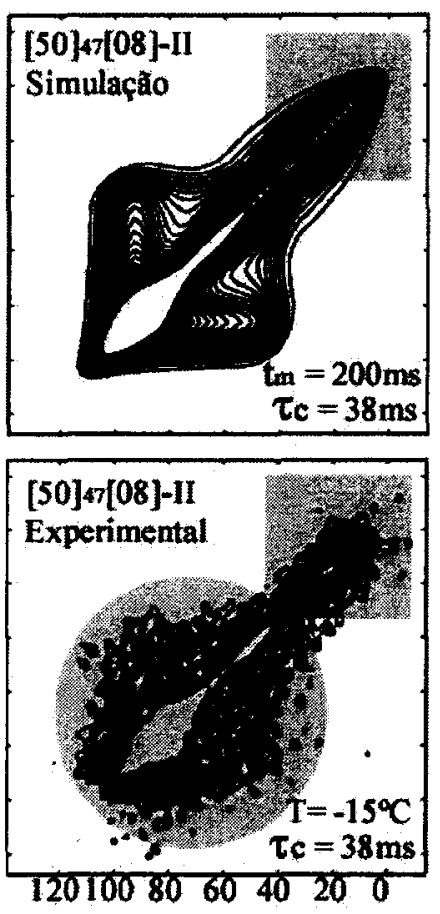

$\omega_{2}(\mathrm{ppm})$

Figura 4.7: Espectros de Exchange 2D da Ormolita [50 ${ }_{47}[08]-\mathrm{II}$ ampliados na região entre -20 a $100 \mathrm{ppm}$ referente as temperaturas $\mathrm{T}=-33^{\circ} \mathrm{C}, \mathrm{T}=-25^{\circ} \mathrm{C}$ e $\mathrm{T}=-15^{\circ} \mathrm{C}$ e suas respectivas simulaçð̃es.

Ampliando a região espectral de 32 a 95 ppm, restringimos a observação do movimento do segmento molecular ao grupo $\left\{\mathrm{CH}_{2}-\mathrm{CH}_{2}-\mathrm{O}\right\}_{\mathrm{n}}$, onde o comportamento do movimento é menos heterogêneo em relação aos grupos de conexão. Este comportamento é mostrado na Figura 4.7, onde o movimento isotrópico é mais abrangente com o aumento da temperatura e nesta mesma Figura observamos os diferentes tempos de correlação médios obtidos por simulação do espectro 2D, lembrando que os experimentos foram realizados próximos da $T_{\mathrm{g}}$ [20], onde para $\mathrm{T}=-33^{\circ} \mathrm{C},\left\langle\tau_{c}\right\rangle=570 \mathrm{~ms} ; \mathrm{T}=-25^{\circ} \mathrm{C},\left\langle\tau_{c}\right\rangle=160 \mathrm{~ms} \mathrm{eT}=-15^{\circ} \mathrm{C},\left\langle\tau_{c}\right\rangle=38 \mathrm{~ms}$. Uma 
outra forma de estudar o comportamento do movimento do segmento $\left\{\mathrm{CH}_{2}-\mathrm{CH}_{2}-\mathrm{O}\right\}_{\mathrm{n}}$ das ormolitas a diferentes temperaturas está relacionado com o comprimento da cadeia polimérica, ou seja, o parâmetro $n$. Como as amostras aqui estudadas têm uma diferença do comprimento da cadeia polimérica de um fator 4 , devido ao peso molecular utilizado, é claramente observada esta diferença quanto a amplitude do movimento molecular das amostras $[50]_{11}[08]-\Pi$ e $[50]_{47}[08]-\Pi$, referentes a temperatura de $-15^{\circ} \mathrm{C}$, onde há uma maior mobilidade do segmento molecular $\left\{\mathrm{CH}_{2}-\right.$ $\left.\mathrm{CH}_{2}-\mathrm{O}\right\}_{\mathrm{n}}$ da ormolita [50 $]_{47}[08]-\mathrm{II}$ em relação a [50] $]_{11}[08]-\Pi$ [20].
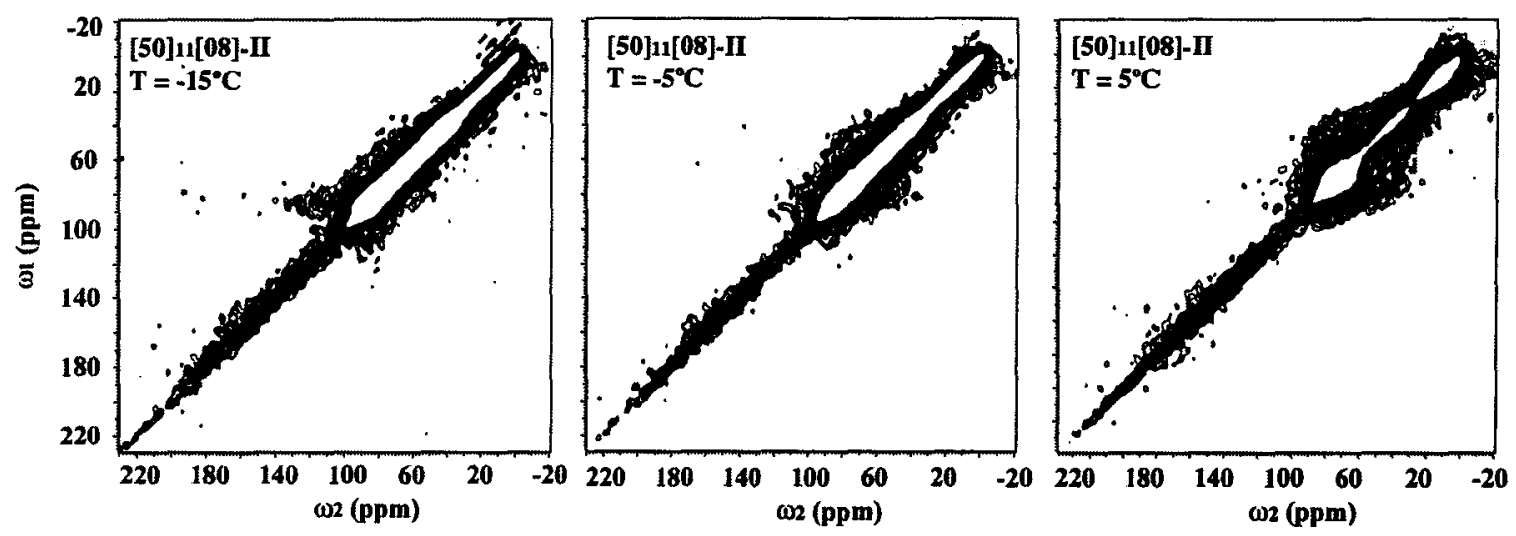

Figura 4.8: Espectros de 2D Exchange obtidos nas temperaturas $\mathrm{T}=-15^{\circ} \mathrm{C}, \mathrm{T}=-5^{\circ} \mathrm{C}$ e $\mathrm{T}=5^{\circ} \mathrm{C}$ da ormolita [50 $]_{11}[08]$-II. O tempo de mistura $t_{\mathrm{m}}$ foi fixo de $200 \mathrm{~ms}$. $\mathrm{O}$ incremento da figura foi de 0,5 e o contorno foi de $30 \%$ do máximo da altura.

\subsection{Resultados 1D PUREX NMR das ormolitas.}

Na Figura 4.9 são mostradas as curvas 1D PUREX versus $\mathrm{t}_{\mathrm{m}}$ como função da temperatura, com o intuito de se medir a escala de tempo do movimento do segmento molecular. O tempo entre os pulsos foi de $\tau=250 \mu$ s com tempo de mistura $t_{m}$ variado entre 2 a $600 \mathrm{~ms}$. As temperaturas foram escolhidas propositalmente para que pudéssemos observar o movimento do segmento molecular próximo da $T_{\mathrm{g}}$ das amostras $[50]_{47}[08]$-II e [50] $]_{11}[08]$-II. Para obtenção da fração móvel $f_{\mathrm{m}}$ relacionada a 
cada $t_{\mathrm{m}}$ de cada temperatura, as intensidades espectrais $S$ e $S_{0}$ foram obtidas pela integração do espectro na região entre 50 a 110 ppm, isto é, somente o segmento molecular $\left\{\mathrm{CH}_{2}-\mathrm{CH}_{2}-\mathrm{O}\right\}_{\mathrm{n}}$ que foram considerados mais móveis. Seguindo a metodologia citada $[11,13]$ podemos ver a amplitude da fração móvel das amostras $[50]_{47}[08]-$ II e [50 $]_{11}[08]-$-II na Figura 4.9. As curvas PUREX 1D foram ajustadas com a função de correlação $K W W$ (Kohlrausch-Willians-Watt) ou stretched exponential[11,13]:

$$
E\left(t_{m}, \delta \tau_{C S A}\right)=f m\left\{1-\exp \left[\left(-t_{m} / \tau_{0}\right)^{\beta}\right]\right\}
$$

onde a $f_{\mathrm{m}}$ é a fração móvel do segmento molecular; $\mathrm{t}_{\mathrm{m}}$ é o tempo de mistura, $\beta$ é uma constante da curva, que está correlacionada com a distribuição dos tempos de correlação. Este parâmetro varia dentro do intervalo de $0<\beta \leq 1[17,21]$. A coleção de curvas PUREX 1D da amostra [50 ${ }_{47}[08]$-II, foi realizada nas temperaturas: -35 , $30,-25$ e $-20^{\circ} \mathrm{C}$, com a variação do tempo de mistura $t_{m}$, observando o comportamento da distribuição dos tempos de correlação.

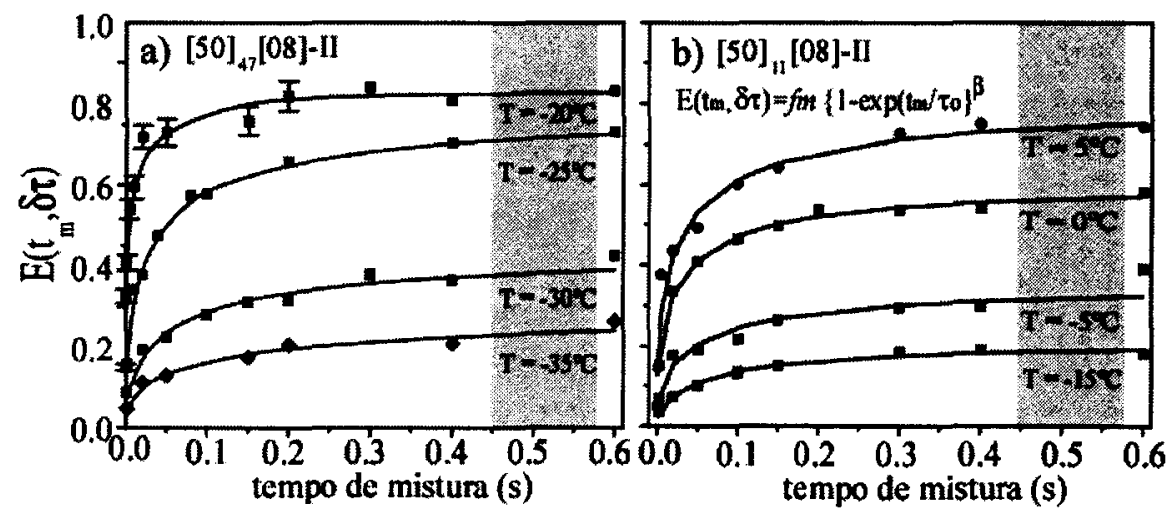

Figura 4.9: a) Curvas de 13C obtidas através da sequência de pulso PUREX 1D para as amostras $[50]_{47}[08]-$ II e [50 $]_{11}[08]-$ II com quatro temperaturas diferentes. Com a variação de somente $5^{\circ} \mathrm{C}$ já podemos observar uma diferença na intensidade da curva PUREX 1D [20,22]. 
Podemos ver explicitamente na Figura 4.9 que a fração móvel aumenta significativamente, quando ocorre uma variação de temperatura de $5^{\circ} \mathrm{C}$ na amostra, e isso se torna mais sensivel quando a variação da temperatura está próxima da $T_{\mathrm{g}}$ $\left(-25^{\circ} \mathrm{C}\right)$ da amostra $[50]_{47}[08]-$ II. Observa-se que para a temperatura de $-35^{\circ} \mathrm{C}$ a amplitude movimento do segmento molecular é menor em relação à curva obtida a temperatura de $-20^{\circ} \mathrm{C}$, onde a amplitude do movimento molecular maior $[20,22,23]$. Por outro lado, o tempo de correlação médio $\left\langle\tau_{c}\right\rangle$ é quase o dobro quando a temperatura varia apenas $5^{\circ} \mathrm{C}$. Os tempos de correlação estimados dos experimentos realizados foram de $334 \mathrm{~ms}\left(-35^{\circ} \mathrm{C}\right), 173 \mathrm{~ms}\left(-30^{\circ} \mathrm{C}\right), 94 \mathrm{~ms}\left(-25^{\circ} \mathrm{C}\right)$ e $48 \mathrm{~ms}$ $\left(-20^{\circ} \mathrm{C}\right)$, para a amostra $[50]_{47}[08]-$-II. O cálculo do tempo de correlação médio $<\tau_{c}>$ é dado da seguinte forma:

$$
<\tau_{c}>=\left(\frac{\tau_{0}}{\beta}\right) \Gamma\left(\frac{1}{\beta}\right)
$$

onde $\Gamma$ é a função Gama.

Os parâmetros $f_{\mathrm{m}}, \beta_{K W W}$ e $\tau_{0}$ da função KWW estão mostrados na forma de tabela abaixo.

Tabela 4.3: Parâmetros das curvas PUREX ID obtidos a partir da função KWW stretched exponential para a Ormolita [50] ${ }_{47}$ [08]-II.

\begin{tabular}{cccc}
\hline Temperatura $\left({ }^{\circ} \mathrm{C}\right)$ & $\beta$ & $f_{\mathrm{m}}$ & $\tau_{\mathrm{C}}(\mathrm{ms})$ \\
-35 & 0,43 & 0,28 & 334 \\
-30 & 0,45 & 0,42 & 173 \\
-25 & 0,45 & 0,75 & 94 \\
-20 & 0,38 & 0,82 & 48 \\
\hline
\end{tabular}

Tabela 4.4: Parâmetros das curvas PUREX 1D obtidos a partir da função KWW stretched exponential para a Ormolita [50] 11 [08]-II.

\begin{tabular}{|c|c|c|c|}
\hline Temperatura $\left({ }^{\circ} \mathrm{C}\right)$ & $\beta$ & $f_{\mathrm{m}}$ & $\tau_{\mathrm{C}}(\mathrm{ms})$ \\
\hline-15 & 0,55 & 0,20 & 134 \\
\hline-5 & 0,47 & 0,34 & 131 \\
\hline-0 & 0,41 & 0,6 & 95 \\
\hline 5 & 0,40 & 0,79 & 125 \\
\hline
\end{tabular}




\subsection{Energia de Ativação por PUREX 1D.}

A partir da obtenção dos parâmetros do experimento PUREX 1D é possível estimar a energia de ativação aparente da amostra [50 $]_{47}[08]-$ II. A energia de ativação pode ser expressa da forma[13]:

$$
<\tau_{c}>=\tau_{0} \exp \left(E_{a} / k T\right)
$$

aplicando o $\ln$ na função $\left\langle\tau_{c}>\right.$

$$
\begin{aligned}
& \ln <\tau_{c}>=\ln \tau_{0}+\left(E_{a} / k T\right) \\
& E_{a}=\ln \left(\frac{<\tau_{c}>}{\tau_{0}}\right) \cdot k T
\end{aligned}
$$

e a energia de ativação aparente obtida através deste cálculo é de $0,66 \mathrm{eV}$.

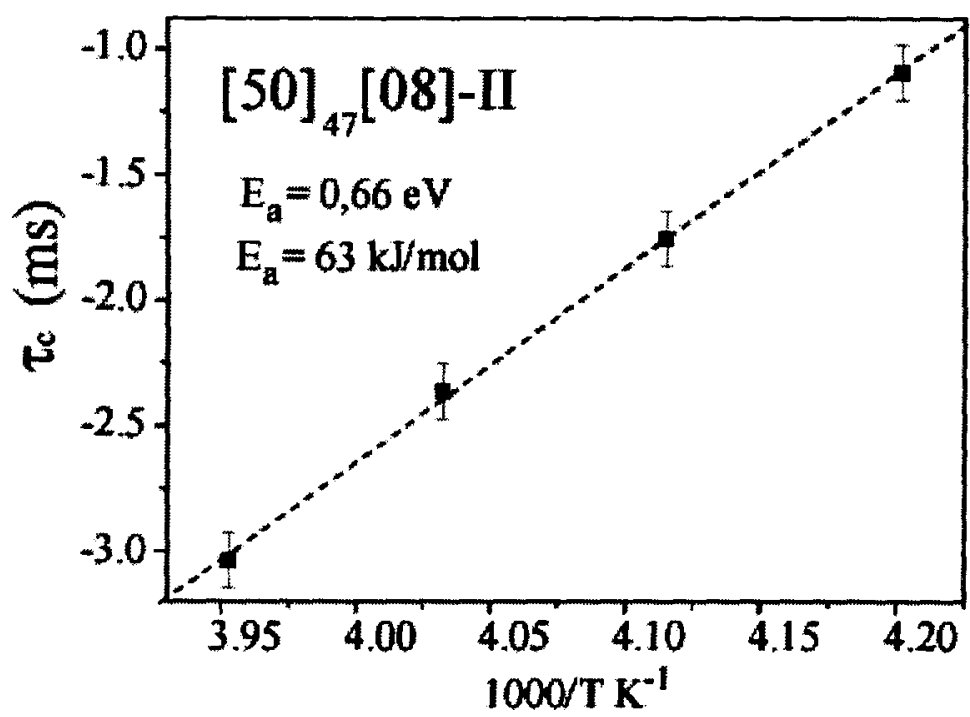

Figura 4.10: Obtenção da Energia de Ativação a partir da .Escala de tempo em função da temperatura, $\left\langle\tau_{c}\right\rangle$ em escala logarítmica. 


\subsection{Resultados 1D PUREX do - $\left(\mathrm{CH}_{2}\right)_{3}-(\mathrm{PEG})_{n}$.}

Analisando a Figura 4.11 na temperatura de $\mathrm{T}=5^{\circ} \mathrm{C}$ na região entre 60 a $110 \mathrm{ppm}$, o decaimento nesta região espectral marcada com asterisco $\left({ }^{*}\right)$ é devido à reorientação do segmento molecular $\left\{\mathrm{CH}_{2} \mathrm{CH}_{2} \mathrm{O}\right\}_{\mathrm{n}}$. Explicitando um maior movimento deste segmento molecular em relação ao grupo de conexão $-\left(\mathrm{CH}_{2}\right)_{3}-(\mathrm{PEG})_{\mathrm{n}}$ que possui uma movimento muito menor devido estar ligado quimicamente com a sílica.

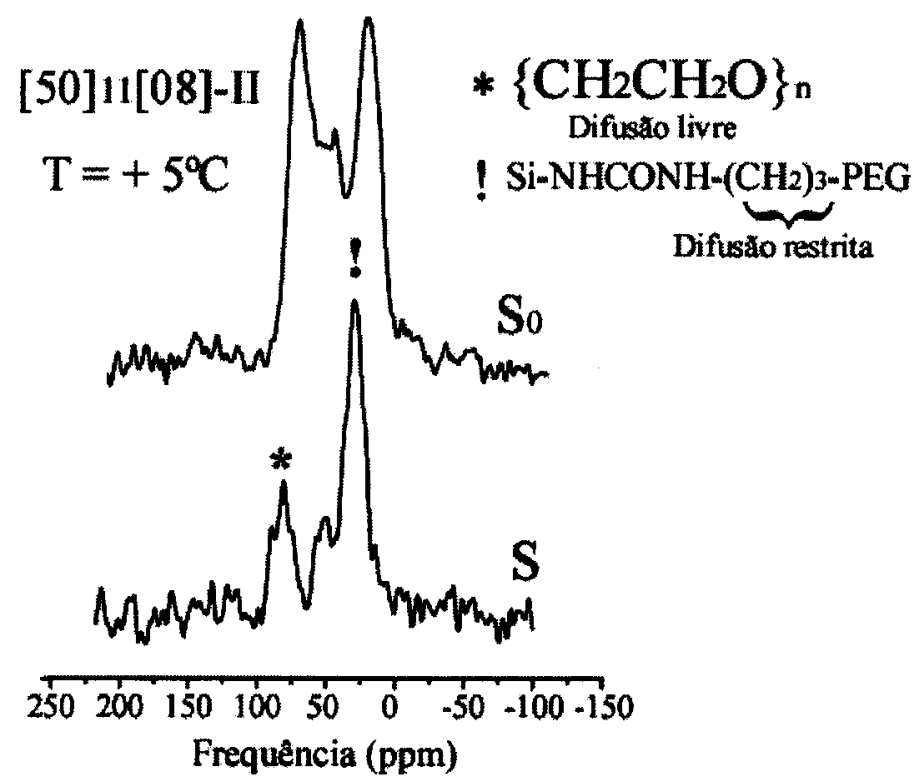

Figura 4.11: Experimento PUREX $1 \mathrm{D}{ }^{13} \mathrm{C}$ da Ormolita [50 $]_{11}[08]-\mathrm{II}$ com tempo de mistura $\mathrm{t}_{\mathrm{m}}=200 \mathrm{~ms}$ e a uma temperatura $10^{\circ} \mathrm{C}$ acima da $T_{\mathrm{g}}$ da amostra. $\mathrm{O}$ espectro $S_{0}$ é a intensidade de referência e o espectro $S$, é a intensidade PUREX, o decaimento na região espectral marcado com asterístico $\left(^{*}\right)$ é devido a reorientação do segmento molecular.

Na Figura 4.12 estão mostradas as curvas 1D PUREX como função da temperatura para as ormolitas com diferentes níveis de dopagem de lítio (parâmetro [Y]), [50 $]_{47} \amalg$ (não dopada), [50 $]_{47}[08]-\Pi I,[50]_{47}[15]-I I,[50]_{47}[30]-\Pi[$ [20, 22, 23]. Pode-se notar claramente que a intensidade máxima PUREX $E\left(t_{m}, \delta \tau_{C S A}\right)$ versus $\mathrm{T}\left({ }^{\circ} \mathrm{C}\right)$ varia de acordo com a concentração de lítio sendo maior para a amostra com maior 
concentração, [50 $]_{47}[08]$-II. Simulações das curvas utilizando a metodologia descrita no capítulo 3 para distribuições de tempo de correlação do tipo log-Gaussian também estão mostradas. As energias de ativação e as distribuições de tempo de correlação que melhor representam as curvas experimentais estão mostradas na figura. Fazendo-se uma análise comparativa, nota-se uma clara tendência de diminuição da distribuição de tempos de correlação do movimento molecular com o aumento da dopagem de $\mathrm{Li}$. Isto por sua vez, mostra que as heterogeneidades dinâmicas dos movimentos moleculares responsáveis pela transição vítrea do polímero na ormolita diminuem com a concentração de Lítio. Isso indica que a dinâmica molecular $\left\{\mathrm{CH}_{2}-\mathrm{CH}_{2}-\mathrm{O}\right\}_{n}$ é sensível a presença do Lítio[20, 22, 23] , sendo que o aumento da concentração deste cátion implica na uniformização da dinâmica molecular responsável pela transição vítrea do polímero. A distribuição de tempos de correlação na dinâmica responsável pela transição vítrea é um fenômeno largamente observado em polímeros amorfos, sendo geralmente associadas com heterogeneidades locais provocadas pela distribuição de massa molecular que influenciam na uniformidade da dinâmica cooperativa responsável pela transição vítrea destes polímeros. Dependendo do tipo de polímero a dinâmica molecular na transição vítrea pode envolver distribuições de tempos de correlação que variam deste 0.5 década (caso da maioria dos elastômeros sintéticos com baixa polidispersividade, pequena distribuição de massas moleculares $[24,25])$ até 4 décadas (para polímeros com grande distribuição de massas moleculares como o polipropileno atático $[24,25])$. No caso das ormolitas, a variação da distribuição de tempos de correlação com a concentração de Lítio não pode ser atribuída a mudanças na polidispersividade, já que esses materiais são preparados a partir do mesmo precursor (PEG). Deve, portanto, estar ligada a uma mudança na morfologia local 
das cadeias do PEG induzidas pela presença do cátion. Os resultados de análise da largura de linha também mostram um comportamento diferenciado para amostras com diferentes concentrações de Li. De fato, uma claro deslocamento da temperatura de estreitamento para regiões de maior temperatura é observado em amostras mais dopadas. Isto é geralmente atribuído a presença de ligações de entrecruzamento das cadeias via $\mathrm{Li}$, o que aumenta as barreiras energéticas que devem ser vencidas pelo movimentos termicamente ativados. Esta verificação parece a princípio ser contrária à diminuição da largura da distribuição de tempos de correlação como função do aumento da dopagem, observado aqui. Uma possível explicação para tal discrepância, pode estar associada ao fato das heterogeneidades responsáveis pelo aumento da distribuição de tempos de correlação serem heterogeneidades dinâmicas. A conseqüência disso é que se imaginarmos que em um polímero muito dopado, de modo que haja ligações de intercruzamentos, será realmente necessário ceder mais energia para que os movimentos moleculares tenham início, explicando assim o aumento da temperatura de transição vítrea. Porém uma vez disparado o processo, ou seja dada energia suficiente para "romper" as ligações de intercruzamento, as cadeias poliméricas poderão iniciar o movimento molecular quase que conjuntamente, o que explicaria a diminuição da distribuição de tempos correlação dos movimentos moleculares. No entanto, está interpretação não pode ser tomada como absoluta, já que efeitos como presença de separação de fases (regiões com maior ou menor concentração de $\mathrm{Li}$ ) ou outros fatores relacionados com a preparação da amostra podem estar presentes sendo muito difíceis de serem controlados. 


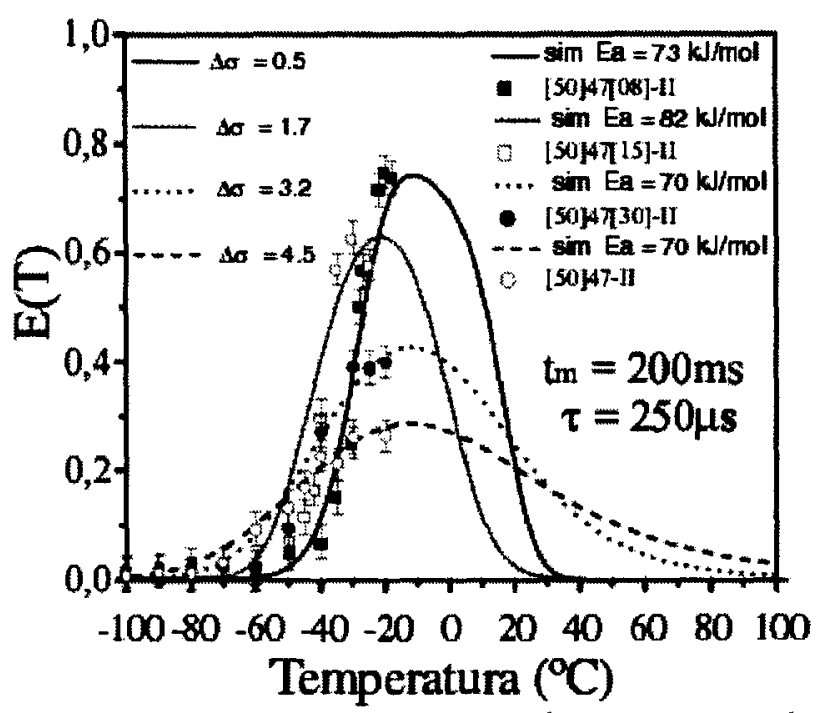

Figura 4.12: Regime do movimento do segmento molecular $\left\{\mathrm{CH}_{2} \mathrm{CH}_{2} \mathrm{O}\right\}_{\mathrm{n}}$ na escala de $m s$ a $s$ envolvendo a distribuição do tempo de correlação. As linhas são as simulações de cada amostra referente ao parâmetro [Y].

\subsection{Conclusões e Perspectivas.}

As técnicas de RMN de Exchange 2D e PUREX 1D foram utilizadas nos estudos, permitindo determinar as amplitudes de movimentos moleculares em diferentes regiões do polímero. Foi mostrado diretamente que pela técnica Exchange 2D os movimentos moleculares em segmentos mais próximos das estruturas de sílica são altamente restritos, enquanto para segmentos afastados destas estruturas, a dinâmica molecular durante a transição vítrea são mais móveis e bastante similar a polímeros totalmente amorfos. De fato, foi observado que este comportamento ocorre somente em amostras com polímeros de maior peso molecular. Para amostras com cadeias poliméricas menores, o efeito da restrição do movimento pelas estruturas de sílica se estendem para a maioria dos segmentos moleculares do polímero. Finalmente, utilizando a técnica PUREX 1D, a distribuição de tempos de correlação do movimentos moleculares envolvidos na transição vítrea foi estimada para amostras com diferentes concentrações de Li. Neste caso, foi 
verificado que a distribuição de tempos de correlação é menor para amostras com maior concentração de Li. Quanto as perspectivas, há interesse em estudar o de Exchange de ${ }^{7} \mathrm{Li}$, onde é empregado o eco de Jeener-Broekart, o qual pode ser gerado por uma seqüência $X_{90^{\circ}}-t_{p}-Y_{45^{\circ}}-t_{m}-X_{45^{\circ}}-t_{p}$. O sinal de RMN envolvendo o Hamiltoniano quadrupolar $H_{Q}$ gerada pela seqüência Jeener-Broekaert é dado por $S_{2}^{Q}\left(t_{p}, t_{m}, t\right)=\frac{9}{20}\left\langle\operatorname{sen}\left[\omega_{Q}(0) t_{p}\right] \operatorname{sen}\left[\omega_{Q}\left(t_{m}\right) t\right]\right\rangle$, o símbolo brackets $\langle\ldots\rangle$ indica uma média sobre todo o pó e as notações $t_{\mathrm{p}}, t_{\mathrm{m}}$ e $t$ são tempo de preparação (ou evolução), tempo de mistura e tempo de refocalização (ou de detecção) respectivamente. No experimento de Spin-alignment, o sinal $S_{2}^{Q}$ pode decrescer com a função do tempo de mistura, isso devido à escala de tempo $\tau_{Q}$ (evolução quadrupolar) quando a freqüência $\omega_{Q}$ muda durante $t_{\mathrm{m}}$ ou pode decair devido ao efeito de relaxação que ocorre na escala de tempo da freqüência de Larmor. Este experimento de Spin-alignment gera informações tanto da contribuição da parte dipolar quanto da parte quadrupolar do sistema em estudo. A variação do sinal de RMN $S_{2}^{Q}$ em função do tempo de mistura $t_{m}$ com o tempo $t_{p}$ fixo, informa a respeito da melhor amplitude do eco do experimento Spin-alignment. Quanto o sinal de RMN $S_{2}^{Q}$ em função da temperatura informa a respeito da dinâmica do íon utilizado, como amplitude do movimento, como também tempo de correlação e energia de ativação. E o sinal $S_{2}^{Q}$ com variação de $t_{\mathrm{p}}$ mostra realmente que a evolução do experimento Spin-alignment gera um espectro de estado puro quadrupolar. E estes parâmetros de dinâmica do íon podem ser correlacionados com o polímero. 


\subsection{Referências:}

1. Dahmouche, K., et al., New Li+ ion-conducting ormolytes. Solar Energy Materials and Solar Cells, 1998. 54(1-4): p. 1-8.

2. Dahmouche, K., et al., Investigation of new ion-conducting ORMOLYTES: Structure and properties. Journal of Sol-Gel Science and Technology, 1997. 8(1-3): p. 711-715.

3. Dahmouche, K., et al., Investigation of new ion conducting ormolytes silicapolypropyleneglycol. Journal of Sol-Gel Science and Technology, 1998. 13(1-3): p. 909-913.

4. Donoso, J.P., et al., Nuclear Magnetic-Relaxation Study of Poly(Ethylene Oxide) Lithium Salt Based Electrolytes. Journal of Chemical Physics, 1993. 98(12): p. 10026-10036.

5. Donoso, J.P., et al., Nuclear Magnetic-Relaxation Study of Poly(Propylene Oxide)Complexed with Lithium Salt. Electrochimica Acta, 1995. 40(13-14): p. 2361-2363.

6. Donoso, J.P., et al., Magnetic-Resonance Study of Water-Absorption in Some Peg-Lithium Salt Polymer Electrolytes. Electrochimica Acta, 1995. 40(1314): p. 2357-2360.

7. Benavente, E., et al., Lithium-induced self-assembling of poly(ethylene oxide) intercalated in molybdenum disulfide. Electrochimica Acta, 2003. 48(14-16): p. 1997-2002.

8. Souza, P.H., et al., Solid-State NMR, Ionic Conductivity, and Thermal Studies of Lithium-doped Siloxane-Poly(propylene glycol) Organic-Inorganic Nanocomposites. Chem. Mater., 2001. 13(10): p. 3685-3692.

9. Mello, N.C., et al., NMR Study of Ion-Conducting Organic-Inorganic Nanocomposites Poly(ethylene glycol)-Silica-LiClO4. Macromolecules, 2000. 33(4): p. 1280-1288.

10. Souza, P.H., et al., Solid-State NMR, Ionic Conductivity, and Thermal Studies of Lithium-doped Siloxane-Poly(propylene glycol) Organic-Inorganic Nanocomposites. Chem. Mater., 2001. 13(10): p. 3685-3692.

11. deAzevedo, E.R., et al., Motional Heterogeneities in Siloxane/Poly(ethylene glycol) Ormolyte Nanocomposites Studied by 13CNMR Solid-State Exchange NMR. Chem. Mater., 2003. 15(10): p. 2070-2078.

12. deAzevedo, E.R., T.J. Bonagamba, and K. Schmidt-Rohr, Pure-Exchange Solid-State NMR. Jounal of Magnetic Resonance, 2000. 142: p. 86-89.

13. deAzevedo, E.R., Novas Metodologias de Ressonância Magnética Nuclear para o Estudo da Dinâmica Lenta em Materiais Orgânicos no Estado Sólido: Aplicações em Polímeros e Proteínas, in Instituto de Física de São Carlos. 2001, Universidade de São Paulo: São Carlos. p. 197.

14. Schmidt A, Et Al., Chemical-Exchange Effects In The Nmr-Spectra Of Rotating Solids. Journal Of Chemical Physics, 1986. 85(8): P. 4248-4253.

15. Schmidt A And V. S, Nmr Line-Shape Analysis For 2-Site Exchange In Rotating Solids. Journal Of Chemical Physics, 1987. 87(12): P. 6895-6907.

16. Luz Z, Poupko R, And A. S, Theory Of Dynamic Magic-Angle-Spinning Nuclear-Magnetic-Resonance And Its Application To C-13 In Solid Bullvalene. Journal Of Chemical Physics, 1993. 99(10): p. 7544-7553. 
17. Schmidt-Rohr, K. and H.W. Spiess, Multidimensional Solid-State NMR and Polymers. 1994, San Diego CA: Academic Press. 478.

18. Wefing, S. and H.W. Spiess, Two-Dimensional Exchange Nmr of Powder Samples .1. 2-Time Distribution-Functions. Journal of Chemical Physics, 1988. 89(3): p. 1219-1233.

19. Wefing, S., S. Kaufmann, and H.W. Spiess, Two-Dimensional Exchange Nmr of Powder Samples .2. The Dynamic Evolution of 2-Time DistributionFunctions. Journal of Chemical Physics, 1988. 89(3): p. 1234-1244.

20. Bathista, A.L.B.S., et al. Correlation between slow carbon and lithium dynamics in lithium doped-Siloxane/Poly(Ethylene Glycol) Nanocomposites. in XXVII Encontro Nacional de Física da matéria Condensada. 2004. Poços de Caldas.

21. Chmelka, B.F., K. Schmidt-Rohr, and H.W. Spiess, Molecular Dynamics in Polymers Studied by Multidimensional Solid-State NMR, in Nuclear Magnetic Resonance Probes of Molecular Dynamics, R. Tycko, Editor. 1994, Kluwer Academic Publishers: Netherlands. p. 113-153.

22. Bathista, A.L.B.S., et al. Estudo de Compostos Híbridos OrgânicosInorgânicos Condutores iônicos por RMN de Estado Sólido. in III Encontro do Instituto do Milênio de Materiais Poliméricos. 2004. Atibaia.

23. Bathista, A.L.B.S., et al. Estudo de Compostos Híbridos OrgânicoInorgânicos Condutores Iônicos por RMN do Estado Solido. in VI Simpósio em Ciência e Engenharia de Materiais. 2003. São Carlos.

24. Schaefer, D. And H. Spiess, 2-Dimensional Exchange Nuclear-MagneticResonance Of Powder Samples .4. Distribution Of Correlation Times And Line-Shapes In The Intermediate Dynamic-Range. Journal Of Chemical Physics, 1992. 97(11): P. 7944-7954.

25. Heuer A, et al., Geometry and time scale of the complex rotational dynamics of amorphous polymers at the glass transition by multidimensional nuclear magnetic resonance. Journal Of Chemical Physics, 1996. 105(16): p. 70887096. 


\section{Apêndice}

\section{Introdução.}

Nesta sessão será apresentado o princípio computacional, algoritmos dos programas utilizados para simular os resultados obtidos por experimentos de forma de linha, Exchange 2D e PUREX 1D, os resultados das simulações obtidas para ormolitas, foi utilizado o programa em FORTRAN. A estação de processamento utilizada para realização das simulações, foi uma plataforma Pentium $600 \mathrm{MHz}, 128$ Mb RAM, com tempo de duração de 7 a 50 minutos por Matriz de Exchange espectros 2D Exchange. Enquanto que para as curvas simuladas da $2 / 3$ da altura máxima foi gasto um total de 12 horas.

\section{1 Simulações dos espectros obtidos.}

A interpretação quantitativa dos resultados obtidos é feita através de simulações dos espectros experimentais. De forma geral, estas simulações são realizadas utilizando aspectos geométricos, isto é, as freqüências de RMN são calculadas antes e depois do tempo de mistura, utilizando-se as respectivas orientaçס̃es do sistema de eixos principais (SEP) do tensor de deslocamento químico. Este tratamento geométrico é válido assumindo que o movimento molecular ocorre na escala de tempo do tempo de mistura e também que os pulsos de radiofreqüência sejam curtos o suficiente para que sua banda de excitação cubra toda a faixa espectral, o que é geralmente cumprido para a interação de deslocamento químico. 


\section{2 Cálculo das frequiências de RMN em experimentos de Exchange estáticos.}

Como já foi discutido, a freqüência observada em um experimento de $\mathrm{RMN}$ é definida essencialmente pela orientação do campo magnético externo, $\vec{B}_{o}$, relativamente ao SEP da interação durante a detecção do sinal. Um vetor unitário ao longo do campo magnético externo, $\vec{b}_{o}$, pode ser representado no SEP do tensor de deslocamento químico, $\tilde{\sigma}$, através da seguinte expressão:

$$
\tilde{b}_{o}=\left(\begin{array}{c}
\operatorname{sen} \theta \cos \phi \\
\operatorname{sen} \theta \operatorname{sen} \phi \\
\cos \theta
\end{array}\right)
$$

onde $\vec{b}_{o}=\frac{\vec{B}_{o}}{B_{o}}$ e os ângulos $\theta$ e $\phi$ são as coordenadas polares do vetor $\vec{b}_{o}$ no sistema de eixos principais do tensor de deslocamento químico, $\tilde{\sigma}^{S E P}$. Conhecendo-se o tensor de deslocamento químico no seu respectivo SEP, a freqüência de RMN pode ser calculada como:

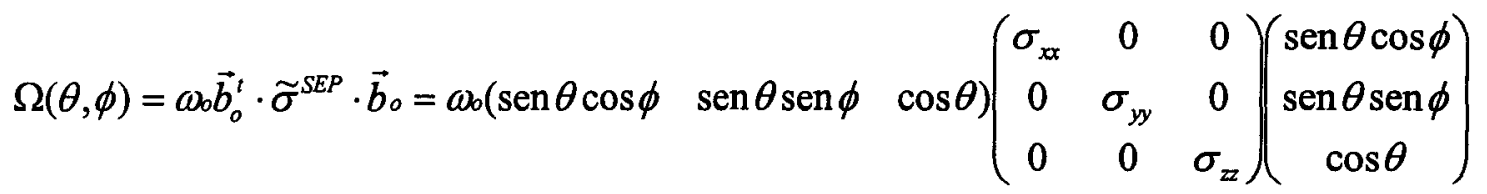

Entretanto, como em experimentos de Exchange há dois sistemas de eixos principais envolvidos, associados aos tensores de deslocamento químico antes e depois de $t_{m}$, a situação é ligeiramente mais complicada. Todos os cálculos devem ser realizados em um mesmo sistema de coordenadas, sendo necessário expressar os tensores de deslocamento químico antes e depois de $t_{m}$ em um dos dois SEPs. Se um deles for tomado como base, por exemplo, o SEP do tensor deslocamento químico 
antes de $t_{m}$, os demais valores poderão ser representados nesse sistema de coordenadas através dos ângulos de Euler, como ilustrado na figura I.1 para o caso da transformação do SEP para o Sistema Molecular, que será comentado adiante. Estes valores estão diretamente relacionados com os ângulos de reorientação do movimento molecular, que caracterizam a reorientação, permitindo que as frequiências de $\mathrm{RMN}$ antes e depois de $\mathrm{t}_{\mathfrak{m}}$ possam ser calculadas para cada orientação, assumindo uma dada geometria do movimento.

(a)

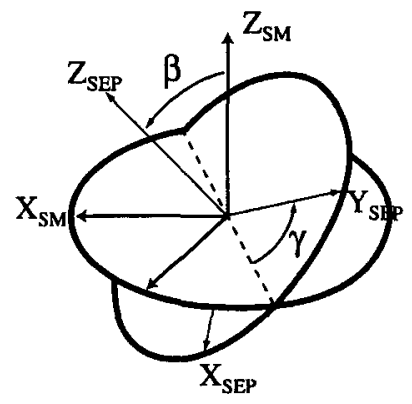

(b)

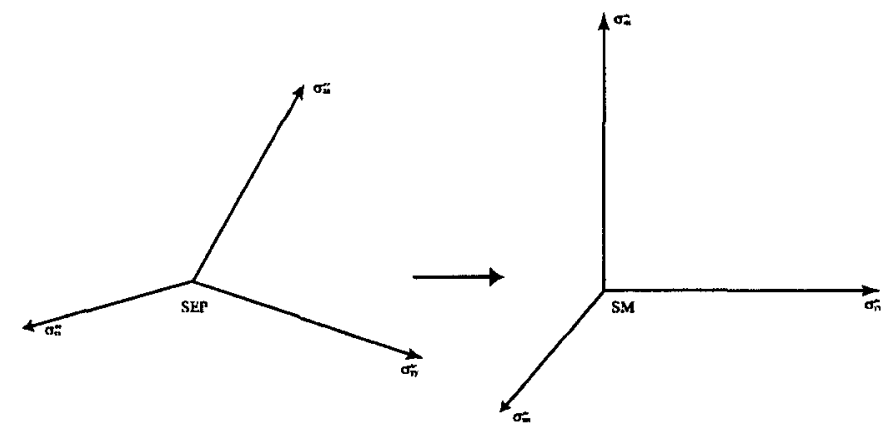

Figura I.1: Definição dos ângulos de Euler $\alpha, \beta$ e $\gamma$ (a) que determinam a orientação relativa entre - Sistema Molecular (SM) e o Sistema de Eixos Principais (SEP) e uma transformação esquemática (b).

Os tensores de deslocamento químico antes, $\tilde{\sigma}^{A}$, e depois, $\tilde{\sigma}^{D}$, de $\mathrm{t}_{\mathrm{m}}$ podem ser representados neste sistema de coordenadas como:

$$
\begin{gathered}
\tilde{\sigma}^{A}=\tilde{\sigma}^{S E P}=\left(\begin{array}{ccc}
\sigma_{x x}^{S E P} & 0 & 0 \\
0 & \sigma_{y y}^{S E P} & 0 \\
0 & 0 & \sigma_{z z}^{S E P}
\end{array}\right) \\
T(\alpha, \beta, \gamma)=\left(\begin{array}{ccc}
\cos \alpha \cos \beta \cos \gamma-\operatorname{sen} \alpha \operatorname{sen} \gamma & \operatorname{sen} \alpha \cos \beta \cos \gamma+\cos \alpha \operatorname{sen} \gamma & -\operatorname{sen} \beta \cos \gamma \\
-\cos \alpha \cos \beta \operatorname{sen} \gamma-\operatorname{sen} \alpha \cos \gamma & -\operatorname{sen} \alpha \cos \beta \operatorname{sen} \gamma+\cos \alpha \cos \gamma & \operatorname{sen} \beta \operatorname{sen} \gamma \\
\cos \alpha \operatorname{sen} \beta & \operatorname{sen} \alpha \operatorname{sen} \beta
\end{array}\right) \\
\tilde{\sigma}^{D}=\tilde{T}(\alpha, \beta, \gamma) \cdot \tilde{\sigma}^{S E P} \cdot \widetilde{T}^{-1}(\alpha, \beta, \gamma)=\left(\begin{array}{ccc}
\sigma_{s s}^{D} & \sigma_{s y}^{D} & \sigma_{x z}^{D} \\
\sigma_{y x}^{D} & \sigma_{y y}^{D} & \sigma_{y z}^{D} \\
\sigma_{z x}^{D} & \sigma_{z y}^{D} & \sigma_{z z}^{D}
\end{array}\right)
\end{gathered}
$$


A matriz $\widetilde{T}$ representa uma rotação de Euler do sistema de eixos principais do tensor que ocorre devido à reorientação do segmento molecular. Deste modo, os ângulos $\alpha, \beta$ e $\gamma$ representam três ângulos de Euler que estão diretamente relacionados com os ângulos de reorientação do movimento molecular, que caracterizam a geometria do movimento. Uma vez que os tensores foram adequadamente representados, as freqüências antes e depois de $t_{m}$ são calculadas de acordo com a expressão (I.2), resultando em:

$$
\begin{aligned}
& \Omega_{1}(\theta, \phi)=\omega_{o} \vec{b}_{o}^{t} \cdot \widetilde{\sigma}^{A} \cdot \vec{b}_{o} \\
& \Omega_{2}(\theta, \phi)=\omega_{o} \vec{b}_{o}^{t} \cdot \widetilde{\sigma}^{D} \cdot \vec{b}_{o}
\end{aligned}
$$

Deste modo, as frequêencias de $R M N$ antes e depois de $t_{m}$ podem ser calculadas para cada orientação $(\theta, \phi)$, assumindo uma dada geometria do movimento molecular.

Embora esse procedimento seja a base geral do cálculo das freqüências, nem sempre a orientação relativa entre os sistemas de eixos principais antes e depois de $t_{m}$ (ângulos de Euler $\alpha, \beta \mathrm{e} \gamma$ ) é facilmente relacionada com os ângulos de reorientação envolvidos no movimento. No entanto, a orientação do SEP do tensor de deslocamento químico é geralmente expressa em relação a um sistema de coordenadas relacionado com a orientação molecular (sistema molecular - SM), o que torna possivel relacionar diretamente a orientação relativa dos dois SEPs, antes e depois de $t_{m}$, e os ângulos envolvidos na reorientação. Considerando que as orientações dos SEPs antes e depois de $t_{m}$ relativas ao sistema molecular sejam dadas, respectivamente, pelos ângulos $\left(\alpha_{S M}^{A} \beta_{S M}^{A} \gamma_{S M}^{A}\right)$ e $\left(\alpha_{S M}^{D} \beta_{S M}^{D} \gamma_{S M}^{D}\right)$, os correspondentes tensores de deslocamento químico podem ser representados por: 


$$
\begin{aligned}
& \widetilde{\sigma}_{S M}^{A}=\widetilde{T}\left(\alpha_{S M}^{A} \beta_{S M}^{A} \gamma_{S M}^{A}\right) \cdot \widetilde{\sigma}^{S E P} \cdot \widetilde{T}^{-1}\left(\alpha_{S M}^{A} \beta_{S M}^{A} \gamma_{S M}^{A}\right) \\
& \widetilde{\sigma}_{S M}^{D}=\widetilde{T}\left(\alpha_{S M}^{D} \beta_{S M}^{D} \gamma_{S M}^{D}\right) \cdot \widetilde{\sigma}^{S E P} \cdot \widetilde{T}^{-1}\left(\alpha_{S M}^{D} \beta_{S M}^{D} \gamma_{S M}^{D}\right)
\end{aligned}
$$

onde a matriz $\widetilde{T}$ representa uma rotação dos SEPs antes e depois de tm para o sistema molecular. Considerando agora que os ângulos $\theta$ e $\phi$ representam as coordenadas polares do versor campo magnético no sistema molecular, as freqüências de RMN são calculadas como:

$$
\begin{aligned}
& \Omega_{1}(\theta, \phi)=\omega_{b} \vec{b}_{o}^{t} \cdot \widetilde{\sigma}_{S M}^{A} \cdot \vec{b}_{o} \\
& \Omega_{2}(\theta, \phi)=\omega_{b} \vec{b}_{o}^{t} \cdot \widetilde{\sigma}_{S M}^{A} \cdot \vec{b}_{o}
\end{aligned}
$$

\section{I.3 Algoritmos dos programas utilizados para simulação dos espectros de RMN de Exchange e PUREX 10.}

\section{I.3.1. Exchange.}

Nos experimentos de Exchange, a simulação do experimento consiste em, inserir a orientação inicial e final do sistema de eixos principais com relação ao sistema molecular e uma distribuição de ângulos de reorientação, calcular os dois padrões espectrais, antes e depois de $t_{\mathrm{m}}$, e somá-los em um mapa bidimensional. Um programa de simulação básico pode ser escrito baseado no seguinte algoritmo: 
Passo 1: Leitura dos dados de entrada - INPUT

- Valores principais do tensor de deslocamento em ppm $\left(\sigma_{x x}^{S E P}, \sigma_{y y}^{S E P}, \sigma_{z z}^{S E P}\right)$

- Orientação relativa entre o Sistema Molecular (SM) e o Sistema de Eixos Principais (SEP):

1. Antes de $\mathrm{t}_{\mathrm{m}} ; \quad \alpha_{S M}^{A} \beta_{S M}^{A} \gamma_{S M}^{A}$

2. Depois de $\mathrm{t}_{\mathrm{m}} ; \alpha_{S M}^{D} \beta_{S M}^{D} \gamma_{S M}^{D}$

- Número de pontos do espectro $2 \mathrm{D} ; \mathrm{n}_{\mathbf{x}}, \mathrm{n}_{\mathrm{y}}$

- $\quad$ Limites da banda espectral em ppm; $\left(\omega_{1 \max }, \omega_{2 \max }\right) ;\left(\omega_{1 \min }, \omega_{2 \min }\right)$

- Freqüência do núcleo em observação em ppm $f_{0}: \omega_{0}=2 \pi f_{0}$.

Passo 2. Obtenção dos tensores de deslocamento químico no sistema molecular

- Operações matriciais: $\begin{aligned} & \tilde{\sigma}_{S M}^{A}=\widetilde{T}\left(\alpha_{S M}^{A} \beta_{S M}^{A} \gamma_{S M}^{A}\right) \cdot \widetilde{\sigma}^{S E P} \cdot \widetilde{T}^{-1}\left(\alpha_{S M}^{A} \beta_{S M}^{A} \gamma_{S M}^{A}\right) \\ & \tilde{\sigma}_{S M}^{D}=\widetilde{T}\left(\alpha_{S M}^{D} \beta_{S M}^{D} \gamma_{S M}^{D}\right) \cdot \tilde{\sigma}^{S E P} \cdot \widetilde{T}^{-1}\left(\alpha_{S M}^{D} \beta_{S M}^{D} \gamma_{S M}^{D}\right)\end{aligned}$

Passo 3. Cálculo do padrão de Exchange 2D (integral nos ângulos $\theta$ e $\phi$ )

- Iniciar laço do ângulo $\theta$;

- Variar $\theta$ no intervalo $[1,181]$ :

$($ argumento-teta $)=\theta-1$;

- Criar tabelas para valores do seno e do cosseno de $\theta$ :

$($ cosseno-teta $)(\theta)=\cos ($ argumento-teta $)$,

$($ seno-teta $)(\theta)=\operatorname{seno}($ argumento-teta $)$.

- Iniciar laço do ângulo $\phi$;

- Variar $\phi$ no intervalo $[0,180]$; 
- Obter a diferencial do cosseno:

se $\theta>1$ então: (dcosseno-teta) $(\theta)=\mid(\operatorname{cosseno-teta})(\theta)-(\operatorname{cosseno}-$ teta $)(\theta-$ 1)|,

caso contrário: $($ dcosseno-teta $)(\theta)=0$;

- Criar tabelas para valores do seno e do cosseno de $\phi$;

$(\operatorname{cosseno}-f i)(\theta)=\cos ($ argumento-fi $)$,

$($ seno-fi) $(\theta)=$ seno(argumento-fi);

- Obter as componentes do versor campo magnético em coordenadas esféricas;

- Obter as frequiências de RMN antes $\left(\omega_{1}\right)$ e depois $\left(\omega_{2}\right)$ de $t_{m}$ (multiplicações matriciais);

- Calcular as frequêencias mínima e máxima;

- Calcular o espectro bidimensional:

espectro $\left(\omega_{1}, \omega_{2}\right)=($ dcosseno-teta $)(\theta)+$ espectro $\left(\omega_{1}, \omega_{2}\right)$;

- Fim do laço em $\theta$;

- Fim do laço em $\phi$;

- Escrever os resultados em um arquivo.

Este é o algoritmo de um programa básico para simular espectros de Exchange levando em conta um único ângulo de reorientação. 


\section{I.3.2. PUREX 1D.}

A simulação do experimento PUREX 1D experimento, segue da mesma forma os passos 1 e 2 da simulação de Exchange 2D, diferenciando no $3^{\circ}$ passo, pois nesta fase é inserida a função de modulação PUREX.,

Passo 1: Leitura dos dados de entrada - INPUT

- Valores principais do tensor de deslocamento em ppm $\left(\sigma_{x x}^{S E P}, \sigma_{y y}^{S E P}, \sigma_{z z}^{S E P}\right)$

- Orientação relativa entre o Sistema Molecular (SM) e o Sistema de Eixos Principais (SEP):

3. Antes de $\mathrm{t}_{\mathrm{m}} ; \quad \alpha_{S M}^{A} \beta_{S M}^{A} \gamma_{S M}^{A}$

4. Depois de $\mathrm{t}_{\mathrm{m}} ; \quad \alpha_{S M}^{D} \beta_{S M}^{D} \gamma_{S M}^{D}$

- Número de pontos do espectro $2 \mathrm{D} ; \mathrm{n}_{\mathrm{x}}, \mathrm{n}_{\mathrm{y}}$

- Limites da banda espectral em ppm; $\left(\omega_{1 \max }, \omega_{2 \max }\right) ;\left(\omega_{1 \min }, \omega_{2 \min }\right)$

- Freqüência do núcleo em observação em ppm $f_{0}: \omega_{0}=2 \pi f_{0}$.

Passo 2. Obtenção dos tensores de deslocamento químico no sistema molecular

- Operações matriciais: $\begin{aligned} & \tilde{\sigma}_{S M}^{A}=\widetilde{T}\left(\alpha_{S M}^{A} \beta_{S M}^{A} \gamma_{S M}^{A}\right) \cdot \widetilde{\sigma}^{S E P} \cdot \tilde{T}^{-1}\left(\alpha_{S M}^{A} \beta_{S M}^{A} \gamma_{S M}^{A}\right) \\ & \tilde{\sigma}_{S M}^{D}=\widetilde{T}\left(\alpha_{S M}^{D} \beta_{S M}^{D} \gamma_{S M}^{D}\right) \cdot \widetilde{\sigma}^{S E P} \cdot \widetilde{T}^{-1}\left(\alpha_{S M}^{D} \beta_{S M}^{D} \gamma_{S M}^{D}\right)\end{aligned}$

\section{Passo 3. Cálculo do padrão de Exchange 2D (integral nos ângulos $\theta$ e $\phi$ )}

- Iniciar laço $\mathrm{k}$, para incrementar o valor de $\tau: k=1: \mathrm{n}_{\mathrm{t}}$ 


$$
\tau(k)=\tau_{\min }+(k-1) *\left(\tau_{\max }-\tau_{\min }\right) / n_{\tau}
$$

- Iniciar os vetores que conterão as intensidades como função de $\tau$ : $S(k)=0 S(0)=0$

- Iniciar o laço $\mathrm{i}$, para incrementar ângulo $\theta: \mathrm{i}_{\theta}=1: \mathrm{n}_{\theta}$;

1 Definir ângulo $\theta$ em radianos: $\theta_{i}=\pi^{*}\left(i_{\theta}-1\right) /\left(n_{\theta}-1\right) \Rightarrow 0 \leq \theta_{i} \leq \pi$

2 Calcular o fator de peso para o espectro de pó $\mathrm{d}(\cos \theta)$ :

$$
d \cos \theta_{i}=\cos \theta_{i}-\cos \theta_{i-1}
$$

- Iniciar ângulo $\phi$ em radianos: $\theta_{j}=\pi^{*}\left(j_{\phi}-1\right) /\left(n_{\phi}-1\right) \Rightarrow 0 \leq \phi_{i} \leq \pi$

- Calcular as freqüências antes e depois de $t_{m}$ :

- Montar matriz $\tilde{b}_{o}=\left(\begin{array}{c}\operatorname{sen} \theta \cos \phi \\ \operatorname{sen} \theta \operatorname{sen} \phi \\ \cos \theta\end{array}\right)$

- Calcular as freqüências de RMN antes $\left(\omega_{1}\right)$ e depois $\left(\omega_{2}\right)$ de $t_{m}$ em

$$
\begin{array}{ll}
\text { ppm: } \quad & \omega_{1}\left(\theta_{i}, \phi_{i}\right)=\vec{b}_{0}^{t} \cdot \tilde{\sigma}_{S M}^{A} \cdot \vec{b}_{0} \\
& \omega_{2}\left(\theta_{i}, \phi_{i}\right)=\vec{b}_{0}^{t} \cdot \tilde{\sigma}_{S M}^{D} \cdot \vec{b}_{0}
\end{array}
$$

- Calcular as intensidades espectrais;

Converter as freqüências calculadas para rad/s: $\begin{aligned} & \omega_{1 R A D}=\omega_{0} \omega_{1}\left(\theta_{i}, \phi_{i}\right) \\ & \omega_{2 R A D}=\omega_{0} \omega_{2}\left(\theta_{i}, \phi_{i}\right)\end{aligned}$

Calcular o fator de modulação PUREX para o $\tau(k)$ corrente:

$$
M f(k)=2 * \operatorname{sen}^{2}\left[\left(\omega_{1 R A D}-\omega_{2 R A D}\right) \frac{\tau(k)}{2}\right]
$$

Calcular a intensidade normalizada PUREX para o $\tau(k)$ corrente:

$$
\begin{aligned}
& S(k)=M f(k)^{*} d \cos \theta_{i}+S(k) ; S(0)=d \cos \theta_{i}+S(0) \\
& E(k)=(S(k)-S(0)) / S(0)
\end{aligned}
$$

- $\quad$ Fim do laço em i; 
- Fim do laço em j;

- Escrever os resultados em um arquivo.

Este é o algoritmo de um programa básico para simular Intensidade PUREX 1D.

\section{I.4. Algoritmos do programa utilizado para simulação da largura de linha dos espectros de Polarização Cruzada.}

A simulação de largura de linha também utilizada os dois primeiros passos de ambos os experimentos citados, descartando os parâmetros $\mathrm{t}_{\mathrm{m}} \mathrm{e}$ levando em consideração somente o espectro simulado $S(0)$, ou seja, o espectro de referência. Onde esta simulação pode ser realizada em função da taxa de movimento molecular. A partir daqui, podemos simular espectros e compará-los aos espectros adquiridos experimentalmente e extrair o tempo de correlação correspondente ao espectro. Vale lembrar que experimentos de largura de linha em função da temperatura, revela os movimentos que promediam as interações envolventes na forma do espectro, o qual conseqüentemente está relacionado com a taxa de movimento. Logo podemos simular espectros e compará-los a cada espectro experimental associado a uma temperatura. Lembrando que também podemos obter uma curva a meia altura ou a 2./3 da altura máxima, podemos fazer uma 
Passo 1: Leitura dos dados de entrada - INPUT

- Valores principais do tensor de deslocamento em ppm $\left(\sigma_{x x}^{S E P}, \sigma_{y y}^{S E P}, \sigma_{z z}^{S E P}\right)$

- Orientação relativa entre o Sistema Molecular (SM) e o Sistema de Eixos Principais (SEP): $\quad \alpha_{S M} \beta_{S M} \gamma_{S M}$

- Limites da banda espectral em ppm; $\left(\omega_{1 \max }, \omega_{1 \max }\right)$

- $\quad$ Limites do valores de $T_{2}$ em ms; $\left(T_{2 \max }, T_{2 \min }\right)$

- Limites do valores de $\tau_{c}$ em ms; $\left(\tau_{c \max }, \tau_{c \min }\right)$

- Freqüência do núcleo em observação em ppm $f_{0}: \omega_{0}=2 \pi f_{0}$;

- Números de tempos de correlação $\tau_{c}$;

- Valora 2/3 da altura máxima.

Passo 2. Obtenção dos tensores de deslocamento químico no sistema molecular

Operações matriciais: $\tilde{\sigma}_{S M}^{A}=\tilde{T}\left(\alpha_{S M} \beta_{S M} \gamma_{S M}\right) \cdot \tilde{\sigma}^{S E P} \cdot \tilde{T}^{-1}\left(\alpha_{S M} \beta_{S M} \gamma_{S M}\right)$

Passo 3. Cálculo do padrão de Pó $1 D$.

Lê os parâmetros calculados anteriormente e inicia o cálculo do espectro de padrão de Pó do experimento $\mathrm{CP}$. 


\section{I.5 Referências:}

Schmidt-Rohr, K., Spiess, H. W. (1994). Multidimensional Solid-State NMR and Polymers. London, Academic Press.

deAzevedo, E. R. (2001). Novas metodologias de Ressonância Magnética Nuclear para o Estudo da Dinâmica Lenta em Materiais Orgânicos no Estado Sólido: Aplicações em Polímeros e Proteínas. Tese de Doutorado - Departamento de Física e Informática - Instituto de Física de São Carlos. São Carlos, Universidade de São Paulo.

Schmidt-Rohr, K., Wilhelm, M., Johansson, A., Spiess, H. W. (1993). "Determination of Chemical-Shift Tensor Orientations in Methylene Groups by Separated-Local-Field NMR", Magnetic Resonance in Chemistry 31: 352-356. 